U. S. DEPARTMENT OF COMMERCE

R. P. LAMONT, Secretary

BUREAU OF MINES

SCOTT TURNER, Director

Bulletin 361

\title{
HEAT TRANSFER FROM A GAS STREAM TO A BED OF BROKEN SOLIDS
}

BY

C. C. FURNAS

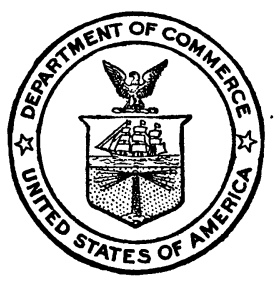

UNITED STATES

GOVERNMENT PRINTING OFFICE

WASHINGTON: 1932

For sale by the Superintendent of Documents, Washington, D. C. - - - - Price 10 cents 



\section{CONTENTS}

Introduction

Acknowledgments

Summary of findings.

Accuracy of data

Work of previous investigators.

Transfer from gases

First experimental method

Apparatus

Procedure

Heat losses

Experimentel dif

Interpretation of results

Data obtained

Effect of gas velocity

Effect of particle size

Second method: Temperature history

Schumann's method........... Example of application.... Limits of application .....

Alternative method of solution

Method of solution for coefficient

Advantages of method.....

Experiments with water......

Apparatus for heat transfer from water.

Inconsistencies in data......

Method of determining average coefficient

Solution for coefficient

Application of Schumann's curves to gases..........

Apparatus _...............

Procedure . . . . . . . . . . . . .

Temperature range and gas composition . . . . . . . . .

Computation of coefficient . -

Definition of "temperature of solid"

Computation of heat capacity.

Effect of gas velocity . ......

Effect of temperature

Effect of voids

Effect of particle size.

Summarizing equation........

Conversion to English units... -

Standard coefficients . . .....-

Anomalous behavior of cooling coke.

Heats of transition

Calcination of limestone.......
Page

1

Surface area.

Lifting the solid charge........

Comparison of two experimental methods

Heat transfer per unit of area. Comparison with coefficients for conduits

Systems of mixed sizes........

Blast-furnace stock . . . . . .

Definition of average particle size ........................

Experiments with producer gas. Elimination of dust.

Decrease of sulphur........

Similarity of air and producer gas. . . . .

Effect of molecular weight ....

Thermal conductivity of iron oxide

Cooling of iron sphere

Computation of conductivity of iron ore

Computation of degree of applicability of Schumann's theory

Equations for heating spheres.

Important factors in heat transfer

Problem illustrating the transfer of heat in batch-type apparatus

Possible applications of heattransfer data to other systems.

The steady state . . . . . . . . Effect of heat capacity on temperature gradient...... Temperature of combustion.Equations for variable $k_{\text {. . . . - }}$

Page

44

Problen

Effect of change of particle size

Shortening the column.-

Conversion of units ....-

Appendix 1.-Nomenclature ..-

Conversion of units

Appendix 2. - Principal data obtained in heat-transfer study -

Appendix 3.-Derivation of equations for rate of heating and the steady state...... 
Appendix 3-Contd.

Derivation of equation 36 for rate of heating of a highly conductive sphere

Page

Derivation of equations for the steady state; no heat losses through walls ..... -

Determination of temperature gradient of solid....
Appendix 3-Contd.

Solid temperature at bottom of furnace. . . . .......

Gas temperatures........

Indeterminate form......

Temperature of combustion................

Equations involving heat loss through walls.

\section{ILLUSTRATIONS}

Fig.

82

82

83

84

84

1. First form of heat transfer apparatus

2. Diagram of apparatus for the study of heat transfer

3. Details and position of thermocouple shields . . . . .

4. Relation between gas velocity and apparent temperature with shielded thermocouples

5. Typical gas and solid temperature record from the chart of the recording potentiometer

6. Relation between rate of

7. Schumann's curves for temperature history of solid for values of $\bar{y}$ from 0 to 10

8. Schumann's curves for temperature history of gas for values of $y$ from 1 to 10 .

9. Computed temperature history of solid for values of $y$ from 9 to 25

10. Computed temperature history of gas for values of $y$ from 9 to $25 \ldots$

11. Computed temperature history of solid for values of $y$ from 25 to $100 \ldots$

12. Computed temperature history of gas for values of $y$ from 25 to 100

13. Computed temperature history of solid for values of $y$ from 100 to 500 -

14. Computed temperature history of gas for values of $y$ from 100 to 500 -

15. Diagram of apparatus for the determination of the coefficient of heat transfer between water and a bed of iron balls

16. Relation between $T_{s} / T_{o}$ and $y$ for various values of $z_{\ldots}$

17. Relation between $\int T_{s} d y$ and $y$ for various values of $z_{\ldots} \ldots$

18. Relation between $z$ and the proportion of total heat absorbed, $Q_{s} / Q_{o--}$

19. Diagram of heat transfer-equipment . .

20. Apparatus for studying the transfer of heat from gases to solids . ....

21. Logarithmic relation between $z$ and $T_{o} / T_{o}$ for various values of $y_{-\ldots}$

22. Typical temperature history of gas stream at top of column

23. Effect of gas velocity on the coefficient of heat transfer.

24. Effect of voids on the coefficient of heat transfer

25. Effect of particle size on the coefficient of heat transfer....

26. Effect of particle size on the coefficient of heat transfer for cooling coke-

27. Diagram of apparatus for determination of coefficient of heat transfer from producer gas to a bed of broken solids.

28. Temperature history of the center of spheres $5.2 \mathrm{~cm}$ in diameter, cooling in still air

29. Gurney and Lurie data for temperature history of center of spheres

30. Graphical solution for thermal conductivity of iron ore

31. Relative values of the over-all heat-transfer coefficient $k$ and of the amount of heat absorbed $Q$ at different times during the heating period.

32. Relative over-all heat-transfer coefficient for different percentages of heat absorbed

33. Diagram of temperature condition in steady-state countercurrent heat-transfer equipment.

34. Effect of relative heat capacities of gas and solid streams upon the temperature gradient in a steady-state apparatus..............

35. Computed temperature of solids in the column of a cupola..... 


\title{
HEAT TRANSFER FROM A GAS STREAM TO A BED OF BROKEN SOLIDS ${ }^{1}$
}

\author{
By C. C. Furnas ${ }^{2}$
}

\section{INTRODUCTION}

This study of heat transfer is part of an extensive program of research of the iron blast furnace which the Bureau of Mines is conducting in the laboratory and in the field. ${ }^{3}$ However, the applications of the results of this study are not limited to blast-furnace practice. The transfer of heat from a gas stream to a bed of broken material is one of the most common industrial processes. It takes place in every fuel bed, under boilers, in gas producers, or in watergas generators. The increasingly important dry quenching of coke is one of the more obvious applications. Some drying operations are primarily controlled by heat transfer of this sort. The cupola column and the shaft of a limekiln furnish direct applications of the data involved. Checker brick in furnace regenerators furnish an analogous field. Empirical formulas for the design of regenerators are available; but, as far as the author knows, fundamental correlation of all the variables involved is lacking. The mathematical solution for this particular kind of cyclic heating has not been developed. Packed still columns are essentially pieces of heat transfer equipment, though condensing vapor films present special problems. The making of cakes of sintered material is another field of possible direct application. Some types of ceramic kilns undoubtedly furnish a field of possible use. Roasting or sintering in rotary kilns or hearth furnaces is a closely analogous field to which some of the principles might be applied with special study.

1 Work on manuscript completed June, 1931.

2 Physical chemist, North Central Experiment Station, U. S. Bureau of Mines.

3 Royster, P. H., Joseph, T. L., and Kinney, S. P. (a) Reduction of Iron Ore in the Blast Furnace; (b) Significance of Hearth Temperatures; (c) Heat Balance of the Bureau of Mines Experimental Blast Furnace; (d) Time Element in Iron-Ore Reduction; (e) Influence of Ore Size on Reduction: Blast Furnace and Steel Plant, vol. 12, 1924, pp. 35-38; 154-158; 200-204; 246-250; 274-280.

Joseph, T. L., Royster, P. H., and Kinney, S. P., Utilization of Manganiferous Iron Ores: Tech. Paper 393 , Bureau of Mines, $1926,28 \mathrm{pp}$.

Joseph, T. L., and Kinney, S. P., Minnesota Manganiferous Iron Ore in Relation to the Iron and Steel Industry: Univ. Minnesota Sch. Mines Exper. Sta., Bull. 12, Feb. 10, 1927, 101 pp.

Joseph, T. L., Barrett, E. P., and Wood, C. E., Minnesota Manganiferous Iron Ores in Relatior. to the Iron and Steel Industry: Trans. Am. Inst. Min. and Met. Eng., vol. 75, 1927, pp. 292-338.

Kinney,S.P., Royster,P.H., and Joseph, T. L., Iron Blast-Furnace Reactions: Tech. Paper 391, Bureau of Mines, $1927,65 \mathrm{pp}$.

Kinney, S. P., Composition of Materials from Various Elevations in an Iron Blast Furnace: Tech. Paper 397, Bureau of Mines, 1926, 22 pp.; The Blast-Furnace Stock Column: Tech. Paper 442, Bureau of Mines, 1929, 148 pp.; Effect of Sized Ore on Blast-Furnace Operation: Tech. Paper 459, Bureau of Mines, 1930, $92 \mathrm{pp}$.

Kinney, S. P., and Furnas, C. C., Gas-Solid Contact in the Shaft of a 700-Ton Blast Furnace: Rept. of Investigations 2939 , Bureau of Mines, $1929,10 \mathrm{pp}$.

Furnas, C. C., Flow of Gases Through Beds of Broken Solids: Bull. 307, Bureau of Mines, 1929, 144 pp.; Controlling Furnace Burden by Gas Analysis: Blast Furnace and Steel Plant, vol. 17, 1929, p. 1791.

Furnas, C. C., and Joseph, T. L., Stock Distribution and Gas-Solid Contact in the Blast Furnace: Tech. Paper 476, Bureau of Mines, 1930, 73 pp.; Blast-Furnace Filling and Size Segregation: Am. Inst. Min. and Met. Eng., Tech. Pub. 249, 1929, 29 pp. 
The data presented in this bulletin by no means cover all of the possibilities mentioned above, though a considerable range of materials, particle sizes, gas velocities, and temperatures has been covered. In so far as possible the data are presented in a general form so that they may be used for any type of system which is similar to the one studied.

The general principles, presented in the portion dealing with overall or integral effects, by no means need to be confined to heat transfer. They are applicable to any sort of system where material or energy is transferred by the same mechanism as is assumed as a basis for all heat-transfer study, namely, that the rate of transfer is between two phases and is directly proportional to the driving force (concentration difference, temperature difference, etc.) applied to the system. Purification of water upon passing through filter beds, clarifying sirups, oils, etc., by activated carbon, purifying coke-oven gas by passage through beds of iron ore, etc., are examples of transfer systems which furnish possible applications of the principles involved.

\section{ACKNOWLEDGMENTS}

The author wishes to acknowledge the aid and suggestions, throughout the investigation, of T. L. Joseph and W. F. Holbrook. For suggestions made during the progress of the work he is indebted to Dr. T. E. W. Schumann and Dr. S. P. Burke, formerly of the Combustion Utilities Corporation; to Prof. W. H. McAdams, of the Massachusetts Institute of Technology; and to Prof. W. L. Badger, of the University of Michigan.

\section{SUMMARY OF FINDINGS}

As an aid to the clear explanation of the subject, the results will first be briefly summarized; then the theoretical and experimental work will be explained in detail throughout the course of the bulletin.

The experimental data have been interpreted as showing that the coefficient of heat transfer from a gas stream to a bed of broken solids can best be expressed by the empirical equation

In the metric system:

$$
k=\frac{A u^{0.7} T^{0.3} 10^{1.68 f-3.56 f}}{d^{0.9}} .
$$

$k=$ calories per second per degree centigrade per cubic centimeter of overall volume of bed; 4

$u=$ rate of flow in standard liters per second per square centimeter of crosssectional area of the bed;

$T=$ degrees centigrade absolute;

$d=$ particle diameter in centimeters;

$f=$ the fractional value of the voids in the bed (no units); and

$A=$ a constant for each substance.

For the English system:

$k=$ B. t. u. per second per degree Fahrenheit per cubic foot of over-all volume of the bed; 5

$u=$ rate of flow in standard cubic feet per second per square foot of crosssectional area of the bed;

$T=$ degrees Fahrenheit absolute;

$d=$ particle diameter in feet;

$f=$ fractional value of voids in the bed (no units); and

$A=$ a constant for each substance.

4 For a discussion of $k$ expressed in terms of unit area instead of volume, see p. 45

6 See footnote 4 . 
The above equation holds for both heating and cooling of most substances. The value of $A$ in most cases is greater for cooling than for heating, as is shown in Table 1. When coke is cooled it has an anomalous behavior, and the equation for $k$ is

(Units same as above.)

$$
k=\frac{A u^{0.7} T^{0.310^{1.68 f-3.56 f}}}{d^{1.5}} .
$$

The necessary data for the use of the above equations are given in Table 1.

The gases used were air or flue gases, which approximated air very closely in density and viscosity. Experiments were also run on bosh gas, such as is generated in the hearth of a blast furnace, but it had no properties which were significantly different from air. Fortunately, most gases used industrially have physical properties closely approximating those of air, so the data have wide application. For discussion of other gases, see page 51 .

Two different methods were used for determination of the coefficients. The relative merits of the two methods are discussed. (See p. 45.)

A few data of doubtful accuracy were obtained for the transfer of heat from a stream of water to iron balls. (See p. 29.)

Equations 1 and 2 are not in themselves applicable to many particular physical engineering problems, for the heat-transfer coefficient $k$ is only a differential quantity, and most applications involve an over-all or integral effect. Consequently, equations and problems are given for both the steady state (see p. 63) and for the temperature history of any point in a mass of material in a batch apparatus which is being heated or cooled by the through passage of a gas. (See p. 13 and figs. 7 to 14.) These integrated equations are applicable as a first approximation to any fluid and do not need to be confined to a gas stream.

The data obtained and the equations given are approximately applicable to systems where relatively small heats of reaction are involved.

Data are given on the rate of calcination of limestone and the attending heat-transfer phenomena. (See p. 43.)

The theoretical and experimental work of previous investigators which has a possible bearing on this problem is summarized and discussed. (See p. 4.)

The theoretical aspects of the present problem are discussed in so far as the data will permit. (See p. 59.)

The method used permits approximate determination of the heat capacity of the solid bed. These data are reported for the various materials used. (See p. 35 and Table 4.)

The principal variables studied were those indicated in equations 1 and 2. There is additional discussion of the effect of shape of particle, normal voids, thermal conductivity, and heat capacity of the solid itself. (See p. 59.)

\section{ACCURACY OF DATA}

The data are reproducible with a maximum variation of about \pm 10 per cent. The method finally adopted is of such a nature that apparently no systematic error in one direction was observed, so the 


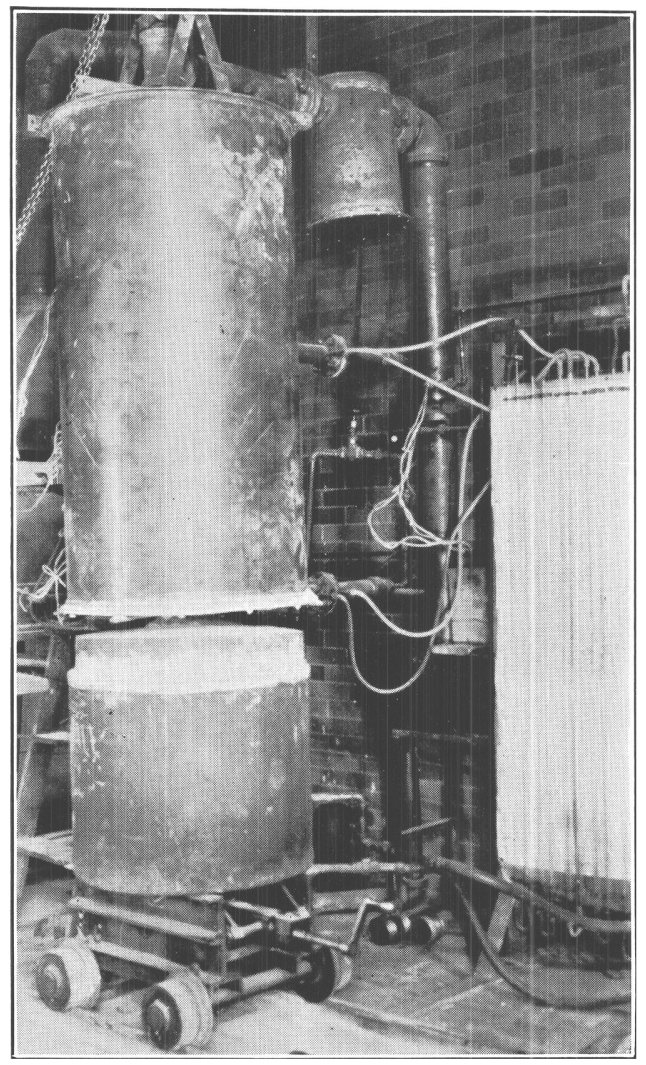

Figure 20.-Apparatus for studying the transfer of heat from gases to solids 

reproducibility (within \pm 10 per cent) must represent the accuracy of the data. The samples used in most cases consisted of several hundred pieces of material, so variations in the character of different pieces of material were practically eliminated.

\section{WORK OF PREVIOUS INVESTIGATORS}

The kinetics of heat flow into or out of a fluid system has furnished working material for many of the world's best physicists for many years. Probably the first clear conceptions came as a result of James Clerk Maxwell's classical formulation of the kinetic theory. ${ }^{6}$

Nearly all treatises on the kinetic theory devote some space to the mechanism of the transfer of heat through or by means of a fluid. Although extremely interesting, these discussions are usually found to bear little fruit for the engineer, except as they may aid his formation of concepts.

A much more useful mode of attack has been found along almost purely mathematical lines, mainly by methods of dimensional analysis.

Very probably Reynolds ${ }^{7}$ was the first to make an adequate formulation of the variables controlling heat transfer. His pioneer work was later supplemented by that of Boussinesq, Nusselt, McAdams, Rice, Russel, Stanton, ${ }^{8}$ and others.

In recent years numbers of publications have dealt with the numerous phases of heat transfer. Many of them are valuable contributions to the theoretical and experimental knowledge of the subject. The author makes no pretense of giving a complete bibliography of the work, so many contributions are not mentioned. There are, however, two works, one by Monrad and Badger, ${ }^{9}$ the other by Colburn and Hougen, ${ }^{10}$ which should be mentioned. Both of these papers contain important data and theoretical discussions. They give good résumés of the existing knowledge on their own particular phases of the subject and have quite complete bibliographies. Monrad's collection of 54 references and Colburn's group of 82 give the key to a quite complete study of the heat-transfer field.

The principal equations which govern heat transfer have been collected and discussed in several different books. ${ }^{11}$

6 Maxwell, James Clerk, Scientific Papers: Edited by W. P. Niven, Cambridge University Press, Cambridge, vol. 2, 1890, pp. 1-78.

7 Reynolds, Osborne, Scientific Papers: Cambridge University Press, Cambridge, 1901, pp. 81-85.

8 Boussinesq, J., Sur de pouvoir refroidissant d'un courant liquide ou gaseux: Compt. rend., vol. 133, 1901, p. 257.

Nusselt, W., (a) Der Warmeübergang in Rohrleitungen; (b) Condensation of Steam; (c) Heat Dissipation from Horizontal Tubes or Wires to Gases and Liquids: Ztschr. Ver. deut. Ing., vol. 53, 1902, pp. 1750, 1808; vol. 60, 1916, pp. 541, 569; vol. 73, 1925, p. 1475; Fundamentals of Heat Transfer: Ing., vol. 38, 1915, pp. $477,490$.

Nusselt, W., and Jürges, -, Temperature Field over a Vertical Heated Pipe: Ztschr. Ver. deut. Ing., vol. 72, 1928, p. 597 .

McAdams, W. H., and Frost, T. H., Heat Transfer by Conduction and Convection: Ind. and Eng.

Chem., vol. 14, 1922, pp. 1101-1105.
Rice, C. W., Forced Convection of Heat in Gases and Liquids: Ind. and Eng. Chem., vol. 16, 1924, pp. $460-467$.

Russel, A. S., The Convection of Heat from a Body Cooled by a Stream of Fluid: Proc. Phys. Soc. London, vol. 22, 1909-10, p. 432.

Stanton, T. E., On the Passage of Heat Between Metal Surfaces and Liquids in Contact with Them:

Phil. Trans. Roy. Soc. London, vol. 61, 1897, p. 287.

9 Monrad, C. C., and Badger, W. L., The Condensation of Vapors: Ind. and Eng. Chem., vol. 22, 1930, pp. 1103-1112.

${ }_{10}$ Colburn, Allan P., and Hougen, Olaf A., Studies in Heat Transmission: Bull. Univ. Wisconsin Eng. Exp. Sta. Ser. 70, October, 1930, $158 \mathrm{pp}$.

${ }_{11}$ Walker, W. H., Lewis, W. K., and McAdams, W. R., Principles of Chemical Engineering: New York, 1st ed., 1923, p. 141; 2d Ed., 1927, pp. 118-187.

Badger, W. L., Heat Transfer and Evaporation: New York, 1926

Royds, R Heat Transmission by Radiation, Conduction, and Convection: London, 1921.

Badger, W. L., and McCabe, W. L., Elements of Chemical Engineering: Now York, 1931, pp. 116-159. 
A large amount of work has been done on systems where gas is the heat carrier, but the different data do not always agree-a common phenomenon in heat-transfer studies. Weber ${ }^{12}$ collected data for gases from various sources and found that they were best interpreted by the equation

where

$$
K_{1}=\frac{0.88(u)^{0.8} C_{p} S^{0.2} T^{0.5}}{m^{0.3}},
$$

$K_{1}=$ coefficient of heat transfer measured in B. t. u. per square foot per second per degree Fahrenheit temperature difference;

$u=$ velocity in pounds per square foot per hour;

$C_{p}=$ average specific heat at constant pressure of gas in B.t. u. per pound;

$S=$ surface factor in reciprocal feet;

$T=$ arithmetic mean temperature of the gas in degrees Fahrenheit absolute; and

$m=$ molecular weight of gas.

A more recent summary ${ }^{13}$ of the data for gas flowing inside conduits is given by

where

$$
K_{1}=0.22 C_{p} T_{f}^{2 / 3} \frac{u^{0.3}}{D^{0.2}}
$$

$T_{f}=$ mean temperature of gas film in degrees Fahrenheit absolute; and

$D=$ equivalent diameter of the passage in inches.

Turther work has been done on summarizing data for flow at right angles to pipes. ${ }^{14}$ For a single pipe,

where

$$
K_{1}=0.8 T_{f}^{1 / 3} \frac{u^{n}}{D^{0.53}}
$$

$n=0.60+0.08 \log _{10} D ;$ and

$D=$ outside diameter of pipe in inches.

For air flow at right angles to a group of staggered pipes,

where

$$
K_{1}=\frac{0.8 T_{f}^{1 / n} u^{n}}{D^{0.53}}\left(1+\frac{D}{W}\right)
$$

$u=$ pounds of air per second per square foot of minimum free area between pipes in a plane at right angles to air flow; and

$W=$ distance in inches between centers of adjacent pipes, taken at right angles to direction of flow.

It is evident that each change in the arrangement of the apparatus causes a decided change in the form and constants of the equation which correlates the data. Therefore, any detailed analysis of the kinetics of heat transfer from a gas stream to a bed of broken solids would lead to a result which, to say the least, would be extremely complicated. In a bed of broken material there is great variation in the shape, arrangement, and surface conditions of particles. Besides

\footnotetext{
12 Weber, Undergraduate Thesis, Massachusetts Inst. Technol., 1919.
}

See also Badger, W. L., Heat Transfer and Evaporation: New York, 1926, p. 45; and Walker, W. H., Lewis, W. K., and McAdams, W. R., Principles of Chemical Engineering: New York, 1st ed., 1923, p. 149.

${ }^{13}$ Walker, W. H., Lewis, W. K., and McAdams, W. R., Principles of Chemical Engineering: New York, 2d ed., 1927, p. 149.

14 Chappell, E. L., and McAdams, W. R., Heat Transfer for Forced Flow of Air at Right Angles to Cylinders: Trans. Am. Soc. Mech. Eng., vol. 48, 1926, p. 1201. 
this, the gas follows an undetermined path at an unknown velocity. An accurate, quantitative analysis of the problem, apparently, is not possible. However, if an experimental method can be devised to measure the over-all coefficient, it should be possible to obtain empirical relations between variables which would permit application of the data.

As far as the author knows, only one other investigator has published experimental results on heat transfer from fluid streams to beds of broken solids. One piece of experimental work has been done in England ${ }^{15}$ which has given a few valuable data. The work was confined to single pieces of very thin beds of coal, clay, or copper cubes. The data obtained on coal agreed fairly well with the results of the present investigation, although the methods used were quite different. Gilbert's data were not sufficiently extensive to permit formulation of general empirical laws of heat transfer in such systems.

From a somewhat similar investigation Colburn ${ }^{16}$ determined the over-all coefficients of heat transfer from a gas stream in a packed column to a fluid surrounding the tube and obtained results comparable to those obtained in the present study.

\section{FIRST EXPERIMENTAL METHOD}

The method first used for the determination of heat-transfer coefficients utilized direct measurement of the temperature difference between the gas and solid stream and determination of the rate of heat acquisition of the solid. This work was previously reported in the technical press. ${ }^{17}$ The results probably are not as reliable as those produced during a later study, but they are given because they permit comparison and because the method used probably has further possibilities.

\section{APPARATUS}

In this apparatus air was passed through a bed of iron balls covered with $\approx$ thin coating of iron oxide. The term "air" is not quite correct, as the gas was constantly recirculated in a closed system to minimize oxidation, passing over hot copper to remove oxygen. The oxygen content of the system averaged 6 to 10 per cent. This was effective in preventing further oxidation of the balls, but the physical properties of the gas studied may appropriately be considered those of normal air.

A diagram of the apparatus used is shown in Figure 2. Air from a 4-unit 700-liter tank, $t$, was passed through a closed, constantvolume, positive-pressure blower, $b$, having a capacity of 10 liters per second and then through a coil placed in pot furnace $h$. The coil contained 8 meters of extra-heavy wrought-iron pipe $2.5 \mathrm{~cm}$ ( 1 inch) in inside diameter; the inside diameter of the turns of the coil was $28 \mathrm{~cm}$. The coil was heated with a single gas burner set tangentially at the bottom of the furnace. A full flow of gas could be heated to $900^{\circ} \mathrm{C}$. by this apparatus. The coil would stand about 40 hours' service. From the top of the coil the gas passed through a

15 Gilbert, W., The Heating and Drying of Granular Materials by Convection: Engineer, vol. 150, 1930, pp. 500-502, 530-532, 574-575, 617-619, 640-642.

${ }_{16}$ Colburn, Allen P., Heat Transfer in Packed Tubes: Trans. Am. Inst. Chem. Eng., vol. 26, 1931, pp. 166-178; Ind. Eng. Chem., vol. 25, 1931, pp. 910-13.

${ }_{17}$ Furnas, C. C., Heat Transfer from a Gas Stream to a Bed of Broken Solids: Ind. and Eng. Chem., vol. 22, 1930, p. 26. 
heavily insulated pipe to the bottom of the column of material. The container was made of extra heavy pipe, $15 \mathrm{~cm}$ in inside diameter and $105 \mathrm{~cm}$ in height insulated with walls of Sil-o-Cel powder, $14 \mathrm{~cm}$ thick on the lower half and $12 \mathrm{~cm}$ thick on the upper half of the column.

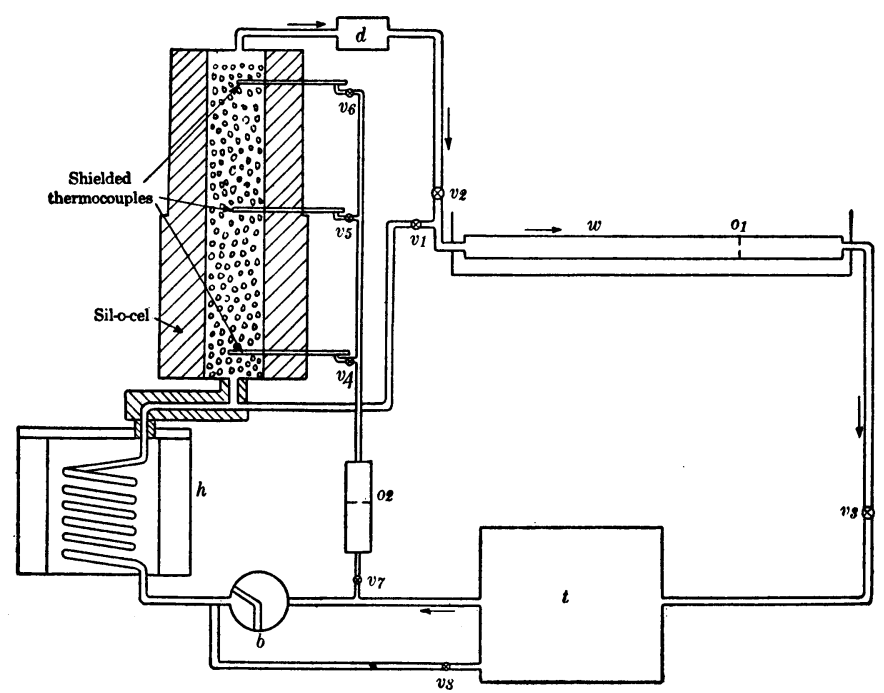

Figure 2.-Diagram of apparatus for the study of heat transfer

Temperature measurements of both gas and solid were made with three shielded thermocouples in the positions shown. From the top of the column the gas passed through pipe $d$, containing copper turnings which were kept at 600 to $700^{\circ} \mathrm{C}$. by means of a gas flame, and on through water-cooled valve $v_{2}$, inta water cooler $w$, which consisted of extraheavy pipe $10 \mathrm{~cm}$ in diameter and 4 meters long, immersed in a water bath. The rate of gas flow was measured by a calibrated orifice, $O_{1}, 2.08 \mathrm{~cm}$ in diameter, placed 1 meter from the end of the cooler. The gas completed the cycle by passing back into receiving tank $t$, at room temperature. The amount of pressure on the column and the amount of gas flowing through it were controlled by manipulation of valves $v_{2}, v_{3}$, and $v_{8}$. If valve $v_{1}$ were open and valve

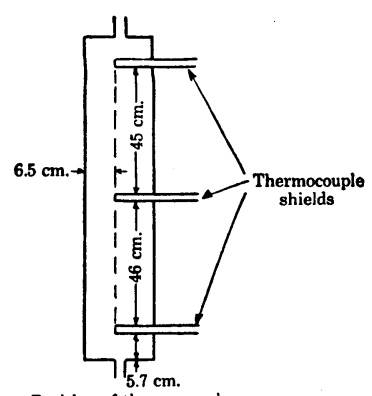

Position of thermocouples

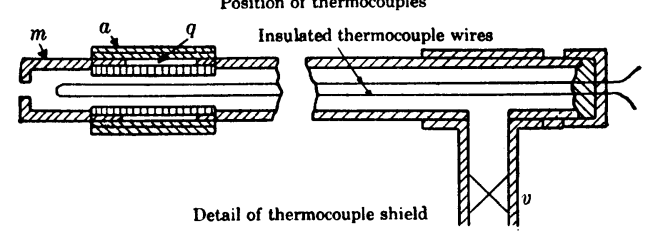

FIGURE 3.-Details and position of thermocouple shields $v_{2}$ closed hot gas could be circulated without passing through the column. A photograph of the heater and column of material is shown in Figure 1.

The details of the thermoc nuple shields and their positions in the column of balls are shown in Figure 3. Each thermocouple shield 
was made from standard $\frac{1 / 4}{4}$-inch $(6-\mathrm{mm})$ pipe. The end was welded shut, then a concentric hole $0.40 \mathrm{~cm}$ in diameter was drilled through it. The inside diameter of the shield was drilled to $1 \mathrm{~cm}$. The inside surface was silver-plated to minimize radiation. To prevent excessive cooling of the shield by conduction to the cold exterior of the apparatus the metal tip of the shield $m$ was made $2 \mathrm{~cm}$ long, and a quartz tube, $q, 0.8 \mathrm{~cm}$ in inside diameter and $1.1 \mathrm{~cm}$ in outside diameter, was inserted in the pipe which was drilled out to a diameter of $1.1 \mathrm{~cm}$. The quartz tube was inserted $0.5 \mathrm{~cm}$ into the metal tube, having been ground to make a practically gas-tight fit. Two layers of asbestos paper $a$, soaked in water glass, were wrapped around the quartz tube to afford mechanical protection. The thermocouples were made of 22-gage, calibrated, chromel-alumel wire. The beads were silver plated. The bead of each thermocouple was placed on a line with the opening of the shield and $0.5 \mathrm{~cm}$ down the tube. The

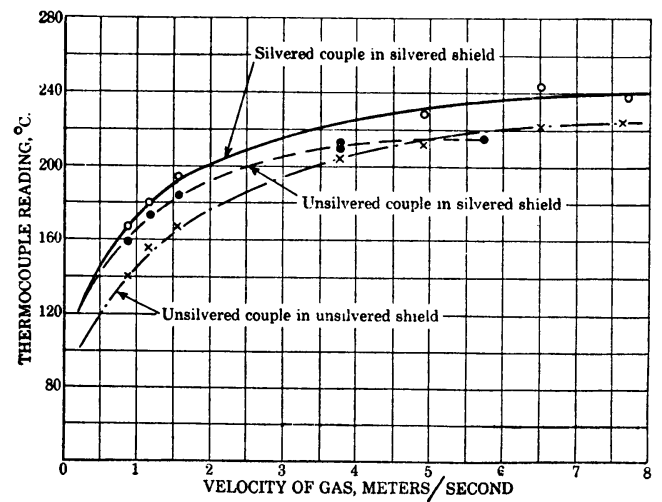

Figure 4.--Relation between gas velocity and apparent temperature with shielded thermocouples standard $1 / 4$-inch $\quad(6-\mathrm{mm})$ pipe, which held the insulated thermocouple wires, extended beyond thequartz section of the tube through the walls of the apparatus and through the insulation. The thermocouple wires were brought out through a gas-tight stuffing box packed with asbestos cord. Gas coming out through the shield passed through a $T$ and valve placed immediately in front of the stuffing box. All connections were made gas-tight.

A special study ${ }^{18}$ was made of the measurement of the true temperature of a gas stream. The method of measuring true gas temperature by forcing a rapid stream past the bead of a shielded couple seems to have been first described in the press by Haslam and Chappell. ${ }^{19}$ The work done in the present investigation consisted of studying the effect of surface conditions upon the temperature reading of the gas stream. The inside of the shields and the bead of the thermocouple were silver plated, and the results compared with those obtained with unplated couples.

The summarized results of the work are given in Figure 4. Three combinations are given: (1) Silvered couple in silvered shield, (2) unsilvered couple in silvered shield, and (3) unsilvered couple in unsilvered shield. In all three combinations the temperature curve has practically reached the asymptotic value of temperature at a linear gas velocity of 7 meters per second. Therefore a linear velocity of 7 feet per second through the shield is sufficient for the measurement of the true gas temperature, whether or not the couple and shield are silver plated. (Note: In Figure 4 the temperature of the gas in

${ }^{18}$ Wolk, I. L., Measurement of the Temperature of a Gas Flowing Through a Bed of Broken Solids; Senior Thesis, Üniv. of Minnesota, School of Chemistry, 1929.

${ }^{19}$ Haslam, R. T., and Chappell, E. L., Measurement of the Temperature of a Flowing Gas: Ind. and Eng. Chem., vol. 17, 1925, pp. 402-408. 
each instance was different, hence there is an apparent discrepancy in temperature reading between the different curves. However, each curve approaches an asymptotic value at approximately the same gas velocity.)

When the valve at the end of the thermocouple shield was closed no gas flowed by the thermocouple, and the couple measured the temperature of the surrounding solids. When the valve was opened gas passed through the shield over the bead, and the couple read practically the true gas temperature.

The gas flowing through the shield passed out from the valves $v_{4}, v_{5}$, or $v_{6}$ (fig. 1 ), through orifice $o_{2}$, through valve $v_{7}$, and back into the circulating gas system.

\section{PROCEDURE}

When a run was started the gas was by-passed around the column through valve $v_{1}$ until the temperature was constant. At a given time the gas was started through the column by opening $v_{2}$ and closing $v_{1}$. Repeated readings were taken on the three shielded thermocouples. The lower thermocouple, for instance, was read with $v_{4}$ closed and again when no gas was flowing through the shield. The couple then read practically the temperature of the surrounding solid particles. Next, the valve was opened, and the gas flowed out through the shield. Within 30 seconds after the valve was opened the couple read practically the true gas temperature. Enough pressure was kept on the system to maintain a linear velocity past the couple of at least 7 meters per second, which gave readings approximating the true gas temperature. After the gas temperature was obtained the valve was closed again, and a little later the couple again read the solid temperature. Thus, by alternating the opening and closing of the valves on the thermocouple shield a single couple could be used to give a double record of solid temperature and gas temperature. Each record was necessarily intermittent, but the points were near enough together to permit satisfactory interpolation. A typical plot of the time record of such a couple is shown in Figure 5.

The record of one of the couples was kept on a Leeds \& Northrup recording potentiometer. The other couples were read with a portable potentiometer.

\section{HEAT LOSSES}

The apparatus was calibrated for heat losses by heating it with a gas stream and then allowing it to cool, the rate of cooling being observed. The author believed that most of the resistance to heat flow through the walls of the apparatus was in the insulation and that it was practically immaterial whether or not gas was flowing. After the apparatus had cooled for a short time the rates became erratic, undoubtedly because of convection currents within the column. Hence, for heat-loss curves only the first few temperature readings were used, the curve being extrapolated to lower temperatures by means of the published relation between the thermal conductivity of Sil-o-Cel powder and temperature.

\section{EXPERIMENTAL DIFFICULTIES}

The difficulties in this form of experimentation are numerous, and most of them are not encountered in "steady-state" measurements. Care must be taken that the tip of the thermocouple shield is sufficiently well insulated from the outside of the apparatus to prevent erroneous readings of the solid temperature. The gas velocity through the shield must be maintained sufficiently high to insure correct reading of the gas temperature. The heat losses often amount to more than half of the total heat transferred and easily lead to in- 
correct results. Even with a bed of solids which apparently is uniform, it is practically impossible to maintain a uniform gas flow over the entire cross section, and this often results in erratic data.

\section{INTERPRETATION OF RESULTS}

By definition, the coefficient of heat transfer is the rate of heat acquisition, measured in calories per second, divided by the temperature difference between the gas stream and the solid. It is common practice to limit the coefficient to the heat transferred per unit of surface area. In the study under consideration the area exposed to the gas stream depends upon the size, shape, and degree of packing of the particles in the bed. Since all these variables are involved it is more convenient to determine the coefficient for a given volume of apparatus and then to compute the coefficient for unit surface area.

The rate of heat absorption is directly proportional to the weight of the solid material, its specific heat, and the rate of temperature change. In addition to the heat actually absorbed by the solids a

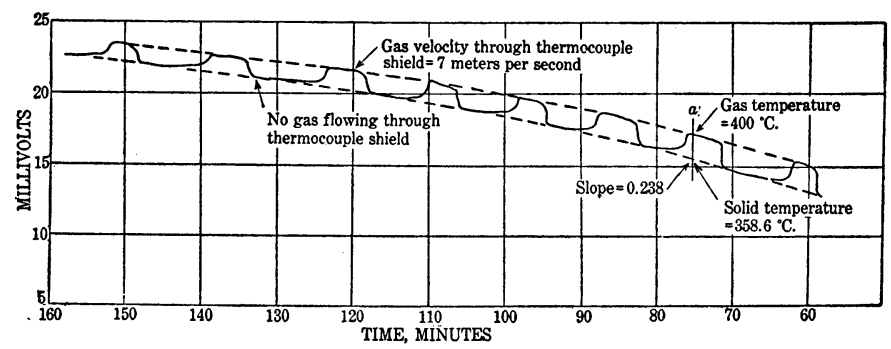

FIGURE 5.-Typical gas and solid temperature record from the chart of the recording potentiometer

further quantity is transferred but lost by conduction through the walls of the apparatus. To evaluate the coefficient of heat transfer it is necessary to determine each of these quantities. The weight of metal per centimeter of length of apparatus was determined at the time the apparatus was set up.

The specific heat of iron was taken from the literature. ${ }^{20}$ The data for rate of temperature change and temperature difference between gas and solid are obtained from the record of the gas and solid temperatures (potentiometer reading) plotted against time (fig. 5). The slope of the curve at any time is the rate of temperature change of the apparatus at the given point and time under consideration. The slope can easily be translated into degrees centigrade per second. This quantity is multiplied by the specific heat of iron at that temperature and by the weight of iron per centimeter of apparatus. To it is added the rate of heat loss, which is determined by the difference between the temperature of the column and the room. The sum is divided by the gas and solid temperatures at this particular time (fig. 5). The quotient is the coefficient of heat transfer measured in calories per second per degree centigrade difference of temperature per centimeter of length of apparatus. To obtain the coefficient for each cubic centimeter of apparatus the above coefficient is divided by the cross-sectional area of the apparatus. If, in turn, this last

${ }^{20}$ Ralston, O. C., Iron Oxide Reduction Equilibria: Bureau of Mines, Bull. 296, 1929, p. 188. 
coefficient is divided by the surface area of particles and container per cubic centimeter of apparatus, the quotient is the usual coefficient measured in calories per second per square centimeter of surface per degree centigrade difference. A sample computation is given below.

Diameter of balls, $3.17 \mathrm{~cm}$.

\section{Sample computation}

Flow $=0.01875$ standard liter per second per square centimeter.

Weight of iron per centimeter of length of apparatus =1,150 grams.

Cross-sectional area of bed $=167.5 \mathrm{~cm}^{2}$.

Room temperature $=30^{\circ} \mathrm{C}$.

From Figure 5:

Gas temperature (potentiometer) $=17.10$ millivolts.

Gas temperature (from calibration curve, not given) $=400^{\circ} \mathrm{C}$.

Solid temperature (potentiometer) $=15.34$ millivolts.

Solid temperature $=358.6^{\circ} \mathrm{C}$.

Gas temperature-solid temperature $=41.4^{\circ} \mathrm{C}$.

Slope of solid temperature curve on chart $=0.238$.

On chart, $1 \mathrm{~cm}$ on ordinate $=2.25$ millivolts $=53^{\circ} \mathrm{C}$; on calibrated couple: $1 \mathrm{~cm}$ on abscissa $=250$ seconds.

Rate of change of temperature of solid $=\frac{0.238 \times 53}{250}=0.0504^{\circ} \mathrm{C}$. per second. Specific heat of iron ${ }^{21}$ at $359^{\circ}$ C. $=0.140$.

Heat capacity of $1 \mathrm{~cm}$ of apparatus $=161$ calories per degree centigrade.

Heat acquired by metal $=161 \times 0.0504=8.1$ calories per second.

Heat loss:

Solid temperature-room temperature $=330^{\circ} \mathrm{C}$.

Coefficient of heat loss at $360^{\circ} \mathrm{C}$. (curve not shown) $=0.006$ calorie per second per centimeter length of apparatus per degree centigrade difference.

Heat loss $=330 \times 0.006=2.0$ calories per second.

Total heat transferred from gas stream $=8.1+2.0=10.1$ calories per second.

Coefficient of heat transfer $=10.1 / 41.4=0.244$ calorie per second per centimeter of apparatus per degree centigrade difference.

Coefficient of heat transfer $=0.244 / 167.5=0.00146$ calorie per second per degree centigrade difference per cubic centimeter of apparatus.

\section{DATA OBTAINED}

Data were obtained on balls $1.85,3.17$, and $4.86 \mathrm{~cm}$ in diameter. The rate of air flow ranged from 0.01 to 0.053 standard liter per second per square centimeter of cross-sectional area of the bed. Temperatures up to $700^{\circ} \mathrm{C}$. were obtained. The voids in the different beds of material ranged from 39.5 to 50.6 per cent.

\section{EFFECT OF GAS VELOCITY}

The data on the effect of changing gas velocity, the temperature remaining constant, for the three sizes of balls are plotted in Figure 6 as straight lines on logarithmic paper. This means that

where

$$
k_{v}=K u^{n} \text {, }
$$

$k_{0}=$ coefficient of heat transfer from gas to solid, in calories per second per degree centigrade difference per cubic centimeter of apparatus;

$K=$ constant;

$u=$ velocity measured in standard liters per second per square centimeter cross-sectional area of the bed; and

$n$ is a constant.

The slope of the plotted line is the value of $n$. According to Figure $\underline{6}$, for balls $1.85 \mathrm{~cm}$ in diameter the coefficient varies approximately

${ }^{21}$ Ralston, O. C., work cited. (See footnote 20.) 
as the 0.74 power of the velocity; for balls $3.17 \mathrm{~cm}$ in diameter, as the 0.76 power; and for balls $4.86 \mathrm{~cm}$ in diameter, as the 0.78 power.

In general, the coefficient is approximately proportional to the $\mathbf{0 . 7 5}$ power of the gas velocity. Therefore

$$
k_{v}=K u^{0.75} \text {. }
$$

Increasing the gas velocity increases the coefficient of heat transfer, probably because the stagnant gas film surrounding the particles becomes thinner as the gas velocity increases. Most of the resistance

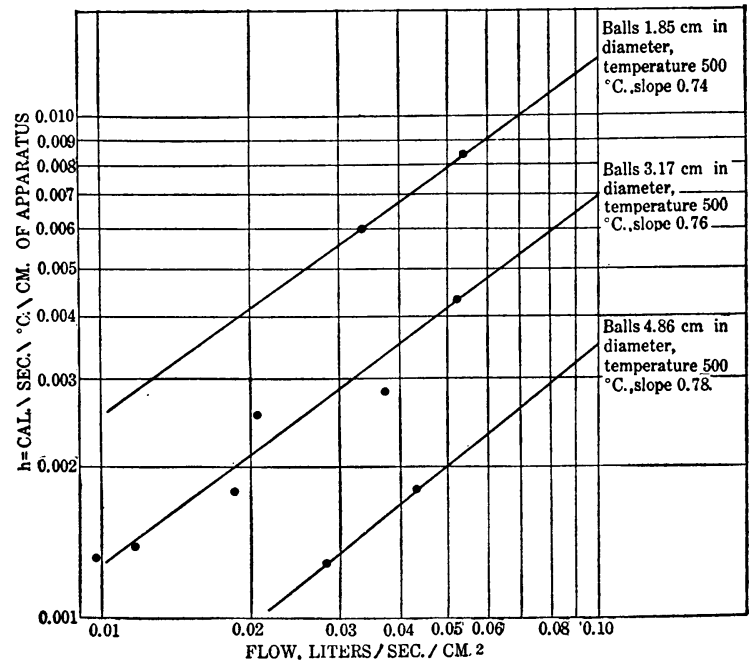

Figure 6.-Relation between rate of gas flow and coefficient of heat transfer

to heat transfer is in this film, so decreasing the thickness of the film may be expected to increase the heat transfer.

\section{EFFECT OF PARTICLE SIZE}

The data on the effect of changing particle size on the coefficient of heat transfer if the rate of flow is constant are given in Table 1.

TABLE 1.-Effect of variation of particle size and of voids on coefficient of heat transfer

[Temperature, $500^{\circ} \mathrm{C}$; flow, 0.06 liter per second per square centimeter]

\begin{tabular}{|c|c|c|c|c|}
\hline Diameter & $\begin{array}{c}\text { Voids in } \\
\text { bed }\end{array}$ & $\begin{array}{c}\text { Surface area } \\
\text { per cm } \\
\text { length } \\
\text { apparatus }\end{array}$ & $k_{\mathrm{L}}$ & $k$ \\
\cline { 1 - 1 } & Per cent & $C m^{2}$ & & \\
1.85 & 39.5 & 370 & 1.55 & 0.00925 \\
3.17 & 45.0 & 224 & .80 & .0048 \\
4.86 & 50.6 & 149 & .39 & .0023 \\
\hline
\end{tabular}

Note: $k_{L}=$ coefficient of heat transfer per unit of length of apparatus; $k=$ coefficient of heat transfer per unit of area.

As will be shown later, the coefficients determined by this method are probably too high. This method does furnish an approximate check on the method used later; and it may have some possibilities 
of further development in a limited field, so it was considered worth while to describe it. However, when it was applied to beds of less conductive material, such as iron ore, it was a complete failure. The data were erratic and not reproducible. It was very evident that some other form of experiment must be used to complete the study of blast-furnace materials.

\section{SECOND METHOD: TEMPERATURE HISTORY}

Dr. T. E. W. Schumann, at the laboratories of the Combustion Utilities Corporation, had done some preliminary experimentation with another method of determining the desired heat-transfer coefficient, according to a letter to the author. His method consisted of determining the temperature history of solid particles in a column of material which is being heated by a gas stream. Each value of coefficient gives a different temperature-history curve, so if the curve is determined experimentally and the mathematical solution of the system is available it should be possible to determine the coefficient from the curve by a cut-and-try solution.

The differential equations for this particular system had never been solved, but Schumann devised and published a very clever solution for this difficult problem. ${ }^{22}$

\section{SCHUMANN'S METHOD}

Schumann's method of attack was somewhat as follows: Assume that a uniform fluid stream is allowed to flow through a bed of broken solids which was initially at some temperature lower than that of the stream. If there is no heat loss through the walls of the apparatus the entire bed of material will eventually arrive at the initial temperature of the fluid. Given the thermal properties of the fluid and solid it should be possible to develop the mathematical relations for the temperature history of any point in the bed.

The problem is difficult, but Schumann presents a very clever and skillful solution. The derivation is rigorously exact only for systems where the thermal properties are constant and for a noncompressible fluid and where the solid particles are so small that there is no temperature gradient within the piece at any time. However, as will be shown later, it was found experimentally that this solution applied quite accurately to systems where the fluid is a gas and where there are considerable variations in thermal properties and the solid pieces are large.

Schumann's mathematical procedure will not be presented, but his computed curves are important and are given in Figures 7 and 8.

The symbols used have the following definitions:

$T_{o}=$ initial uniform temperature of the fluid;

$T_{o}=$ temperature of fluid at any point at any time; and

$T_{s}=$ temperature of solid at any point at any time.

$$
\begin{gathered}
z=\frac{k}{h_{s}(1-f)}\left(t-\frac{f x}{v}\right), \text { and } \\
y=\frac{k}{h_{g}} \frac{x}{v},
\end{gathered}
$$

${ }^{2}$ Schumann, T. E. W., Heat Transfer: A Liquid Flowing Through a Porous Prism: Jour. Franklin Inst., vol. 208, 1929, p. 305.

$112607^{\circ}-32-2$ 
where

$x=$ distance from bottom of column in centimeters;

$t=$ time in seconds;

$v=$ fluid velocity in standard cubic centimeters per second per square centimeter cross-sectional area of bed;

$f=$ fractional voids in bed (no units);

$h_{s}=$ heat capacity of solid in calories per cubic centimeter per degree;

$h_{\sigma}=$ heat capacity of fluid in calories per standard cubic centimeter per degree; and

$k=$ coefficient of heat transfer in calories per degree per second per cubic centimeter of volume of bed.

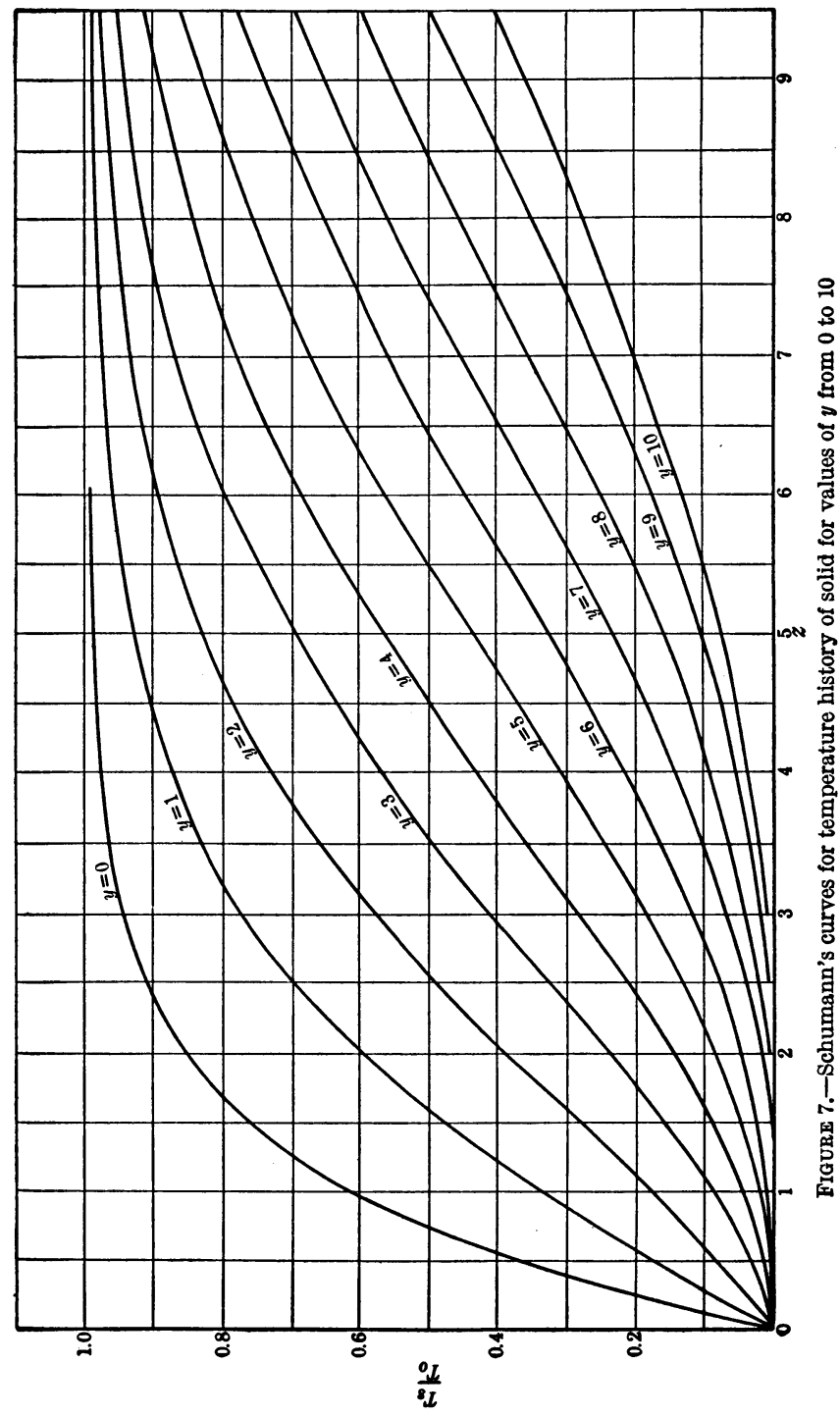

Since the groups of variables of equations 9 and 10 are dimensionless, any system of units may be used instead of the metric, provided they are mutually consistent. 
This paper is concerned primarily with gas streams, and for such a system the quantity $x / v$ is negligible compared with time $t$, so the last term of equation 9 may be dropped, and $z$ may be defined as

$$
z=\frac{k t}{h_{s}(1-f)} .
$$

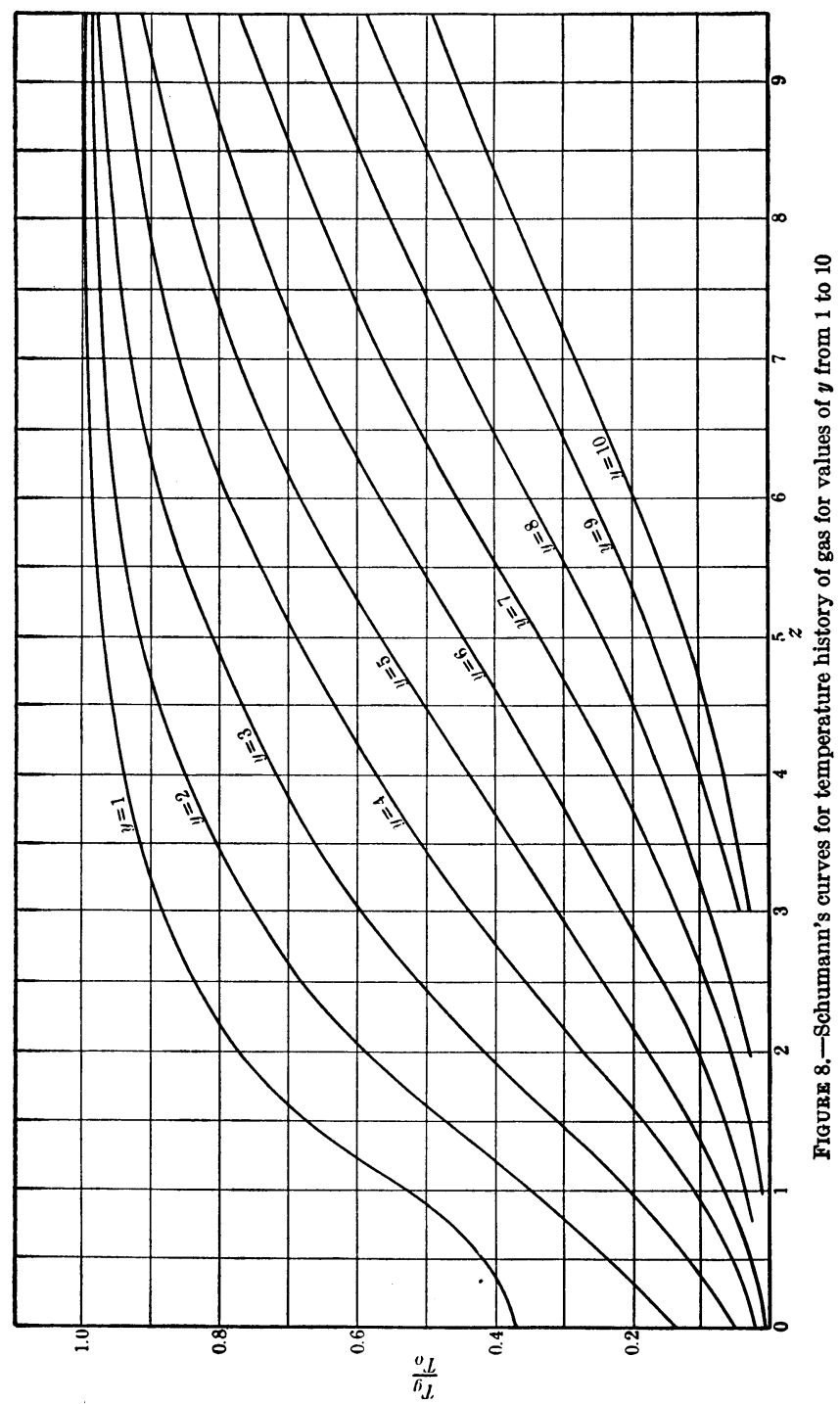

Thus, in Figures 7 and 8 the abscissas are proportional to time; the ordinate is the temperature; and the different values of $y$ on the different curves are proportional to the height of column being considered. 


\section{EXAMPLE OF APPLICATION}

The use of these computed curves may be demonstrated by a simple example.

Problem. - A cold column of broken solids is made up of material which has a heat capacity of 0.25 calorie per cubic centimeter. The voids in the charge make up 50 per cent of the entire column. The column is at an initial temperature of $25^{\circ} \mathrm{C}$. It is being heated by a gas stream, the temperature of which is $1,200^{\circ} \mathrm{C}$. The average heat capacity of the gas is 0.0003 calorie per standard cubic centimeter. The rate of flow is 100 standard $\mathrm{cm}^{3}$ per square centimeter of cross-sectional area of bed per second. The coefficient of heat transfer from the gas stream to the solid is 0.01 calorie per second per degree per cubic centimeter of the bed. What is the temperature of the gas and the solid at a point $30 \mathrm{~cm}$ from the bottom of the bed after the hot gas has been flowing 100 seconds?

Solution.- The initial uniform temperature of the solid is taken as zero. Therefore, $T_{o}$ is $1,175^{\circ} \mathrm{C}$. and $T_{o} / T_{o}$ and $T_{s} / T_{o}$ are proportional parts of this quantity and represent the gas and solid temperature, respectively.

From the condition of the problem, substituting the proper values in equation 10,

$$
y=\frac{0.01 \times 30}{0.0003 \times 100}=10.0 \text {. }
$$

Substituting the proper, designated values in equation 11,

$$
z=\frac{0.01 \times 100}{0.25 \times 0.5}=8.0 \text {. }
$$

The temperature of the solid is found in Figure 7. In this figure, when $y=10.0$ and $z=8.0, T_{s} / T_{o}=0.280$. Therefore, $T_{s}=0.280 \times 1,175=329^{\circ} \mathrm{C}$. Since the initial temperature of the solid was $25^{\circ} \mathrm{C}$. the desired solid temperature is $329+25=354^{\circ} \mathrm{C}$. From Figure 8 the temperature of the gas when $y=10.0$ and $z=8.0$ is $T_{o} / T_{o}=0.375$. Therefore, $T_{o}=0.375 \times 1,175=441^{\circ} \mathrm{C}$. Gas temperature $=441+25=466^{\circ} \mathrm{C}$.

\section{LIMITS OF APPLICATION}

Obviously, if the thermal properties of the system are known the solution of a problem of temperature history becomes one of extreme simplicity, after the curves have been computed, for the temperatures for any given time or position may be read directly from the curves. However, the curves of Figures 7 and 8 have limited application, for the solution of a problem involving a column more than $50 \mathrm{~cm}$ high, over 100 seconds of time, and a coefficient of 0.01 is beyond the limit of the curves. For small coefficients of heat transfer the size of column considered could be somewhat larger but still very limited.

\section{ALTERNATIVE METHOD OF SOLUTION}

The formal integration of the differential equations which Schumann ${ }^{23}$ developed results in an infinite series, each term of which is itself an infinite series - a complicated arrangement. These infinite series are related to the so-called modified Bessel functions of the first kind. Probably the reason that Schumann did not compute the curves for higher values of $y$ and $z$ is that only the small values of these modified Bessel functions are easily available and the direct computation for higher values involves enormous labor.

However, it is possible to solve the equations by graphical integration and for any desired values of $y$ and $z$. The method is a fine

${ }^{23}$ Schumann, T. E. W., work cited. (See footnote 22.) 
illustration of the unique power of graphical methods. Schumann showed that:

$$
\begin{array}{r}
\frac{\delta T_{s}}{\delta z}=T_{o}-T_{s} \\
\frac{\delta T_{g}}{\delta y}=T_{s}-T_{o} \\
T_{s}=T_{o}(U-V) e^{-y-z} \\
T_{o}=T_{o}(U+V) e^{-y-z} \\
V=3 J_{o}(2 i \sqrt{y z})
\end{array}
$$

$T_{s}, T_{o}, T_{o}, y$, and $z$ have already been defined. $J_{o}(2 i \sqrt{y z})$ is a so-called modified Bessel function of the first kind and zeroth order. Schumann's nomenclature differed slightly from that ordinarily accepted, and the function he used is ordinarily represented ${ }^{24}$ by $I_{o}(2 \sqrt{y z})$. This symbol will be used in the following discussion.

From the above equations it can be shown by simple algebra that

$$
\text { - } \frac{T_{o}-T_{s}}{T_{o}}=2 V e^{-y-z}=I_{o}(2 \sqrt{y z}) e^{-y-z} .
$$

From equations 12 and 17, if $y$ is constant

$$
\frac{\delta T_{s}}{T_{o}}=I_{o}(2 \sqrt{y z}) e^{-y-z} \delta z .
$$

The curve of $T_{s}$, then, for each value of $y$ can be obtained by plotting values of the products of the two functions $I_{o}(2 \sqrt{y z})$ and $e^{-y-z}$ against $z$ and integrating graphically from $z=0$ to $z=\infty$. The function $e^{-y-z}$ can be computed exactly, but the $I_{o}$ function, as mentioned above, is known only for small values of $2 \sqrt{y z}$. However equation 18 holds the key to the determination of this function.

Indicating the formal integration of equation 18,

$$
\int_{0}^{T_{o} \frac{\delta T_{s}}{T_{o}}}=\int_{0}^{\infty} I_{o}(2 \sqrt{y z}) e^{-y-z} \delta z .
$$

From the physical conditions of the system it can be seen that the value of this integral from zero to infinity must be equal to unity, for the total possible change in solid temperature, $T_{s}$, is equal to $T_{o}$. Therefore

$$
\int_{0}^{\infty} I_{o}(2 \sqrt{y z}) e^{-y-z} \delta z=1 .
$$

With this criterion, a solution may be assumed for the Bessel function and then tested for its validity. The details of these computations are reported elsewhere. ${ }^{25}$

When the values of the Bessel function for the higher values of $\sqrt{y z}$ have thus been established, they may be used in turn to perform the graphical integration of equation 18 and thus to obtain the curve of $T_{s} / T_{o}$ against $z$, as described in a previous paragraph. Graphical

${ }^{24}$ Gray, Andrew, Mathews, G. B., and MacRobert, T. M., A Treatise on Bessel Functions: New York, 2 d ed., 1922, p. 20.

${ }_{25}^{25}$ Furnas, C. C., Evaluation of the Modified Bessel Function of the First Kind and Zeroth Order: Am. Math. Monthly, vol. 37,1930 , p. 282. 
integration to the limit $\infty$, of course, is impossible; but the curves of the function of equation 18 start at zero, rise to a maximum approximately at the point where $y=z$, and then fall and approach zero so rapidly that the area under the curve for higher values of $\sqrt{y z}$ may

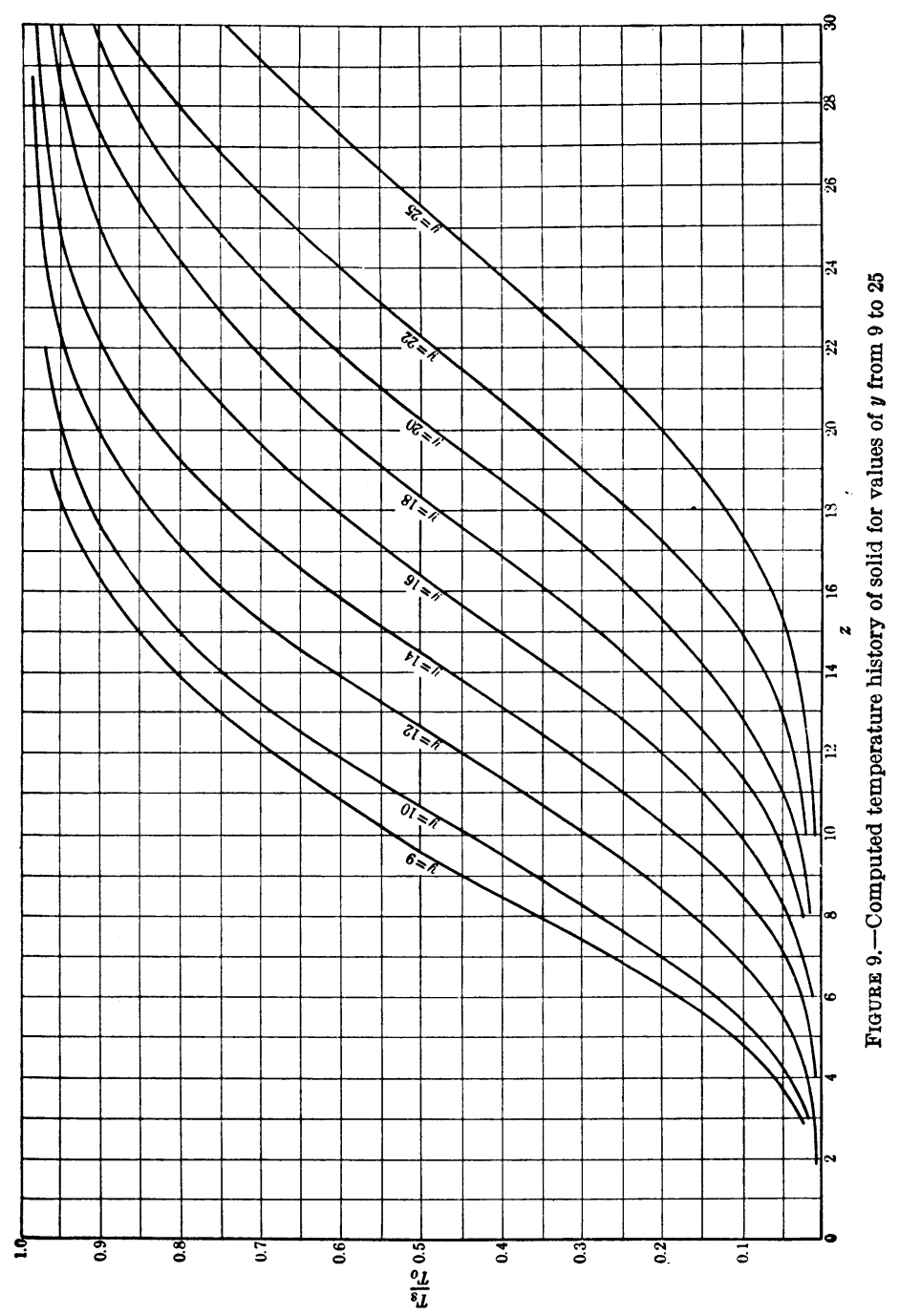

be neglected without loss of accuracy. This very fortunate circumstance makes the graphical method possible.

The method just described furnishes a means of computing the curve of the temperature history of the solid. From equation 12 it is seen that for any value of $z$ the temperature of the gas is

$$
T_{0}=T_{s}+\frac{\delta T_{s}}{\delta z} .
$$


Hence, to obtain the temperature of the gas it is only necessary to add the numerical slope of the curve. The temperature-history curves for both gas and solid have been computed for values of $y$ up to 500 and are shown in Figures 9 to 14 . This value of $y$ is large enough for very long columns of material.

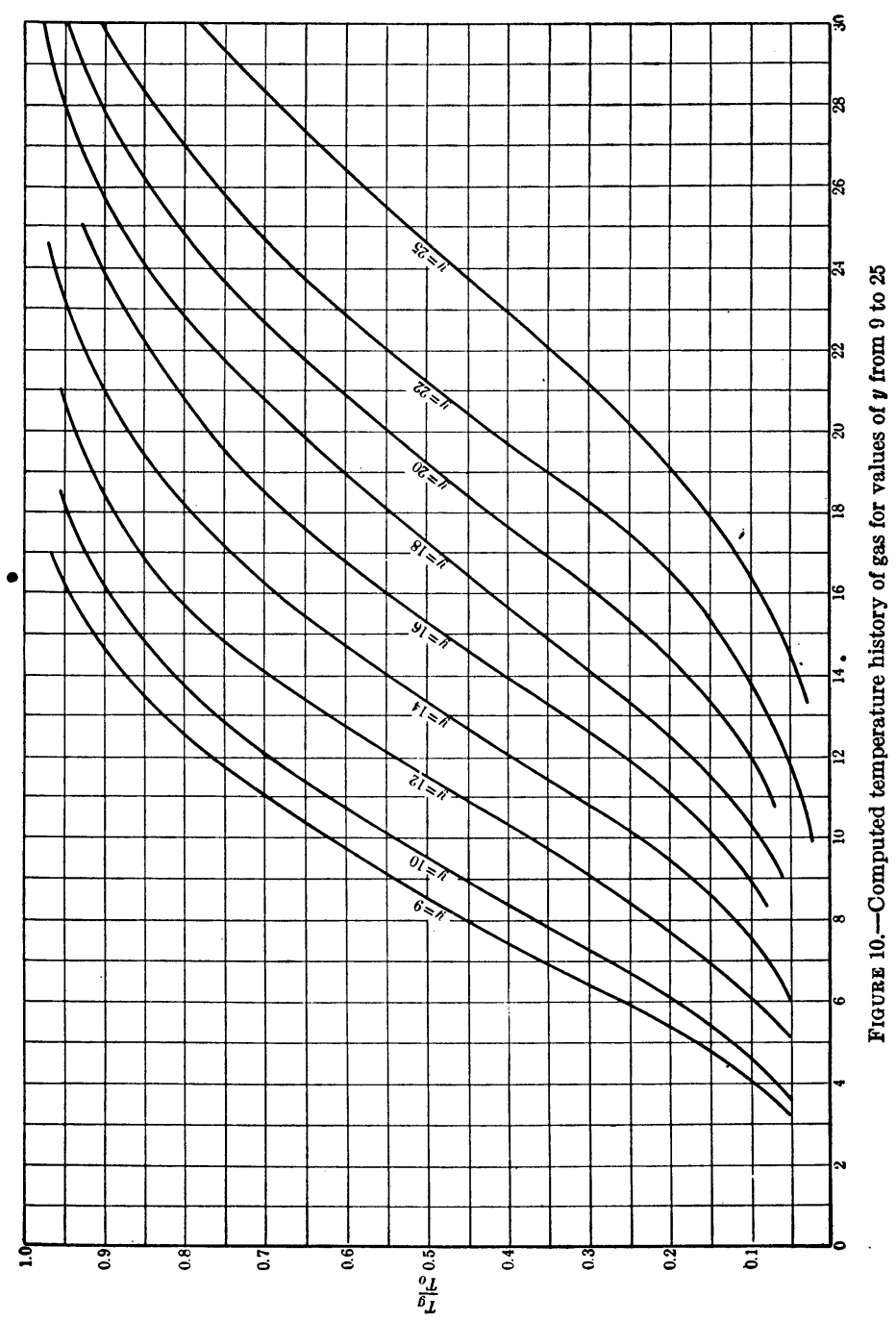

\section{METHOD OF SOLUTION FOR COEFFICIENT}

If the temperature-history curve is obtained for a given system wherein the coefficient of heat transfer is not known, it should be possible to work backward by a trial-and-error method to determine what value of the coefficient makes the observed data fit the theoretical curves. This, then, would afford a means of determining the average heat-transfer coefficient for the system. 


\section{ADVANTAGES OF METHOD}

This method has the advantage of giving results which are the average for the entire bed, small variations within the body of the bed being averaged out. The principal experimental advantage is

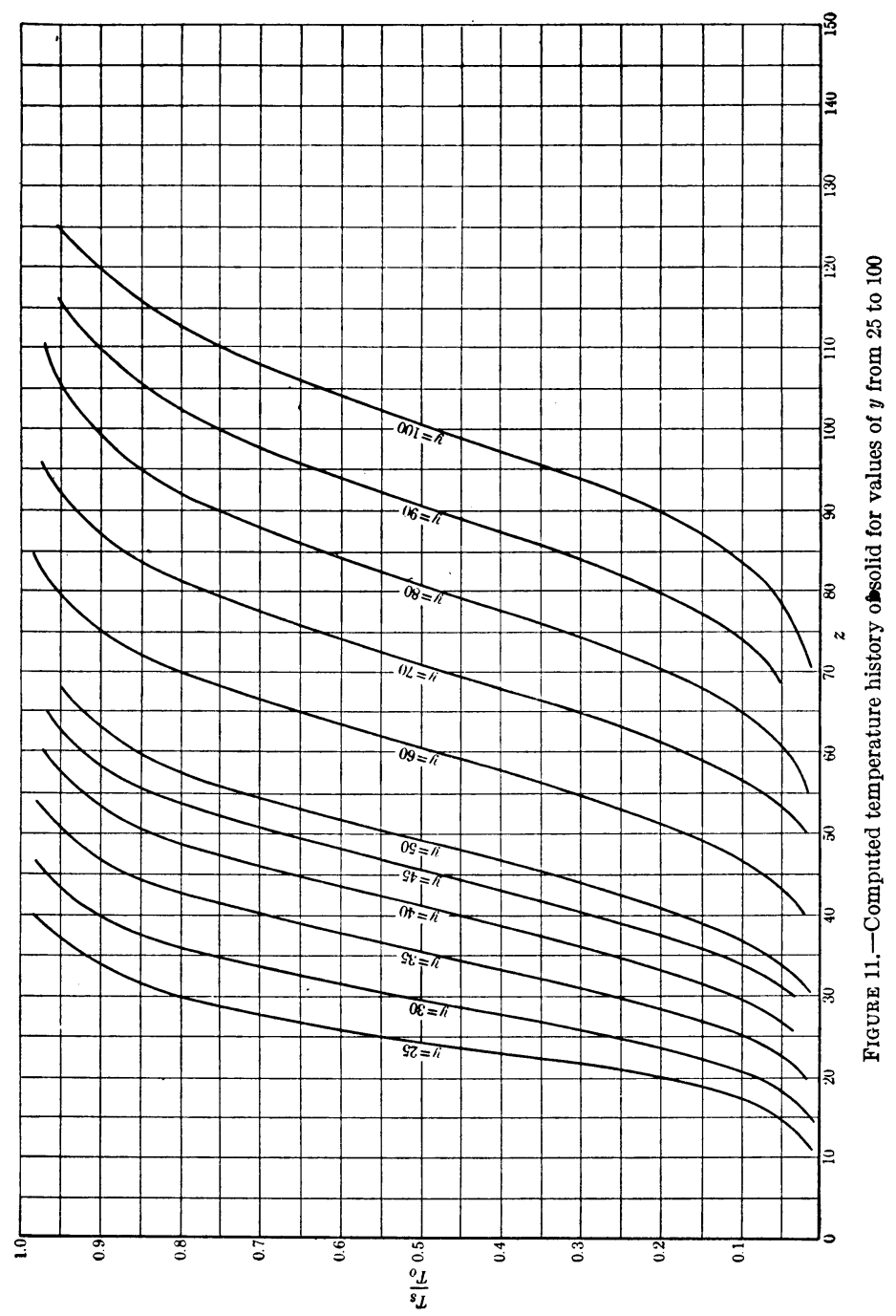

that it is not necessary to measure the temperature difference between two objects. Measurements of such differences are usually liable to lead to considerable error.

The temperature-history curves have been computed for both solid and fluid stream so that measurements can be made upon either for a determination. 


\section{EXPERIMENTS WITH WATER}

The experimental work which Schumann did, and which he described in a communication to the writer, was very limited; and the results were never published, so it was necessary for the author to develop a suitable method to get data to compare with the theoretical

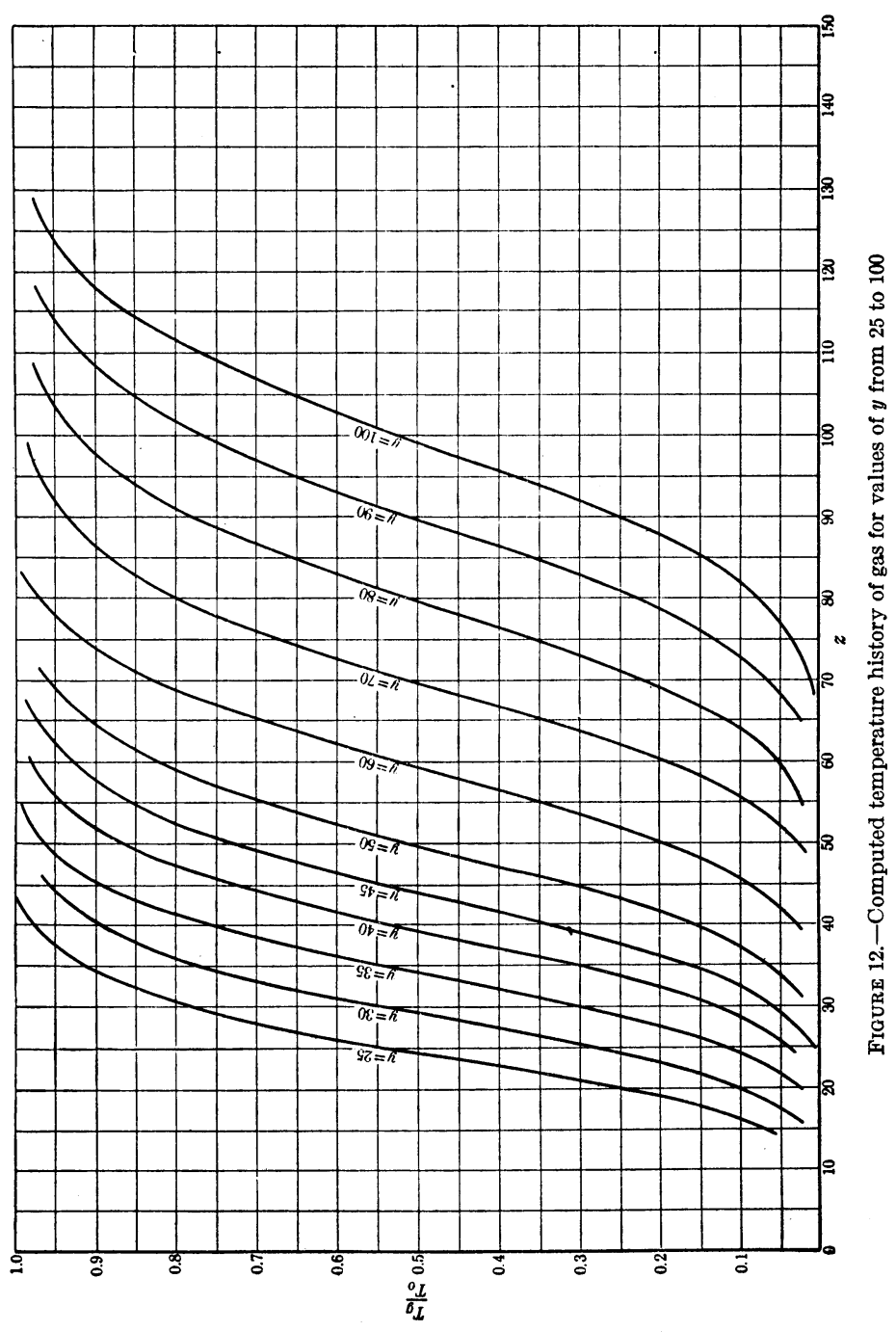

curves. Schumann and Burke suggested to the writer that it might be best, first, to set up experimental conditions which exactly conformed to the hypotheses of the mathematical solution, namely, highly conductive solid material and a noncompressible fluid. For this method of determination to have any significance it is necessary that the experimental data shall fit one of the family of computed curves. If the data do not fit, the mechanism of transfer is not that 
which was assumed, and the curves have no significance in determining the desired value of the coefficient, so it seemed best to make the experimental conditions fit the assumptions as closely as possible. Hence, the first experiments were conducted on a system where water flowed uniformly through a bed of iron balls.

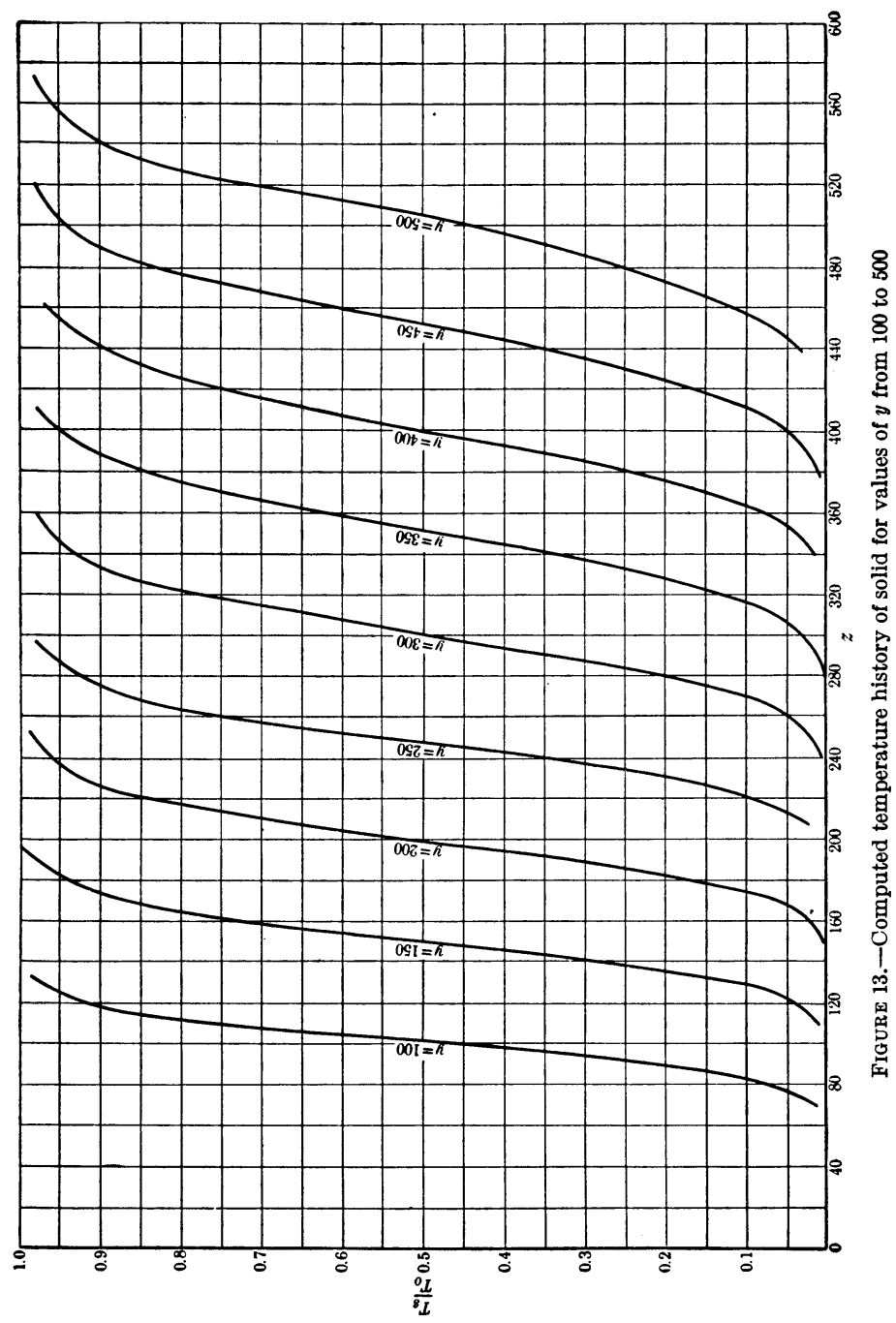

APPARATUS FOR HEAT TRANSFER FROM WATER

A diagram of the apparatus is shown in Figure 15. Water from the cold-water main $C . W$. was forced through valve $V_{1}$, through heater $H$, which contains steam-coil $S$. Until steady temperature conditions were obtained the water would be by-passed through pipe $B_{2}$ by opening valve $V_{3}$ and keeping valve $V_{4}$ closed. When the temperature of the water was constant the run would be started by opening valve $V_{4}$ and closing valve $V_{3}$. Cold water could be by-passed around 
the heater by means of the pipe $B_{1}$, the amount being controlled by valve $V_{2}$. This furnished a means of controlling the water temperature.

The column of material was made up of steel mill balls $3.2 \mathrm{~cm}$ in diameter, with a specific gravity of 7.9. They were packed into a

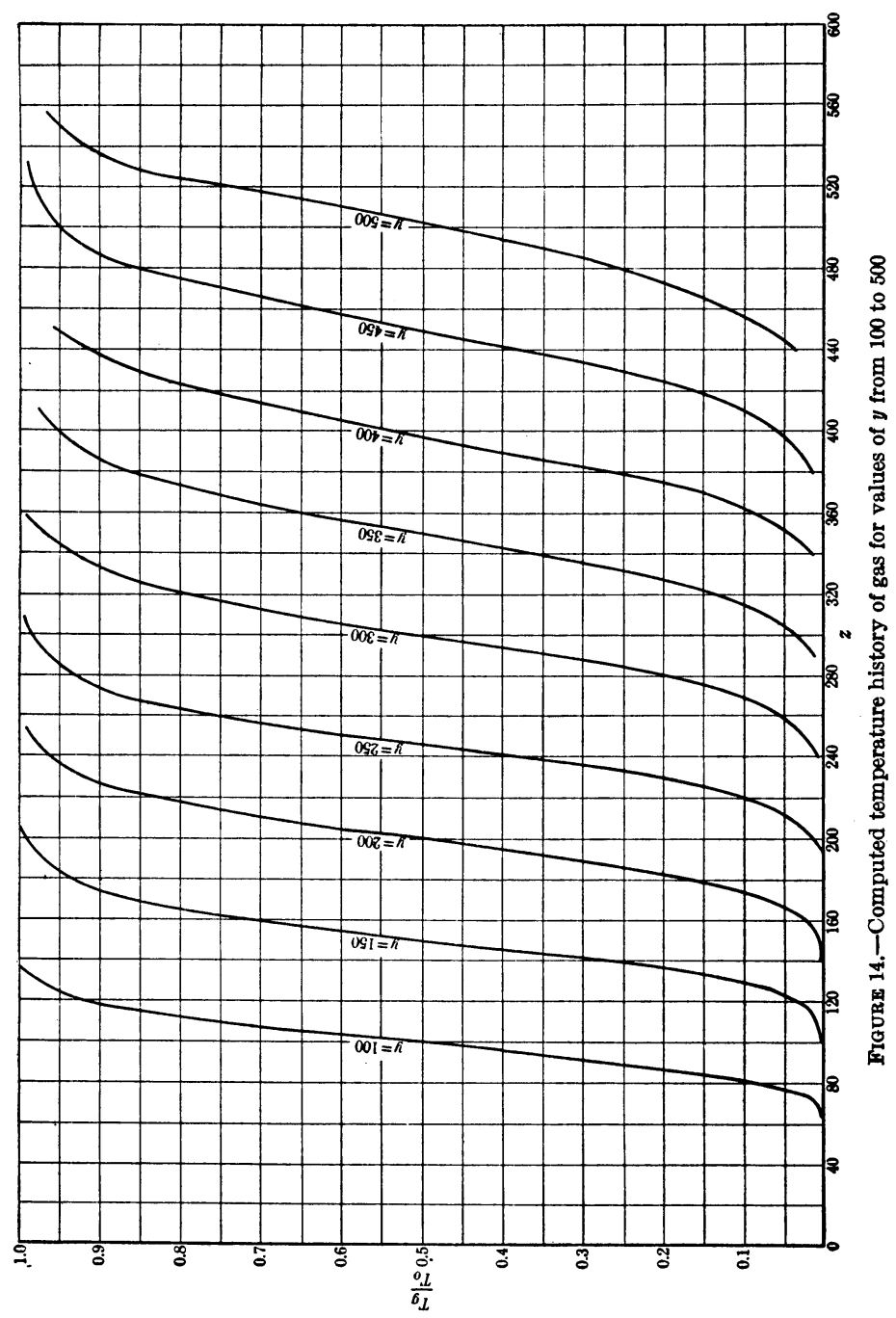

standard 8-inch pipe (20.5 $\mathrm{cm}$ in inside diameter). The voids in the bed were 41.0 per cent. At the bottom the balls rested on a grill work made of iron rods welded across the pipe. The bed itself was $71 \mathrm{~cm}$ in height. A thermocouple, $T_{3}$, was placed in the center of a ball in the center of the top of the column. Twelve other thermocouples were distributed throughout the column, 6 in the water stream and 6 imbedded in balls, but they are not shown in the diagram. The iron pipe was surrounded by a concentric cylinder of 20 -gage sheet, the 
annular space being packed with Sil-o-Cel powder. The width of this insulating layer was $15 \mathrm{~cm}$. The rate of water flow during a run was measured by orifice $O$, which was $1.35 \mathrm{~cm}$ in diameter in a pipe 5.25 $\mathrm{cm}$ in diameter. The orifice was repeatedly checked by measuring the rate of flow into vessels placed at the outlet.

\section{INCONSISTENCIES IN DATA}

The first data obtained were the temperature readings of thermocouple $B$ (fig. 15) at various short intervals of time after the hot water was allowed to start flowing through the column. In later experiments data were taken from several other thermocouples placed at different positions in the bed. For each datum there is a value of the transfer coefficient $k$ which will satisfy the definition of both $y$ and $z$ (equations 9 and 10), so that the solution will fall upon one of

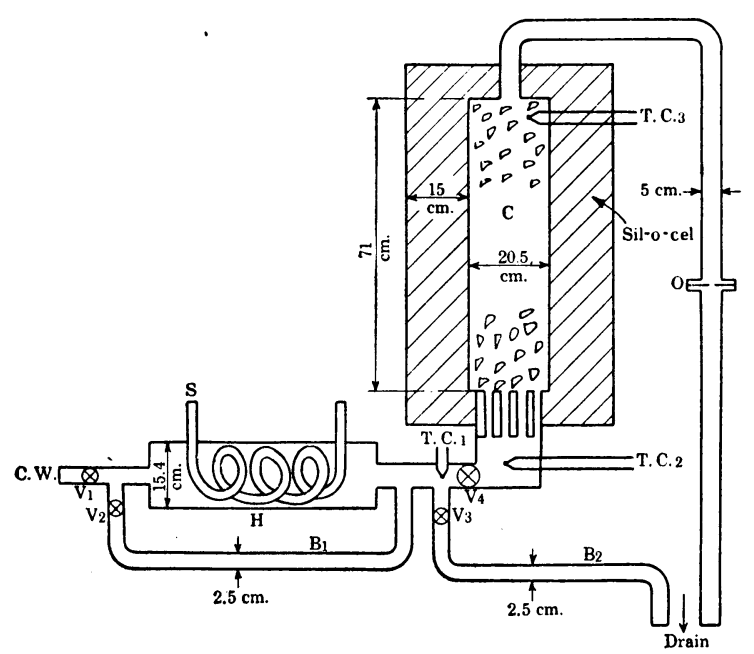

Figure 15.-Diagram of apparatus for the determination of the coefficient of heat transfer between water and a bed of iron balls the curves of Figure 7. By making cut-and try solutions it is possible to find the value of $k$ which satisfies the definition of both $y$ and $z$ for some particular point on one of the family of curves.

Unfortunately, the results were not consistent. In almost all cases the value of $k$ so determined was higher in the first part of the run but tended to approach an apparent constant value in the latter part of the run. Itwas necessary to make a more careful study of the data.

It will be noticed in equation 9 that fluid velocity $V$ is involved. This quantity is measured in volume of liquid per second per square centimeter of bed. In the derivation of the equations for the solution given above it was assumed that the fluid advanced uniformly through all interstices in the bed. However, such is not the case. Measurements of the length of time which it takes for a temperature change to be shown at different distances up the column indicated that only about one-half of the void space was being used for passage of the water. Some earlier work on gas flow through beds ${ }^{26}$ indicated that for gas streams only about one-fourth to one-third of the void space is actually used for the passage of gas.

Hence, the actual linear velocity of the fluid is problematical and might cause the solution to show an error, particularly in the early part of the run where the quantity $\frac{f X}{V}$ is of the same order of magnitude as time $t$. 
Unfortunately, assuming different values of the effective velocity $\frac{V}{f}$ did not help the solution. The coefficient of transfer, which should be constant, still showed decided changes in different parts of the run. It was evident that the mechanism of transfer was not that which had been assumed in Schumann's solution.

\section{METHOD OF DETERMINING AVERAGE COEFFICIENT}

Thermocouples in different parts of the column showed that the flow of the liquid was never uniform across a plane. The temperature change was always more rapid in the center than along the walls, indicating that the water tended to flow in a column through the center, making a sort of channel there. Measurements showed that the heat losses through the walls to the Sil-o-Cel packing were negligible, so nonuniform flow seemed to be the only explanation. Several attempts were made to direct the flow from the bottom by means of baffles, but no noticeable improvement was made. The system, instead of being as Schumann had assumed, was one in which the rate of flow varied across the plane, and the curves of Figure 7 were not strictly applicable.

However, after considerable data had been gathered it seemed that interpretation in some quantitative way should be possible so another method of empirical solution was devised. By using graphical methods, the data of Schumann's curves (fig. 7) were used to compute data on the relation of the proportion of the total heat acquisition, up to a certain point in the apparatus, as related to time. Instead of having curves for the temperature of a particular point in the apparatus for various times (fig. 7) curves were obtained for the total amount of heat which had been absorbed below the given point, up to the given time. Evidently, this latter method of attack gives a result which is the average of the conditions throughout the period and thus should be a tool to permit the averaging of discordant data.

In following through this method of graphical solution, it should be remembered that $y$ is proportional to distance and that $z$ is proportional to time. Therefore, for a constant value of $z$,

$$
\int_{0}^{y} T_{s} d y=Q
$$

where $Q$ is proportional to the total amount of heat absorbed up to point $y$ from zero time to time $z$. Therefore, all that is necessary to obtain the relative values of the heat absorbed $(Q)$ for different times and different lengths of apparatus is to solve (graphically) equation 22.

If cross sections of Figure 7 are plotted Figure 16 is obtained. In this figure, values of $T_{s} T_{o}$ for different constant values of $z$ (proportional to time) are plotted against $y$ (proportional to distance up the column). Then the integral, expressed by equation 22 for any one of these curves, is the area under that curve up to the given value of $y$. These areas were determined by the usual methods of graphical

\footnotetext{
25 Furnas, O. C., The Flow of Gases Through Beds of Broken Solids: Bull. 307, Bureau of Mines, 1929, p. 22.
} 
integration. ${ }^{27}$ The integral curves for various values of $z$ and for values of $y$ up to 10 are given in Figure 17. The ordinate is only graduated in arbitrary units, as the desired results only need to be relative. The curve for $z=\infty$ can be interpreted as the curve of the amount of heat which will be absorbed by the column when it has all come up to a uniform temperature, plotted against the height of column $y$.

If at any particular value of $y$ the value of the ordinate of Figure 17 for different values of $z$ be divided by the ordinate value for $z=\infty$, then the quotient is the relative heat acquisition, $\frac{Q_{s}}{Q_{o}}$, for that particular value of $z$ (proportional to time) and $y$ (proportional to distance). $Q_{o}$ is the total amount of heat which will be acquired when the temperature has become uniform throughout the column. The curves so obtained are plotted in Figure 18. These curves give the relative

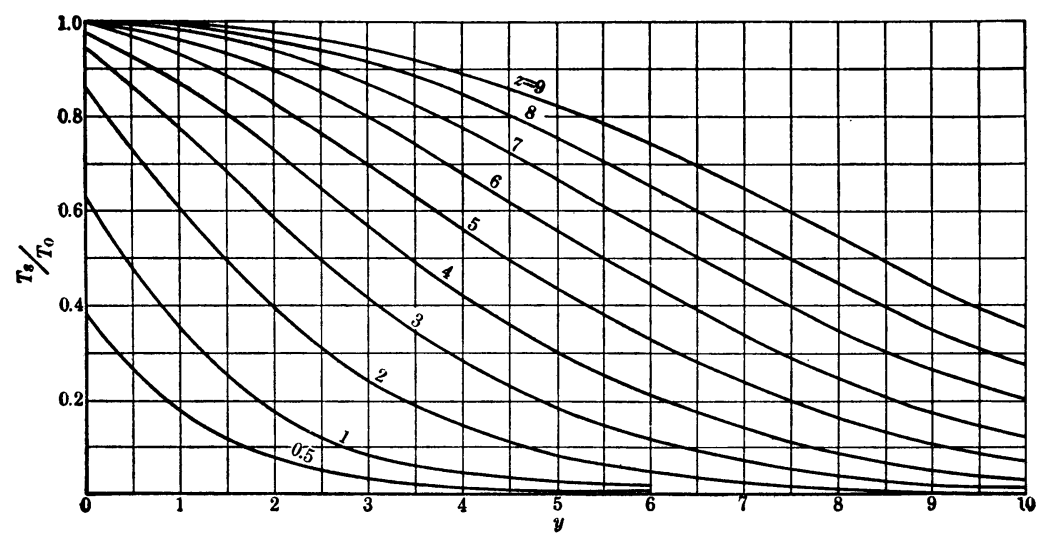

Figure 16.-Relation between $T_{\diamond} / T_{o}$ and $y$ for various values of $z$

amount of heat absorbed along the entire length of the column instead of the temperature of a particular point, as in Figure 7.

\section{SOLUTION FOR COEFFICIENT}

Graphical methods were used in solving for the average over-all coefficient in the apparatus. Data were available on three planes 6, 38 , and $71 \mathrm{~cm}$ from the bottom of the column. Thermocouples were placed in balls in the center and along the walls on each of these. The average temperature of the plane at any time was taken as the average of these two, after the readings had been weighted according to the cross-sectional area involved. When these data were plotted against distance up the column, the area under the curve represented the total amount of heat absorbed up to that point up to that time. When this area was divided by the total area under the curve for infinite time (temperature uniform throughout the apparatus), the quotient was the desired quantity $\frac{Q_{s}}{Q_{0}}$. After this value of $\frac{Q_{s}}{Q_{o}}$ was obtained for a given time it was necessary to use a trial-and-error method of solution to solve for the coefficient.

${ }^{27}$ For example: Running, T. R., Graphical Mathematics: John Wiley \& Sons, New York, 1927. 


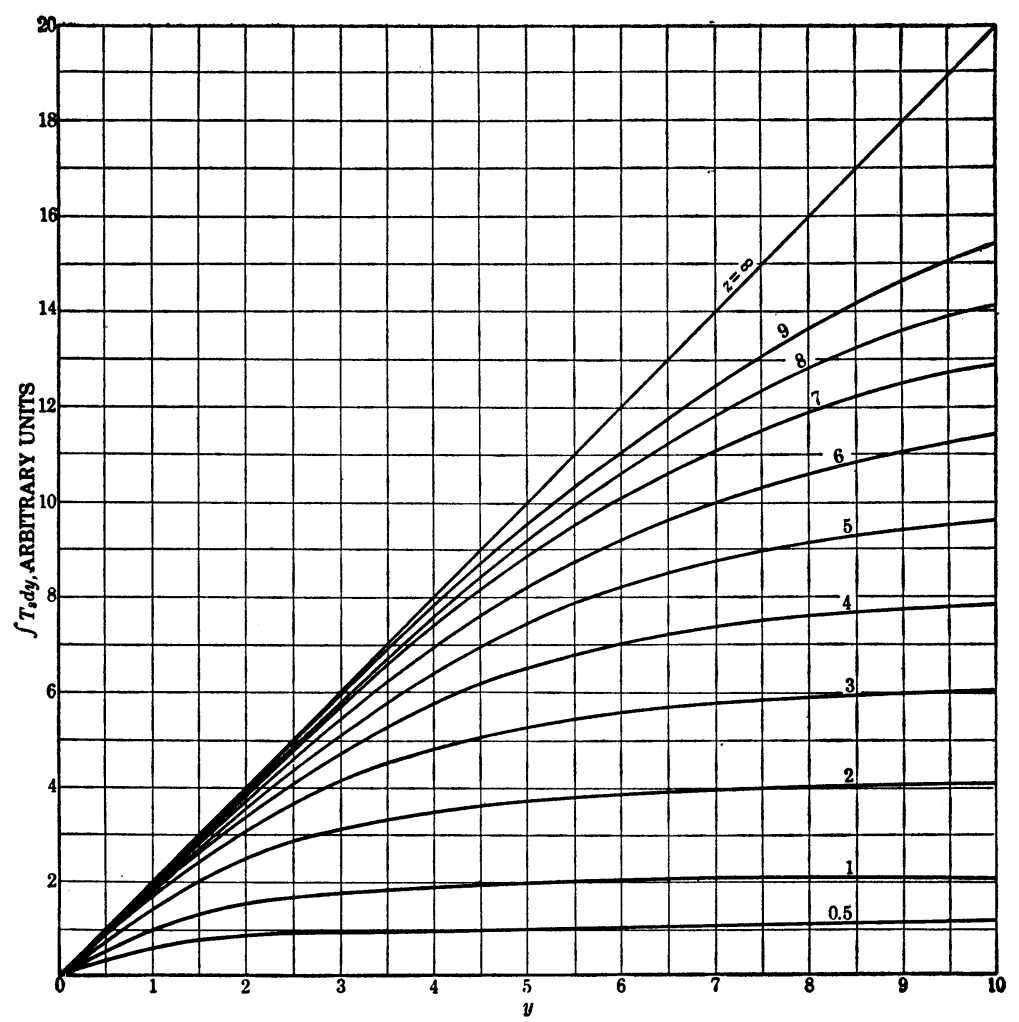

Figure 17.-Relation between $f T_{s} d y$ and $y$ for various values of $z$

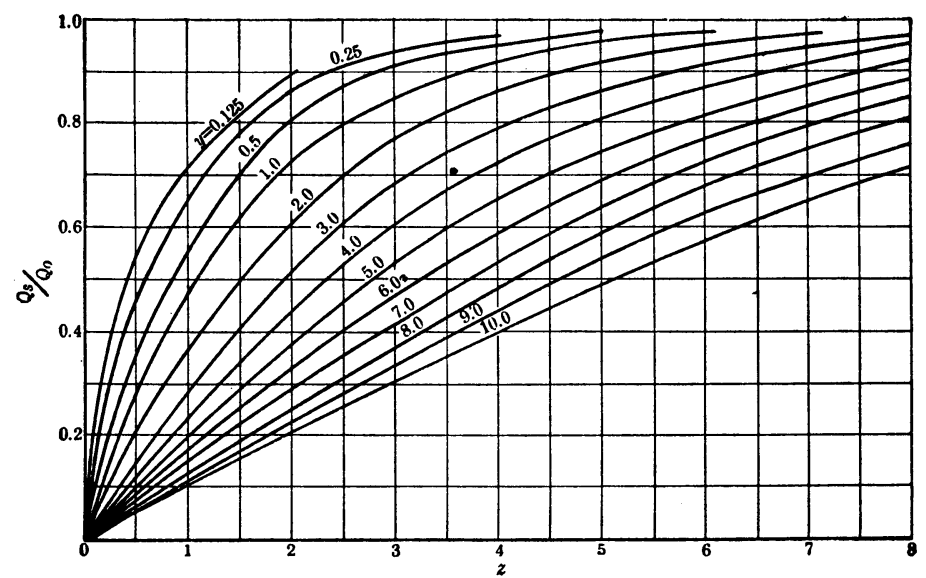

FigurE 18.-Relation between $z$ and the proportion of total heat absorbed, $Q_{0} / Q_{0}$ 
Example.-In run 17, where the rate of water flow was 0.000118 liter per second per square centimeter, when $t-\frac{f x}{v}$ equaled 600 seconds, the value of the ratio $\frac{Q_{s}}{Q_{o}}$ was 0.558 , as determined by graphical integration. Solution:

$$
\begin{gathered}
z=\frac{k}{h_{s}(1-f)}\left(t-\frac{f x}{v}\right), \\
y=\frac{k}{h_{o}} \frac{x}{v},
\end{gathered}
$$

$h_{s}=$ heat capacity of the solid material=calorie per cubic centimeter per degree;

$h_{o}=$ heat capacity of the water $=1$ calorie per cubic centimeter per degree;

$f=0.41$ (see p. 23);

$x=71$;

$\begin{aligned} v & =0.118 \\ t-\frac{f x}{v} & =600 .\end{aligned}$

Assume,

Then,

$$
\begin{aligned}
& y=1.0 . \\
& k=\frac{1.0 \times 0.118 \times 1.0}{71}=0.00166 .
\end{aligned}
$$

The heat capacity of the iron pipe container must be added to that of the balls. Its weight per unit length is 24 per cent of the weight of the balls. The density of the metal will be taken as 7.9 and the average heat capacity as 0.13 calorie per gram per degree.

Then,

$$
z=\frac{0.00166 \times 600}{7.9 \times 0.13 \times 1.24 \times 0.59}=1.326 \text {. }
$$

From the curve of Figure 18, for a value of $\frac{Q_{s}}{Q_{o}}=0.558$ and $y=1.0, z=1.28$. The error then, for $z$ when the assumed value of $y$ is 1.0 is +0.046 . If the same computation is made for an assumed value of $y=0.5$, the error for $z$ from the computed curves is -0.337 . If the true value of $y$ is taken as that obtained by linear interpolation between these two errors to a value which has a zero error, then $y=0.94$.

Then, from equation 10 ,

$$
k=\frac{0.94 \times 0.118 \times 1.0}{71}=0.0016
$$

$k$ is measured in calories per second per degree per cubic centimeter of bed.

It happens that in this bed the surface of iron balls is approximately $1 \mathrm{~cm}^{2}$ per cubic centimeter, so the coefficient per unit area is numerically equal to the coefficient per unit of volume of bed. This coefficient of 0.0016 is equal to $11.8 \mathrm{~B}$. t. $\mathrm{u}$. per hour per square foot per degree Fahrenheit. Observed values of the transfer coefficient for water flowing through pipes in viscous flow range from 10 to 20 (English units), ${ }^{28}$ so the measured coefficient in the present study is comparable to that for pipes. The rate of flow through the bed of balls was very slow, and the water probably was traveling in viscous flow, despite the tortuousness of the path.

The coefficients obtained by the trial-and-error method of handling the data as outlined above were not constant in value throughout the course of a run. A typical set of data of one run is presented in Table 2.

${ }^{28}$ Reynolds, Osborne, Scientific Papers: Cambridge University Press, Cambridge, 1901, p. 158. 
TABLE 2.-Data of run 21

[Water velocity $=0.5 \mathrm{~cm}^{3}$ per second per square centimeter]

\begin{tabular}{|c|c|c|c|c|c|c|c|}
\hline$t-\frac{x}{v}$ seconds & $\begin{array}{c}\text { Obsserved } \\
\frac{Q_{s}}{Q_{0}}\end{array}$ & $y$ & $k$ & $t-\frac{x}{v}$ seconds & $\mid \begin{array}{c}\text { Observed } \\
\bar{Q}_{s} \\
\bar{Q}_{0}\end{array}$ & $y$ & $k$ \\
\hline \multirow{2}{*}{$\begin{array}{l}100 \\
300 \\
400\end{array}$} & \multirow{2}{*}{$\begin{array}{r}0.435 \\
.572 \\
.719 \\
.810\end{array}$} & \multirow{2}{*}{$\begin{array}{r}0.90 \\
.60 \\
.60 \\
.56\end{array}$} & \multirow{2}{*}{$\begin{array}{r}0.0063 \\
.0042 \\
.0042 \\
.0039\end{array}$} & \multirow{2}{*}{ A verage } & $\begin{array}{l}.855 \\
.894\end{array}$ & $\begin{array}{l}.50 \\
.49\end{array}$ & $\begin{array}{l}.0035 \\
.0034\end{array}$ \\
\hline & & & & & & & .0043 \\
\hline
\end{tabular}

The fact that the coefficient did not remain constant throughout the run indicates quite clearly that the mechanism of transfer was not exactly that assumed by Schumann in the derivation of his equations. In all probability the discrepancies were caused by convection currents which could not be eliminated.

Since the study of water was not a major part of the present experimental program it did not seem advisable to spend a great deal of time in making refinements in the work. The average results which were obtained are given in Table 3 . They show the order of magnitude of the coefficient. It is not possible to give any reliable estimate on the probable accuracy of the data.

TABLE 3.-Coefficients of heat transfer from water to iron balls

HEATING

\begin{tabular}{|c|c|c|}
\hline $\begin{array}{l}\text { Rate of } \\
\text { flow, cm } 3 \\
\text { per second } \\
\text { per cm }{ }^{2}\end{array}$ & $\begin{array}{c}\text { Average } \\
\text { value of } \\
y\end{array}$ & $\begin{array}{c}k \text {, calorie } \\
\text { per second } \\
\text { per } \mathrm{cm}^{3} \text { per } \\
\text { degree }\end{array}$ \\
\hline $\begin{array}{r}0.118 \\
.145 \\
.190 \\
.256 \\
.302 \\
.320 \\
.332 \\
.500 \\
.670 \\
.725 \\
1.030\end{array}$ & $\begin{array}{r}0.73 \\
.76 \\
.77 \\
.98 \\
.60 \\
.93 \\
.67 \\
.61 \\
.65 \\
1.83 \\
.98\end{array}$ & $\begin{array}{r}0.0012 \\
.0016 \\
.0021 \\
.0036 \\
.0026 \\
.0042 \\
.0029 \\
.0043 \\
.0061 \\
.0187 \\
.0145\end{array}$ \\
\hline \multicolumn{3}{|c|}{ COOLING } \\
\hline $\begin{array}{r}0.329 \\
.399 \\
.704 \\
.745\end{array}$ & $\begin{array}{l}2.36 \\
3.14 \\
1.44 \\
2.55\end{array}$ & $\begin{array}{r}0.0110 \\
.0176 \\
.0143 \\
.0258\end{array}$ \\
\hline
\end{tabular}

In general, it appears that the coefficient increases approximately as the first power of the mass velocity of the water. The coefficients for cooling (heat flowing from hot solid to cold water) are distinctly higher than for heating. No adequate explanation has been found for this phenomenon, but it was encountered in later work with gases. (See p. 42.) The effect is much greater than the variations in data and so can not be attributed to experimental error. 
If the above method of experiment should ever be used for liquids and solids by some other investigator the author would suggest that more consistent and accurate results probably can be obtained by using higher rates of flow and correspondingly longer columns.

\section{APPLICATION OF SCHUMANN'S CURVES TO GASES}

Although the method of obtaining data to fit Schumann's curves was only partly successful with liquids it did not follow that it would not be applicable to gases. The linear velocity of gases would be much greater than for liquids, and this would tend to eliminate convection currents and decrease the irregularities in the bed. Furthermore, if all the gas flowing through a bed was constricted to a small opening and the temperature of the gas measured there the measured temperature should be an average of the entire cross section of the

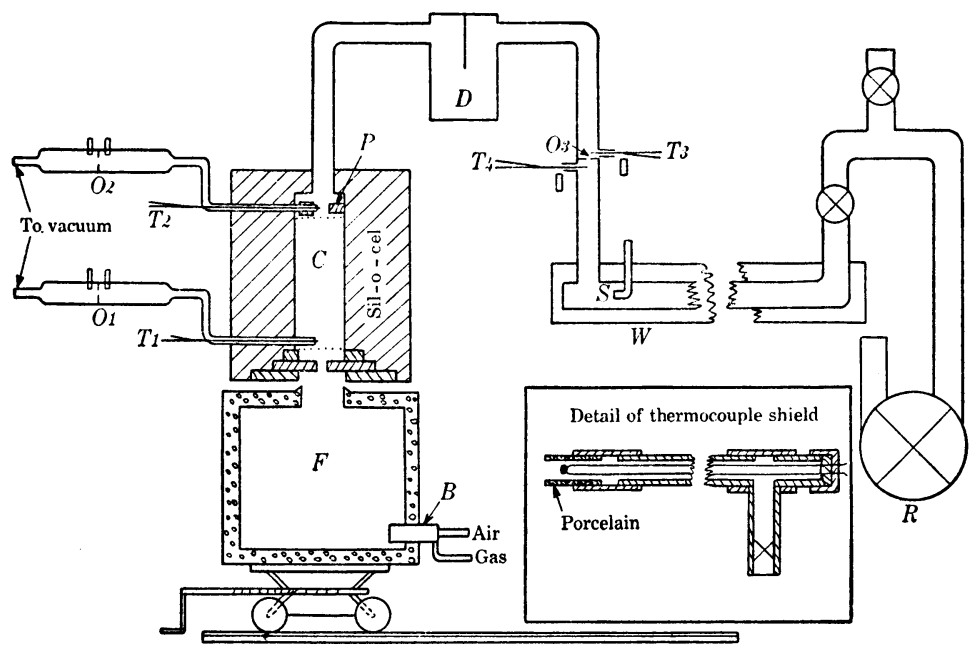

Figure 19.-Diagram of heat-transfer equipment

bed. This would amount to a mechanical averaging device for the entire plane and should give much more satisfactory results than those obtained by measuring the temperature of a single or a few solid pieces in the column.

If the method worked it was the intention to apply it to systems of refractcry solid material of low thermal conductivity. Schumann's theory is strictly applicable only to systems where the thermal conductivity of the solid is very large. On the other hand, it was not unreasonable to suppose that the discrepancies in experimental conditions might have minor importance. If the data fitted the theoretical curves for a wide variety of conditions the computed coefficients would be valid, for the system would be proved to be acting as if the experimental conditions were those specified by the theory and the coefficient was that computed. The theoretical significance of the computed coefficient might be controversial; but there could be no doubt as to its applicability to practical problems, for the system would be acting as if the coefficient was of that value. 
A discussion of some of the data obtained by this method has previously appeared in the technical press. ${ }^{27 a}$

\section{APPARATUS}

On the strength of the above argument an apparatus was constructed to test its validity. A diagram of the apparatus is shown in Figure 19; a view is given in Figure 20.

Hot flue gases were pulled through the column of material and the temperatures measured continuously at the top and bottom of the column. The solid material rested in column $C$, between the screens indicated in the figure. The hot gases were supplied by a pot furnace, $F$, which was heated by a gas burner, $B$. This furnace was mounted on a 4-wheel truck on a track so that it could be rolled out

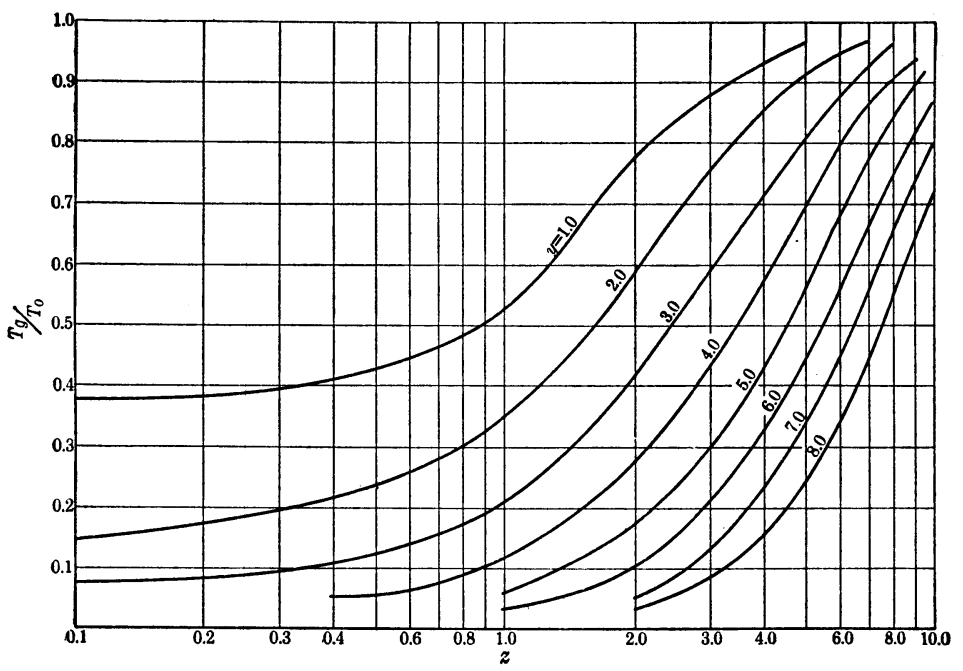

FIGURE 21.-Logarithnic relation between $z$ and $T_{0} / T_{o}$ for various values of $y$

from under the apparatus when desired. The gas and air connections to the burner were flexible hose. A screw-lifting device was attached to the truck so that the furnace could be lifted quickly 10 to $15 \mathrm{~cm}$. A lip of burned carbofrax cement was made around the hole in the top of the lid, and this lip was fitted into the base of the shell containing the material to be tested. This gave a fairly close fit between the furnace and the column.

Rotary blower $R$ would pull the hot gases from the pot up through the column of broken solids $C$, through dust catcher $D$, through the orifice of nichrome plate $O_{3}$, through water cooler $W$ (consisting of a pipe $10 \mathrm{~cm}$ in diameter and 3 meters long in a bath of running water), and thus to the pump and exhaust to the open air. The gases could be further cooled by a fine water spray, $S$, inside the pipe.

The column of material was held in a sheet-metal cylinder made of 16-gage black iron and was surrounded by Sil-o-Cel insulation packed in an outer metal shell made of 20-gage sheet. Two sizes of cylinders were used, the smaller approximately $15 \mathrm{~cm}$ in diameter

27a Furnas, C. C., Beat Transfer from a Gas Stream to a Bed of Broken Solids: Trans. Am. Inst. Chem. Eng., vol. 24, 1930, pp. 142-193; Ind. Eng. Chem., vol. 22, 1930, p. 721. 
and $50 \mathrm{~cm}$ high, in an insulating shell $45 \mathrm{~cm}$ in diameter; the larger cylinder was approximately $23 \mathrm{~cm}$ in diameter and 1 meter high and was packed in an insulating shell $61 \mathrm{~cm}$ in diameter.

Three refractory rings made of one-half fire clay and one-half Carbofrax were placed at the bottom of the column, as shown in Figure 19 , to minimize end-heat loss. The middle ring constricted the passage to $5 \mathrm{~cm}$ in diameter to facilitate mixing of the hot combustion gases and whatever air was being pulled in with them. The charge was held in place at the bottom by means of heavy iron screen placed on iron bars. A similar screen was placed on the top of the column. On top of this was placed a fire-clay plug, $P$, which was sealed tightly around the edge with fire clay, forcing all gases through the central 5-cm hole. Two thermocouples in specially constructed shields were placed in the bottom of the bed (at $T_{1}$ ) and in the center of the passage of the fire-clay plug (at $T_{2}$ ). The details of the construction of the thermocouple shields are also shown in Figure 19. Gases were pulled through these shields by means of a vacuum line and measured by means of orifices $O_{1}$ and $O_{2}$. The temperature of the gases passing through orifice $\mathrm{O}_{3}$ in the main line was measured by two small basemetal thermocouples, $T_{3}$ and $T_{4}$. The thermocouples were all made of calibrated chromel-alumel wire.

Orifices $O_{1}$ and $O_{2}$ were $0.793 \mathrm{~cm}$ in diameter in a pipe $5.24 \mathrm{~cm}$ in diameter. Orifice $O_{3}$ was $5.08 \mathrm{~cm}$ in diameter in a pipe $10.3 \mathrm{~cm}$ in diameter.

The usual orifice formulas were used in estimating the rate of gas flows. Orifice $\mathrm{O}_{3}$ was checked against a standard orifice which had been calibrated by means of a wet-gas meter.

\section{PROCEDURE}

The principal data of the experiments consisted of a continuous record of the gas temperature at the top of the column as obtained by thermocouple $T_{2}$. To determine the error due to heat losses through the walls of the tube preliminary heatings were made by pulling furnace $F$ under the column, lifting it by the screw device, and pulling the hot gases through the column by means of pump $R$. After thermocouple $T_{2}$ had come to a steady state the furnace was removed and the column cooled down with air at room temperature being pulled through the bed. This left the surrounding insulation warm, approximating a mean temperature between the beginning and end of a heating-up period, thus tending to eliminate errors due to heat loss through the walls.

After the preliminary heating the process was repeated. The data obtained for the heat transfer coefficient on the preliminary run nearly always were the same as those obtained on successive runs after the Sil-o-Cel insulation had become heated, so the preliminary heating was dropped as unnecessary. The heat losses through the walls had a negligible effect on the determination of the heat transfer coefficient, though they did tend to affect the apparent heat capacity of the charge to a small degree. Thermocouple $T_{1}$, which was at the bottom of the column, was kept approximately constant. The mass rate of flow of gas as measured by orifice $\mathrm{O}_{3}$ was kept constant. The linear rate of flow of gas over the thermocouple beads was maintained at at least 10 meters per second to insure a reading of the true gas temperature. ${ }^{20}$ The data were recorded on a Leeds \& Northrup recording potentiometer. Similar data were taken for the cooling of the bed, when the furnace was removed and cold air pulled through the column.

\section{TEMPERATURE RANGE AND GAS COMPOSITION}

Gas temperatures up to $1,100^{\circ} \mathrm{C}$. were used on iron ores, limestone, crushed brick, slag, and iron ore sinter. For work on coke

${ }^{29}$ Haslam, R. T., and Chappell, E. L., Measurement of the Temperature of a Flowing Gas: Ind. and Eng. Chem., vol. 17, 1925, pp. 402-408. 
and coal the gas temperatures were kept below $300^{\circ} \mathrm{C}$. to prevent ignition.

The hot gases pulled through the column normally contained about 5 per cent carbon dioxide, 10 per cent water vapor, 10 per cent oxygen, and 75 per cent nitrogen. The density, viscosity, specific heat, and thermal conductivity of such a gas are much the same as for air, so the data obtained may be considered as being those for air.

\section{COMPUTATION OF COEFFICIENT}

A very simple means was devised for computing the average coefficient of heat transfer for an entire run. The method consisted of comparing the shape of the curve of the data with the shapes of the computed curves until the proper fit was found. It is possible to do this if the abscissas are plotted on a logarithmic scale.

The curves of $\frac{T_{g}}{T_{o}}$ against $z$ for different values of $y$ (figs. $8,10,12$, and 14) were plotted on semilogarithmic paper, the abscissa $z$ being the logarithmic scale. These curves for $y$ equals 0 to 10 are shown in Figure 21. The observed data of $\frac{T_{g}}{T_{o}}$ were also plotted against time on the logarithmic scale.

If the observed data conform to Schumann's theory, then the experimental curve should be the same function of the time as some one of the theoretical curves. If the two curves are the same function of the time $t$, then they are also the same function of $\log t$. Since $z$ is proportional to $t$, one of the curves may be in units of $z$ and the other in units of $t$ and the argument is still valid; that is, the shape of the curve is not changed if the $x$-axis is graduated on a logarithmic scale, no matter what units are used. This is true of any logarithmic plot. Hence, if we plot $\frac{T_{0}}{T_{o}}$ for a particular experiment, if the theory is correct, the curve must be identical with some one of the theoretical curves of Figure 21, except for horizontal displacement. By using transparent paper and a through-illuminated drawing board, it was a simple matter to slide a graph of the observed data over the group of theoretical curves until the one was found which fitted approximately throughout the entire length. When this fit was found the value of $y$ for the theoretical curve was that for the experimental curve. This makes a very rapid and easy solution.

The quality of fit is indicated in Figure 22. In this figure the solid line is the theoretical curve for $y=6.0$. The data points are the observed temperatures for various times for a particular run on Danube iron ore. After the observed data were shifted horizontally the coincidence of the two functions was very satisfactory, as is shown in the figure. The abscissa of each function is plotted in its own units ( $z$ for the theoretical, $t$ for the observed), as it makes no difference in the determination of the proper $y$. The value of $y$ is the only datum necessary for computation of the coefficient $k$.

It will be noticed in Figure 21 that there is a considerable change in shape of the curves for different $y$ 's, and this is what makes the comparison method feasible. If all of the theoretical curves had the same shape, this method of solution, of course, would be impossible. 
By this method it is possible to compute the value of $y$ to within 10 per cent. This is of the same order as the experimental error in this type of work.

In this method, it is essential that the horizontal axis of the two curves should coincide. It is only the horizontal shift which is allowed; not vertical or angular.

The value of $T_{o}$ in these cases is that temperature which the gas at the top of the column attains after it has come to a steady state. This is somewhat less than the gas temperature at the bottom, due to heat losses, but that does not affect determination of the coefficient.

It will also be noticed, by observing equation 9 , that for this method of solution to be valid, the quantity $\frac{f x}{v}$ must be negligible compared to $t$. This is true for gas streams, for the values of $\frac{f x}{v}$ are usually a fraction of a second and hence are negligible.

When the value of $y$ is obtained by the method explained above, $k$ is computed by simple arithmetic.

Therefore,

$$
y=\frac{k x}{h_{o} v} .
$$

$$
k=\frac{y h_{o} v}{x} .
$$

The average value of $h_{g}$ for the gases in these runs was taken as 0.000325 calorie per standard cubic centimeter per degree.

Thus for the data shown in Figure $22, k$ is computed as follows:

$$
k=\frac{6.0 \times 0.000325 \times 111}{44.5}=0.0049 .
$$

Temperature histories of the cooling of the column of solid material can be used to compute the coefficient in the same way. It is only necessary to invert the observed $\frac{T_{g}}{T_{o}}$ curves before comparing with the theoretical curves.

\section{DEFINITION OF "TEMPERATURE OF SOLID"}

It must be recognized that this method of solution is only approximate, for the experimental conditions do not fit the theory exactly. However, that does not vitiate the results in the least in the range of accuracy corresponding to the conformation to the theory. Nevertheless, it is well to be as logical as possible, and to do this we must clarify our definition of "Temperature of solid."

The coefficient is defined as the calories transferred per second from gas to solid per second per degree difference in temperature. Naturally, in poorly conducting material such as iron ore, there is a gradient in the piece itself while it is being heated. Undoubtedly there are gradients in the gas stream and considerable variations in rate of flow and temperature from one part of the bed to another. Observed minutely, the situation appears hopeless, but looked upon in the light of statistical averages a definition of conditions appears plausible. If the temperature of the solid at any time is defined as the mass average temperature--that is, the heat content divided by the product of the mass and specific heat-and if the temperature of 
the gas stream is the mass average temperature, then our definition of $k$ is analogous to that of Schumann's theory. The details of the mechanism of heat transfer may be somewhat different from that hypothesized in the mathematical development, but this does not limit the utility; the mathematical correlation of the data is valid in so far as it fits the facts. This is true of any combination of mathematics and physics, for probably no physical action ever exactly fits mathematical hypotheses.

\section{COMPUTATION OF HEAT CAPACITY}

The above method of solution also furnishes a means of determining the average heat capacity of the charge. If equation 11 is solved for $h_{s}$

where

$$
h_{s}=\frac{k t}{z(1-f)}
$$

$h_{s}$ is the specific heat per unit volume of solid material; and

$t$ is the time in seconds which coincides with a particular value of $z$ when the correct theoretical and observed curve coincide. Thus, in Figure 22, when $z=2.0, t=172$, or if $z=4.0, t=344 ; z=8.0, t=688$; it makes no difference which pair of values is used.

$f$ is the fractional voids in the bed.

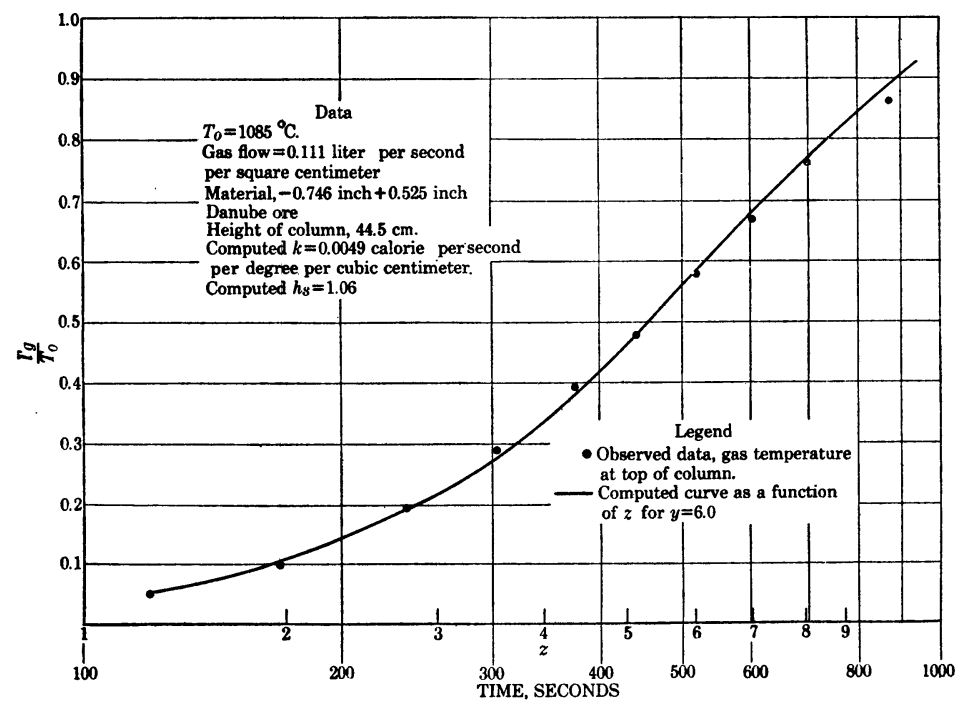

Figure 22.-Typical temperature history of gas stream at top of column

Example.-From the data of Figure 22, $k=0.0049$ and $t=172$ seconds when $z=2.0$.

Therefore,

Heat capacity $=\frac{0.0049 \times 172}{2}=0.42$ calorie per degree per cubic centimeter of bed.

This figure includes the heat capacity of the metal shell, which amounted to approximately 0.06 calorie per degree per cubic centimeter of the bed.

Therefore, heat capacity of bed $=0.42-0.06=0.36$ calorie per degree per cubic centimeter of bed.

The voids in this bed were 0.625 , and the average specific gravity of the ore particles was 3.72 .

Therefore,

$$
\text { Specific heat }=\frac{0.36}{(1-0.625) 3.72}=0.25
$$


This corresponds to previously determined value of the specific heat of ferric oxide at about $375^{\circ} \mathrm{C} .^{30}$ This value, then, is in good agreement with that determined by other methods.

This method of evaluation of the heat capacity furnishes a qualitative check upon the determination of the heat-transfer coefficient. If the computed value of the heat capacity is abnormally high or low, then the heat-transfer coefficient must be proportionally high or low, indicating that the determination has been faulty.

This should not be considered as a precision method, by any means. Its possible error is the same as that of transfer-coefficient determination, but it does give a rough evaluation of different materials.

The figure obtained is for the over-all heat capacity and includes

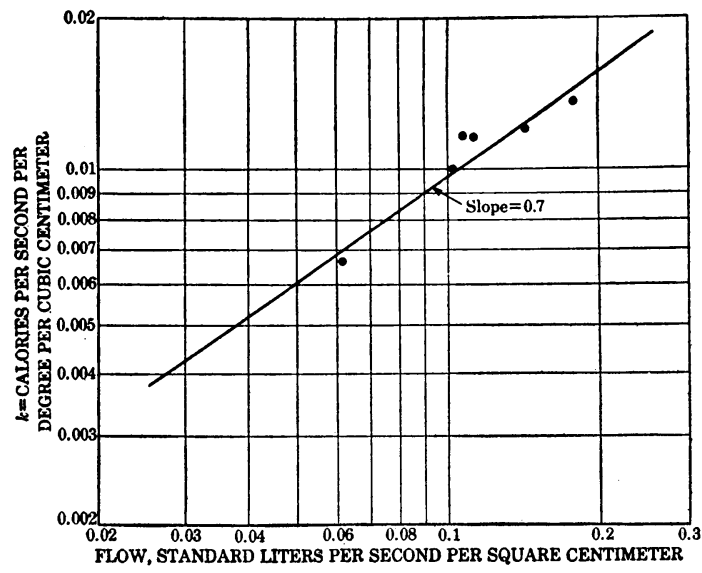

FIGURE 23.-Effect of gas velocity on the coefficient of heat transfer. Material, Corsica iron ore $1.13 \mathrm{~cm}$ in diameter a small loss through the Sil-o-Cel walls. It also includes any heats of reaction in the system. Fortunately,the method for the heat-transfer determination is consistent, even if there is a considerable heat of reaction, as was found in the study of the calcination of limestone.

In general, it may be stated that the shape of the curves of the ratio $\frac{T_{g}}{T_{o}}$ plotted against $\log t$ determines the heattransfer coefficient, and the position of the curve in relation to the coordinate axes determines the heat capacity of the system.

\section{EFFECT OF GAS VELOCITY}

In practically all cases of heat transfer to or from a fluid in conduits the coefficient has been found to vary approximately as the 0.8 power of the fluid velocity. This one figure has been almost the sole point of agreement throughout the mass of experimental data which have been gathered for conduits.

On the other hand, it would seem reasonable to assume that in the case of beds of iron ore or coke, wherein part of the resistance to transfer of heat resides within the particles themselves, the effect of changing gas velocity would be less than for other systems. A series of runs was made on Corsica iron ore through a 0.525 -inch $(13.3-\mathrm{mm})$ on 0.371 -inch $(0.4-\mathrm{mm})$ screen at different gas velocities. The apparatus was not designed to handle great variations in rate of flow, but a span of 3 to 1 in mass velocity of the gas was obtainable.

The data of this series of experiments are plotted in Figure 23 on logarithmic coordinate paper. The straight line drawn through the

${ }^{30}$ Ralston, O. C., Iron Oxide Reduction Equilibria: Bull. 296, Bureau of Mines, 1929, p. 30. 
points has a slope of 0.7. This means that the coefficient for materials of low thermal conductivity varies as the 0.7 power of the mass velocity of the gas, or

$$
k=c u^{0.7} \text {, }
$$

where $u=$ rate of flow in standard liters per second or any other appropriate units.

This exponent varies but little from the value for conduits. It seems remarkable that the high resistance to heat flow on the interior of refractory particles should have such a small effect.

The rates of flow studied have all been relatively high; and particularly in the study of ordinary combustion processes the interest might be centered on lower rates, but the figures given later in this paper may be extrapolated by means of equation 25 with considerable confidence, for all laws of heat flow seem to apply over a wide range. It must be admitted, however, that a study of the low rates of flow would be preferred to the best extrapolation.

\section{EFFECT OF TEMPERATURE}

A study of equation 10 shows that for $y$ to be constant, if the rate of flow is constant, the ratio $\frac{k}{h_{g}}$ must be constant. Since the computed curves have been found to fit the experimental data in all cases it follows that this condition must hold within the range of experimental error. To test this item further, two runs were made on a bed of Corsica ore through 0.525 -inch $(13.3-\mathrm{mm})$ on 0.371 -inch $(9.4 \mathrm{~mm})$ screen, one run with the gas temperature equal to $300^{\circ} \mathrm{C}$. and the other, $1,100^{\circ} \mathrm{C}$. The gas flow in both cases was 0.11 standard liter per second per square centimeter. The column of material was $42.5 \mathrm{~cm}$ high. The value of $y$ for both runs was 14.0. This meant that the ratio $\frac{k}{h_{g}}$ was constant for these temperatures, within the range of experimental error. The coefficient of heat transfer is 0.0017 for the temperature range $25^{\circ}$ to $1,100^{\circ} \mathrm{C}$.

Investigation of equation 9 shows that if the values of $z$ for observed data are to be consistent with the computed curves, $\frac{k}{h_{s}}$ must be constant at all temperatures. This means that the coefficient of transfer must be proportional to the heat capacity of the solid. This is not consistent with the condition required by equation 10 , for the heat capacity of a gas and a solid usually do not vary to the same degree with change of temperature. The only reason, then, that the observed data are consistent with the theoretical curves is that the inconsistencies which occur lie within the range of experimental error. The general relation between the coefficient of heat transfer and temperature, then, is that the coefficient varies in the same proportion as the heat capacity of the system as a whole. This furnishes the means of obtaining a rough approximation of the variation of the coefficient of heat transfer with temperature.

In considering the variation of the heat capacity of the system with temperature, half of the capacity must be assigned to the gas and half to the solid, for all the heat acquired from the solid must have come from the gas. In the case under consideration the mean temperature for the low-temperature run was about $425^{\circ} \mathrm{C}$. absolute and for the 
high-temperature run about $825^{\circ} \mathrm{C}$. absolute. Between these two temperatures the mean heat capacity of the gas (air) increased by about 2.5 per cent, ${ }^{31}$ and the heat capacity of the iron oxide was increased approximately 50 per cent. ${ }^{32}$

Then the increase of the average heat capacity of the gas and solid system was about 26 per cent when the mean absolute temperature was approximatcly doubled. If the variation is assumed to be in an exponential manner, then from these figures the heat capacity, and hence the coefficient of heat transfer, varies approximately as the 0.3 power of the absolute temperature. Therefore, it will be considered that

where $c=$ some constant.

$$
k=c T^{0.3} \text {, }
$$

It is recognized that this is a very unsatisfactory method of obtaining the variation with temperature, but the very fact that the observed data fit the curves computed for constant-transfer coefficient and heat capacity precludes the possibility of direct measurement. This is an unfortunate circumstance which can not be remedied unless some other satisfactory experimental method can be found.

It is quite surprising that the temperature should have such a small effect, considering its importance in some other heat-transfer systems, but the data can not be interpreted in any other manner.

\section{EFFECT OF VOIDS}

The degree of packing in a bed has a very large influence on the resistance to fluid flow ${ }^{33}$ Most things which increase resistance to flow may be expected to increase the coefficient of heat transfer. To study the quantitative effect of this variable a series of tests was made on a Corsica iron ore. The ore was sized to pass a 0.371 -inch (9.4$\mathrm{mm}$ ) and remain on a 3-mesh screen. The average particle size was $0.80 \mathrm{~cm}$. The desired degree of packing was produced by a foundry vibrator, such as is used in making sand molds.

Determination of the amount of voids in a bed of ore is a somewhat arbitrary matter because the particles possess a certain amount of porosity. The effective specific gravity of a particle, then, depends upon whether or not the pore volume is considered part of the piece. It is common usage to speak of the specific gravity when the pore volume is included as the "apparent" specific gravity, whereas the value for the particle exclusive of the pore volume is called the "true" specific gravity. It was found that the apparent specific gravity gave the best correlation of data, so this was the quantity used.

The results are shown in Figure 24. The absolute value of $k$ as shown by these data has no significance when applied to other sizes or other materials; but the change of $k$ with voids is important, and the data may be expressed approximately by the equation

where

$$
\Delta \log _{1} k=1.68\left(f_{2}-f_{1}\right)-3.56\left(f_{2}{ }^{2}-f_{1}{ }^{2}\right),
$$

$f_{1}=$ fractional voids in original bed; and

$f_{2}=$ fractional voids in bed under consideration.

\footnotetext{
${ }^{31}$ Lewis, G. W., and Randall, M., Thermodynamics: McGraw-Hill Book Co., New York, 1923, p. 80. 32 Furnas, C. C., The Thermal Properties of Ferric Oxide: Trans. Am. Inst. Chem. Eng., vol. 18, 1926, p. 309.

${ }^{33}$ Furnas, C. C., The Flow of Gases Through Beds of Broken Solids: Bull. 307, Bureau of Mines, 1929, p. 30 .
} 
This equation gives a somewhat smaller change of slope with changing voids than is shown in the curve of Figure 24, but it gives a better approximation for extrapolation than does the extended curve.

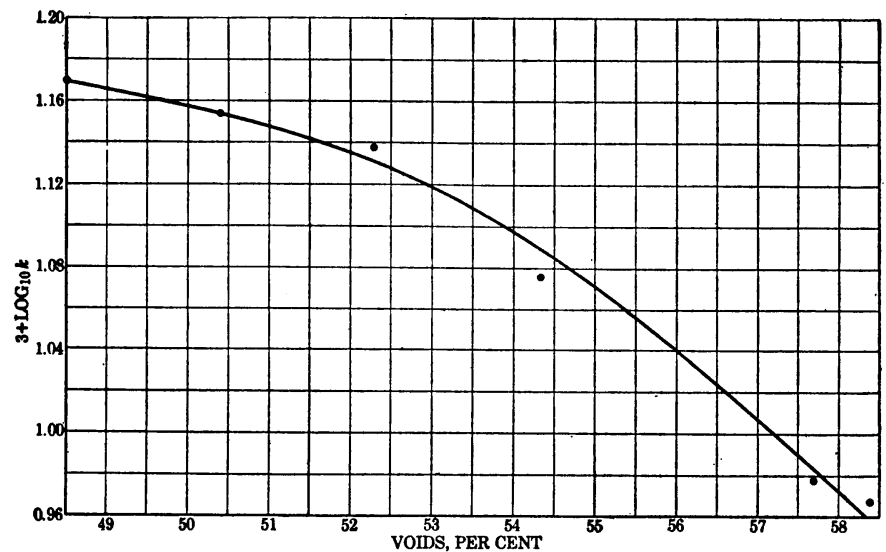

Figure 24.-Effect of voids on the coefficient of heat transfer. Material, Corsica iron ore $0.8 \mathrm{~cm}$ in diameter. Rate of gas flow, 0.1 liter per second per square centimeter.

\section{EFFECT OF PARTICLE SIZE}

Experiments have been made upon various sizes of many kinds of iron ore, coke, bituminous coal, anthracite, limestone, iron balls, crushed brick, and slag and upon a typical blast-furnace charge. The

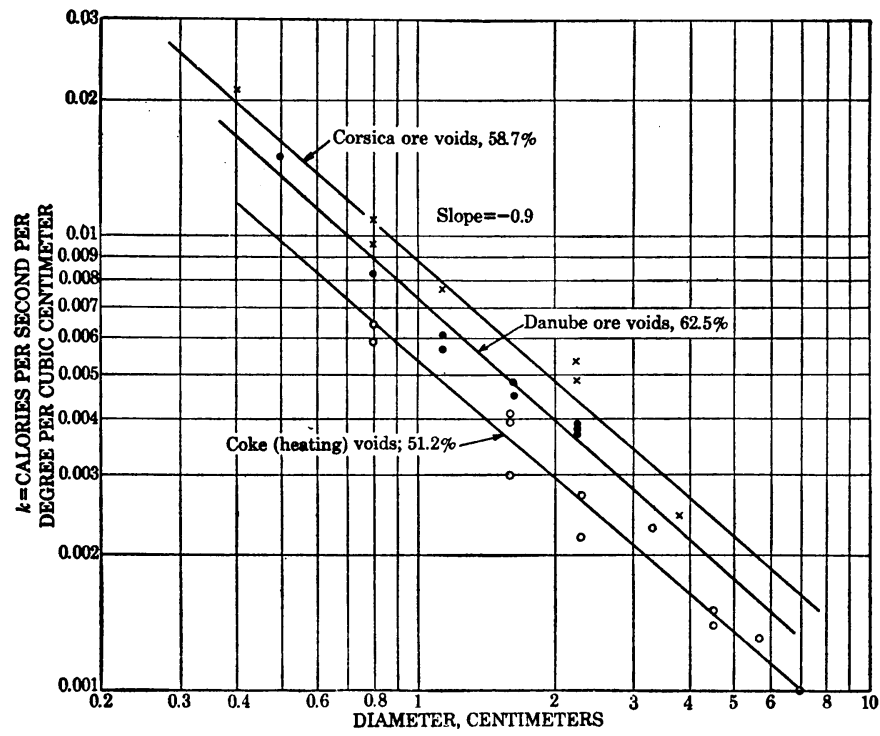

- Fraure 25.-Effect of particle size on the coefficient of heat transfer. Rate of gas flow, 0.1 standard liter per second per square centimeter

blast-furnace charge consisted of $10 \mathrm{~kg}$ of coke 6.3 to $7.6 \mathrm{~cm}$ in diameter, $20 \mathrm{~kg}$ of run-of-mine Evergreen ore, and $3 \mathrm{~kg}$ of limestone $3 \mathrm{~cm}$ in diameter. The average particle was about the same as for a normal 
blast-furnace charge, about $4 \mathrm{~cm}$. In commercial furnaces much of the coke is larger, but there are also some smaller pieces.

Some of the data are shown in Figure 25. For complete data see Appendix 2. The points are plotted on coordinates graduated on a logarithmic scale on both axes. The points vary considerably, as might be expected in a system so complicated, but it seems justifiable to draw straight lines through each set of points. Each of the lines is parallel and has a slope of about -0.9. This means that for the different materials

$$
k=\frac{c}{d^{0.9}}
$$

where $c=$ some constant characteristic of system.

The values of $k$ shown are those computed for a flow of 0.1 standard liter per second per square centimeter. This rate of flow was chosen for comparison, as it is in the range used in blast-furnace work. Equation 25 was used for interpolation to this rate of flow.

It is evident that there is considerable variation between the constants of the different materials.

\section{SUMMARIZING EQUATION}

The foregoing discussion of the effect of the different variables may be summarized in a simple equation.

where

$$
k=\frac{A u^{0.7} T^{0.3} 10^{1.68 f-3.56 f 2}}{d^{0.9}},
$$

$A=$ a constant characteristic of the material;

$u=$ gas velocity, standard liters per second per square centimeter of crosssectional area of the bed;

$T=$ degrees centigrade absolute;

$f=$ fractional voids in the bed; and

$d=$ average particle diameter, centimeter.

The determined values of $A$ for the 27 substances studied are given in Table 4. The detailed data are given in Table 1, in Appendix 2. In all cases the value of $A$ for cooling the solid is greater than for heating. 
TABLE 4.-Summary of significant heat-transfer data for sized material

\begin{tabular}{|c|c|c|c|c|c|c|c|c|}
\hline \multirow[b]{2}{*}{ Material } & \multicolumn{4}{|c|}{ Heating } & \multicolumn{4}{|c|}{ Cooling } \\
\hline & $\begin{array}{c}\text { Number } \\
\text { of } \\
\text { determi- } \\
\text { nations }\end{array}$ & $\begin{array}{c}k_{r}, 1 \\
\text { calorie } \\
\text { per } \\
\text { second } \\
\text { per } \\
\text { degree } \\
\text { per c c c }\end{array}$ & $A$ & $\begin{array}{c}\text { h, } \\
\text { calorie } \\
\text { per } \\
\text { gram } \\
\text { per } \\
\text { degreo }\end{array}$ & $\begin{array}{c}\text { Number } \\
\text { of } \\
\text { determi- } \\
\text { nations }\end{array}$ & $\begin{array}{c}k_{r}, 1 \\
\text { calorie } \\
\text { per } \\
\text { second } \\
\text { per } \\
\text { degree } \\
\text { per c c }\end{array}$ & $A$ & $\begin{array}{c}h, \\
\text { calorie } \\
\text { per } \\
\text { gram } \\
\text { per } \\
\text { degree }\end{array}$ \\
\hline 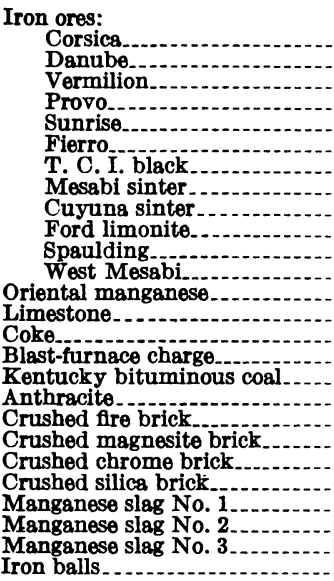 & $\begin{array}{r}19 \\
14 \\
2 \\
2 \\
1 \\
1 \\
1 \\
1 \\
2 \\
1 \\
1 \\
1 \\
1 \\
10 \\
18 \\
4 \\
7 \\
3 \\
1 \\
1 \\
1 \\
1 \\
1 \\
1 \\
1 \\
4\end{array}$ & $\begin{array}{l}0.0095 \\
.0077 \\
.018 \\
.0072 \\
.010 \\
.0075 \\
.010 \\
.0063 \\
.010 \\
.0067 \\
.0094 \\
.0061 \\
.0073 \\
.0069 \\
.0052 \\
.0039 \\
.0060 \\
.0065 \\
.0080 \\
.0077 \\
.0074 \\
.0073 \\
.0089 \\
.013 \\
.0076 \\
.010\end{array}$ & $\begin{array}{l}0.010 \\
.0086 \\
.014 \\
.0085 \\
.0087 \\
.0054 \\
.0026 \\
.0076 \\
.015 \\
.0062 \\
.0075 \\
.0063 \\
.0063 \\
.0057 \\
.0049 \\
.0037 \\
.0042 \\
.0044 \\
.0076 \\
.012 \\
.012 \\
.0099 \\
.0084 \\
.012 \\
.0063 \\
.0059\end{array}$ & $\begin{array}{r}0.19 \\
.19 \\
.26 \\
.32 \\
.30 \\
.40 \\
.30 \\
.56 \\
.36 \\
.31 \\
.30 \\
.28 \\
.32 \\
.21 \\
.22 \\
.37 \\
.29 \\
.29 \\
.28 \\
.25 \\
.31 \\
.20 \\
.23 \\
.21 \\
.15\end{array}$ & \begin{tabular}{r}
19 \\
13 \\
2 \\
\hdashline 1 \\
1 \\
1 \\
-1 \\
1 \\
1 \\
1 \\
1 \\
6 \\
-1 \\
4 \\
3 \\
1 \\
1 \\
1 \\
1 \\
1 \\
1 \\
1 \\
4
\end{tabular} & $\begin{array}{c}0.0011 \\
.0081 \\
.018 \\
.012 \\
.015 \\
.012 \\
.012 \\
.011 \\
.013 \\
.0076 \\
.0012 \\
.0075 \\
.(9) \\
.0047 \\
.0079 \\
.0085 \\
.012 \\
.011 \\
.011 \\
.011 \\
.012 \\
.014 \\
.014 \\
.011\end{array}$ & $\begin{array}{c}0.012 \\
.0096 \\
.014 \\
.011 \\
.011 \\
.0089 \\
.018 \\
.013 \\
.010 \\
.0084 \\
.010 \\
.0065 \\
.0046 \\
.0056 \\
.0062 \\
.012 \\
.0018 \\
.019 \\
.011 \\
.014 \\
.011 \\
.0062\end{array}$ & \begin{tabular}{r}
0.21 \\
.19 \\
.28 \\
\hdashline .36 \\
.38 \\
.32 \\
.- .72 \\
.42 \\
.36 \\
.33 \\
.31 \\
.32 \\
.23 \\
\hdashline.- \\
.35 \\
.27 \\
.41 \\
.31 \\
.32 \\
.32 \\
.30 \\
.31 \\
.26 \\
.15
\end{tabular} \\
\hline
\end{tabular}

Note.-For conversion to English units see below.

$1 k_{r}=$ coefficient of heat transfer, when $u=0.1$ standard liter per second per centimeter ${ }^{2}, d=1.0$ centimeter, and the voids in the bed are normal. See below.

See p. 42.

\section{CONVERSION TO ENGLISH UNITS}

The metric coefficient of heat transfer defined as calories per second per degree centigrade per cubic centimeter must be multiplied by 62.4 to convert it to English units, B. t. u. per second per degree Fahrenheit per cubic foot. Coefficient $A$ of equation 29 (as given in Table 4) must be multiplied by 0.210 to convert the equation to the English system. Then,

$k=$ B. t. u. per second per degree Fahrenheit per cubic foot;

$u=$ standard cubic feet per second per square foot of cross-sectional area of bed;

$d=$ average particle diameter in feet; and

$T=$ degrees Fahrenheit absolute.

\section{STANDARD COEFFICIENTS}

The values of $A$, as given in Table 4, do not necessarily indicate the relative values of the heat-transfer coefficients found in normal beds of material, for the percentage of voids in a normally packed bed differs widely with different materials. Therefore, it is advantageous to compute a coefficient, $k_{r}$, which will indicate the relative ease with which heat is transferred to each material. This coefficient, $k_{r}$, is for a rate of gas flow of 0.1 standard liter per second per square centimeter, an average particle diameter of $1.0 \mathrm{~cm}$, an average temperature of $500^{\circ} \mathrm{C}$., and with normal voids in the bed. 
"Normal voids" may be defined as follows: If a number of pieces of broken material are allowed to drop singly into their positions in a bed, the bed tends to form with a definite percentage of voids that is characteristic of the material. Such an arrangement of material is characterized as having "normal packing," and the percentage of

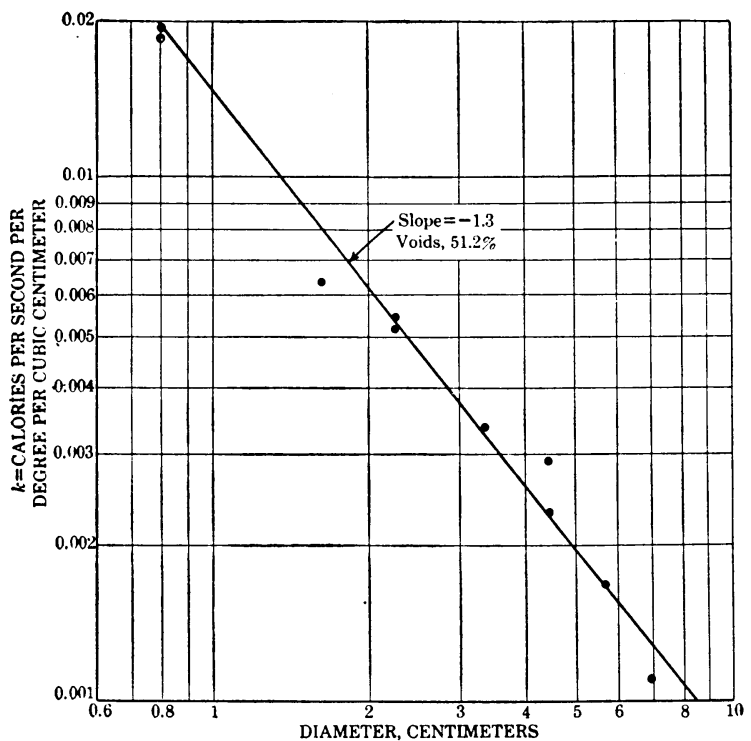

FIGURE 26.-Effect of particle size on the coefficient of heat transfer for cooling coke. Rate of flow, 0.1 standard liter per second per square centimeter square centimeter, a particle size of $1.0 \mathrm{~cm}$, an average temperature of $500^{\circ} \mathrm{C}$., and 50 per cent voids in the bed. such a state will be designated as "normal voids." 34

It will be seen from Table 4 that there is considerable variation in the ability of different classes of material to acquire heat. The factors which probablycause this variation will be discussed later. (See p. 59 .)

The data of normal voids and $k_{\tau}$ for the individual runs are given in Table 1 of Appendix 2. This table also gives the values of $k_{s}$, the coefficient for a gas velocity of 0.1 standard liter per second per voids of the beds in

\section{ANOMALOUS BEHAVIOR OF COOLING COKE}

All of the values of $A$ for cooling given in Table 4 are somewhat higher than for heating, but the variations of the coefficients with particle size all followed equation 29, except for coke, which was being cooled. The coefficients for cooling coke changed with particle size more rapidly than for heating. The data showing this variation are plotted in Figure 26. The coefficient varies inversely as the 1.3 power of the particle diameter, but its variation with voids and gas velocity is practically the same as for other systems. The equation, then, for cooling coke is

$$
k=\frac{A u^{0.7} T^{0.3} 10^{1.68 f-3.56 f^{2}}}{d^{1.3}} .
$$

The value of $A$ for the coke used is 0.0120 . If English units are used, $A=0.000285$.

No explanation has been found for this unexpected behavior of coke. In fact, no adequate explanation has been found for the fact

\footnotetext{
p. 18.

Furnas, C. C., The Flow of Gases Through Beds of Broken Solids: Bull. 307, Bureau of Mines, 1929,
} 
that in all the systems studied the coefficient is greater for cooling than for heating.

\section{HEATS OF TRANSITION}

Ferric oxide has at least two transformation points below $1,000^{\circ}$ C. ${ }^{35}$ It might be expected that such points of isothermal absorption of energy would cause distortions in the time-temperature curves. Contrary to such anticipation, all the heating and cooling curves were found to be very smooth and to fit the theoretical temperaturehistory curves which were developed on a theory that did not take account of any transformation points. The reason for this probably lies in the fact that absorption of the transformation heat is distributed more or less evenly over the entire period of temperature rise as the temperature change advances up the column. Hence the only effect of heats of transformation is to increase the over-all heat capacity of the system. Such a circumstance is very fortunate, for it makes possible the utilization of this method of determining coefficients of heat transfer.

The total heat involved in the transformations mentioned is about 7,500 calories per mol, enough to raise the temperature of untransformed material about $200^{\circ} \mathrm{C}$. If transition points tend to cause serious discrepancies in the results obtained by this method, it would be expected that they would be observed when the energies involved are of this magnitude. The fact that they are not adds considerable confidence to the method.

The heat capacities, as reported in Table 4 and Table 1 of Appendix 2 , of course include the heats of transition in the temperature range considered.

\section{CALCINATION OF LIMESTONE}

When limestone is heated the calcium carbonate decomposes to give $\mathrm{CO}_{2}$ according to the equation

$$
\mathrm{CaCO}_{3}=\mathrm{CaO}+\mathrm{CO}_{2} \text {. }
$$

This is a strongly endothermic reaction, absorbing about 43,000 calories per mol. To determine whether or not the theoretical temperature-history curves would fit when a large heat of reaction was involved a series of runs was made on limestone at a temperature high enough to calcine the material (above $800^{\circ}$ C.). The data are given in Table 1 of Appendix 2 and summarized in Table 4 above. The experimental data fitted the theoretical curves very satisfactorily, showing that this method of the determination of the coefficients of heat transfer is valid for systems involving a relatively large heat of reaction.

The values of specific heat reported in the tables include the heat of the calcination which was being done during the heating-up period. Since calcination proceeded at different rates in the different experiments the quantity of heat so absorbed was quite variable, so the heat capacities reported in the tables are not constant. These figures for heat capacity, then, have no significance, for they include the true, sensible heat acquired by the material and an undetermined

${ }^{35}$ Ralston, O. C., Iron Oxide Reduction Equilibria: Bull. 296, Bureau of Mines, 1929, p. 312. 
amount of heat of reaction. The only meaning of the data is that that much heat was absorbed in that particular experiment.

Calcination takes place in a very narrow zone which is the phase boundary between calcium carbonate and calcium oxide. This zone advances from the outside to the inside of the piece at an approximately constant rate for each temperature, independent of particle size or degree of calcination. The details of this phase of the work have been previously published in the technical press. ${ }^{36}$ The approximate rate of advance of the zone of calcination is given by the empirical equation,

where

$$
\log _{10} R=0.003145 T-3.3085 \text {, }
$$

$R=$ the rate of advance of the line of calcination, centimeters per hour;

$T=$ temperature, degrees centigrade.

\section{SURFACE AREA}

This study furnishes a means of making an approximate determination of the surface area of irregular pieces of limestone. If a piece of limestone is calcined a short distance inward the volume of calcined material is approximately the surface area times the thickness of the calcined layer. The amount of calcination-that is, the volume calcined-is determined by loss of weight. The boundary of the calcined zone is very sharp and uniform around the piece. After breaking the piece the thickness of this zone may be determined by the average of several measurements. Dividing this average thickness into the volume calcined gives the surface area. A number of such determinations were made. It was found that for irregular pieces of limestone the surface area was 20 to 50 per cent greater than for a sphere of the same volume.

A second method was devised for making rough determinations of area. If a moist filter paper is carefully wrapped around an irregular piece of material which has a dusty surface the dust will cling to the moist paper. When the paper is taken off the piece the area covered by the adhering dust can be measured with a planimeter, and this is approximately the surface area of the piece. The true area of a sphere can be checked within 2 per cent by this method. Measurements were made of a number of pieces of different kinds of iron ore, and the areas ranged from 10 to 50 per cent greater than for spheres of the same volume.

As a rough approximation it may be said that for the average particle of broken solid material the area is 25 per cent greater than for a sphere of the same volume. This makes it possible to obtain an approximate value for the surface of the particles.

\section{LIFTING THE SOLID CHARGE}

A series of experiments was made on systems in which the solid particles of ore used were so small that they were lifted by the gas stream. A small screen at the top kept them within the cylinder, but sufficient room was allowed for the particles to move in a free volume one to three times as great as that of the original bed.

Because of the turbulent state of the solid phase the temperaturehistory curves of these systems did not coincide, even approximately,

${ }^{36}$ Furnas, C. C., The Rate of Calcination of Limestone: Ind. and Eng. Chem., vol. 23, 1931, pp. 534-538. 
with the computed curves. To date no means of correlating these data has been found.

For the temperature-history theory to be valid one of the phases of the system must be fixed and immovable.

\section{COMPARISON OF TWO EXPERIMENTAL METHODS}

A comparison of the results of the two methods described for the determination of the heat-transfer coefficient should indicate the probable validity of the first method. (See p. 6.) The data for the first method can be obtained from Figure 5.

The data for iron balls by the second method can be obtained from Table 1 of Appendix 2. Table 5 gives a comparison of the two sets of data for identical conditions. The values obtained by the second method average 57 per cent as large as that obtained by the first.

TABLE 5.-Comparison of coefficients obtained by two methods

[Material: Iron balls]

\begin{tabular}{|c|c|c|c|c|c|c|c|}
\hline \multirow[b]{2}{*}{ Diameter, cm } & \multicolumn{2}{|c|}{$\begin{array}{l}\text { First method; tem- } \\
\text { perature difference }\end{array}$} & \multicolumn{4}{|c|}{ Second method; temperature history } & \multirow{2}{*}{$\begin{array}{c}\text { Rel- } \\
\text { ative } \\
\text { values, } \\
\text { per } \\
\text { cent }\end{array}$} \\
\hline & $\begin{array}{l}\text { Voids, } \\
\text { per } \\
\text { cent }\end{array}$ & $\begin{array}{l}k, \text { at flow } \\
=0.1, \text { tem- } \\
\text { perature }= \\
500^{\circ} \mathrm{C}\end{array}$ & $\begin{array}{l}\text { Voids, } \\
\text { per } \\
\text { cent }\end{array}$ & Flow & $\begin{array}{c}k \text {, at } \\
\text { average } \\
\text { tempera- } \\
\text { ture, } \\
100^{\circ} \mathrm{C} .\end{array}$ & $\begin{array}{l}k, \text { corrected } \\
\text { to voids, } \\
\text { flow, and } \\
\text { tempers- } \\
\text { ture o first } \\
\text { method }\end{array}$ & \\
\hline \multirow{2}{*}{ 3.175 } & 39.5 & 0.013 & \multirow{2}{*}{$\begin{array}{l}40.9 \\
40.9 \\
45.1 \\
45.1\end{array}$} & \multirow{2}{*}{$\begin{array}{r}0.130 \\
.183 \\
.135 \\
.190\end{array}$} & \multirow{2}{*}{$\begin{array}{l}0.0024 \\
.0120 \\
.0032 \\
.0045\end{array}$} & \multirow{2}{*}{$\begin{array}{l}0.0081 \\
.0084 \\
.0034 \\
.0036\end{array}$} & \multirow{2}{*}{$\begin{array}{l}62 \\
64 \\
48 \\
51\end{array}$} \\
\hline & 45.0 & .007 & & & & & \\
\hline A verage & & & & & & & 57 \\
\hline
\end{tabular}

The smaller value, obtained by the second method, is undoubtedly the more reliable. The errors in the second method are such that they tend to neutralize one another while a small error in measuringtemperature differences between gas and solid in the first method can make a large error in the computed coefficient. From the nature of the first method it would be expected that if there were any errors in determination the values of the measured temperature differences would be too small, which would make the coefficient too large, as is found to be the case when comparison is made with the second method. It may be considered, then, that the true heat-transfer coefficient is only about 60 per cent as great as the value determined by the first method (p.6).

\section{HEAT TRANSFER PER UNIT OF AREA}

The coefficients have all been given in terms of quantity of heat transferred per unit of volume of the bed, whereas coefficients are usually reported in terms of units of area. There are two reasons why the data are reported on a volume basis: (1) There is no accurate

$$
112607^{\circ}-32-4
$$


way of determining the actual surface area of the particles, and (2) there is no way of determining what proportion of the total surface is actually in contact with the moving gas stream.

The interlocking positions of the particles in the bed necessarily form many dead spaces through which the gas stream does not pass, leaving many parts of the surface untouched by the moving gas. Previous work ${ }^{37}$ has shown that only about one-fourth of the free cross-sectional area of the bed is effective in allowing the passage of the gas, so it is very probable that a large proportion of the surface area of the particles is not effective in allowing heat to be transferred.

However, a rough evaluation of the total surface area in a bed can be made, and the coefficient can be computed on a surface basis for purposes of comparison.

Consider the condition in a bed of perfect spheres $1 \mathrm{~cm}$ in diameter with 50 per cent voids in the bed. The surface area of each sphere is $\pi \mathrm{cm}^{2}$. The volume of each sphere is $0.5236 \mathrm{~cm}^{3}$. Each cubic centimeter of bed contains $0.5 \mathrm{~cm}^{3}$ of solid material; or on the average, there is $\frac{0.5000}{0.5236}=0.956$ sphere in each cubic centimeter. Therefore, the surface area per cubic centimeter $=0.956 \times \pi=3.00 \mathrm{~cm}^{2}$ per cubic centimeter. For the average irregular piece the area per cubic centimeter of bed $=3.75 \mathrm{~cm}^{2}$. (See section on surface area, p. 44.)

The values of the standard coefficient $k_{s}$ in Table 1 of Appendix 2 are for a system where the particle size is $1 \mathrm{~cm}$ and the voids 50 per cent. The value of the coefficient $A$ of the general equation is 0.761 times the value of $k_{s}$. Hence, to determine the coefficient per unit of area of particles with an average diameter of $1 \mathrm{~cm}$ of any of the materials studied multiply the value of $A$ (Table 4) by $\frac{1}{0.761 \times 3}$ if the material is spherical and by the factor $\frac{1}{0.761 \times 3.75}$ for irregularly shaped pieces.

Thus

$$
\begin{aligned}
& k_{a}=0.44 A \text { (for spheres), } \\
& k_{a}=0.35 A \text { (for irregular particles). }
\end{aligned}
$$

$k_{a}=$ calories per second per degree per square centimeter of surface area of the particle; $A$ can be obtained from Table 4 .

The values obtained by equations 33 and 34 are for an absolute temperature of $500^{\circ} \mathrm{C}$. and a gas flow of 0.1 standard liter per second per square centimeter. For interpolation to other conditions use can be made of the relations that the coefficient varies as the 0.3 power of the absolute temperature and as the 0.7 power of the gas velocity.

The coefficient per unit of area is nearly independent of the particle size. This can be seen by observation of the equations. The coefficient per unit of volume is inversely proportional to the 0.9 power of the particle diameter. The surface area in a given volume of bed is inversely proportional to the 1.0 power of the particle diameter (in case of spheres). Therefore, the coefficient for unit area, which is the coefficient for unit volume divided by the area per unit volume, is proportional to the 0.1 power of the particle diameter. This is only a small degree of variation.

37 Furnas, C. C., The Flow of Gases Through Beds of Broken Solids: Bull. 307, Bureau of Mines, 1929, p. 22. 


\section{COMPARISON WITH COEFFICIENTS FOR CONDUITS}

It is worth while to compare the values of the coefficients in conduits with those obtained for a system of broken solids. For comparison purposes, consider an iron pipe 2 inches in diameter with air flowing through it at an average temperature of $500^{\circ} \mathrm{C}$. at a rate of 0.1 standard liter per second per square centimeter of cross-sectional area. The equation for computing the coefficient may be found in the technical literature. ${ }^{38}$

The equation used is

where

$$
k_{a}=\frac{0.88 u^{0.8} T^{0.5} S^{0.2} C_{p}}{m^{0.3}},
$$

\footnotetext{
$k_{a}=$ B. t. u. per square foot per hour per degree Fahrenheit;

$u=$ pounds of gas per second per square foot of free area;

$m=$ molecular weight of the gas;

$T=$ gas temperature in degrees Fahrenheit absolute;

$s=4$ divided by pipe diameter in feet; and

$C_{p}=$ specific heat of gas.
}

The computed coefficient is 1.97 B. t. u. per square foot per hour per degree Fahrenheit. This is equal to 0.000243 calorie per second per square centimeter per degree centigrade.

From Table 4 , in a bed of iron balls, $A=0.0059$. Then, from equation 33 , the value $k_{a}=0.0059 \times 0.44=0.0026$. Therefore, for a bed of iron balls, the coefficient of transfer is $\frac{0.0026}{0.00024}=10.8$ times as great as for a 2-inch conduit. This figure is for the assumed case where all the surface area is in contact with the gas stream, which, of course, is not true. As far as is known, there is no way of determining the actual amount of contact between gas and solid and hence no way of determining the true surface coefficient.

Probably there are two factors which cause this great increase in the coefficient for beds of material; (1) The actual linear velocity in a bed is several times as great as in a conduit where the mass velocity per unit of cross-sectional area is the same; and, (2) there are a great many head-on collisions between the gas streams and solid particles in a bed, which tend to break down the film and promote heat transfer.

Despite the possibility of computing the approximate coefficients on a basis of area in this manner it is more feasible to leave them in terms of volume of the bed. Computing to a basis of area only adds another complication to an already complicated problem.

\section{SYSTEMS OF MIXED SIZES}

The discussion so far has been confined to systems where the bed was made up of particles of uniform size, but there are many cases in practice where the particles in the bed vary in size over a wide range. It is logical to suppose that in such cases the property of the bed is that of the average-sized particle, but such a condition should not be assumed without experimental proof.

${ }_{38}$ Walker, W. H., Lewis, W. K., and McAdams, W. H., Principles of Chemical Engineering: McGrawHill Book Co., New York, 1923, p. 149. 
It was found ${ }^{39}$ that the resistance to gas flow in systems of two component sizes was much greater than could be expected from consideration of particle size alone, and it is desirable to know if there are any such phenomena in heat-transfer systems.

The last part of Table 1 in Appendix 2 is devoted to the data of systems of two component sizes. The values of $A$ as given were computed on the basis of the average particle size of the system. The values of $A$ are proportional to the values of the heat-transfer coefficients and so may be used for purposes of comparison. For instance, the values of $A$ for systems of mixed sizes of Corsica ore are seen to average considerably less than the average value for $A$ for single sizes given in the first part of the table. This means that the coefficient of heat transfer in the system of mixed sizes in these cases was less than for the uniform bed. However, more careful study shows that for mixed systems where both sized particles are fairly large, the computed values of $A$ are practically the same as for the sized materials, and the discrepancies become worse as the smallest particle size becomes smaller. This indicates that in the systems of mixed sizes, at the gas velocities used, there was a tendency to lift the smallest particles from their places in the bed, which tends to decrease the amount of heat transferred.

The conclusion, then, is that for systems of mixed sizes where the gas velocity is sufficiently low so that the small particles are not lifted the heat-transfer coefficient of the system is the same as for a singlesized system of the same average particle diameter.

\section{BLAST-FURNACE STOCK}

This condition takes care of practically all cases found in practice except the blast furnace. Four experiments were made with blastfurnace stock. Two of them (runs 121A and 121B) were with typical proportions of constituents, run-of-mine Evergreen ore, 60.2 per cent; coke, average size $12 \mathrm{~cm}, 29.3$ per cent; limestone, average size $10 \mathrm{~cm}, 10.5$ per cent (percentages by weight). The coefficients of these runs were 0.00054 and 0.0010 for gas velocities of 0.048 and 0.067 , respectively, and an average temperature of $100^{\circ} \mathrm{C}$.

If gas-velocity and temperature measurements of a blast-furnace stock column are sufficiently complete, it is pcssible, by means of steady-state equations, which will be discussed later, to compute the average heat-transfer coefficient in a furnace shaft. There are at least three sets of data which are sufficiently complete to allow such a computation..$^{40}$

The first furnace was at Holt, Ala.; the second, at the Illinois Steel Co. at South Chicago, Ill.; the third at Provo, Utah. A comparison of the heat-transfer coefficients as computed from furnace data and the average of those computed from the laboratory data of runs $121 \mathrm{~A}$ and $121 \mathrm{~B}$ are given in Table 6.

\footnotetext{
"90 Furnas, C. C., The Flow of Gases Through Beds of Broken Solids: Bull. 307, Bureau of Mines, 1929, p. 60 .

${ }_{10}$ Kinney, S. P., Royster, P. H., and Joseph, T. L., Iron Blast-Furnace Reactions: Tech. Paper 391, Bureau of Mines, 1927, $65 \mathrm{pp}$.

Kinney, S. P., The Blast-Furnace Stock Column: Tech. Paper 442, Bureau of Mines, 1929, 148 pp.; Effect of Sized O're on Blast-Furnace Operation: Tech. Paper 459, Bureau of Mines, 1930, $92 \mathrm{pp.}$
} 
TABLE 6.-Comparison of $k$ computed from blast-furnace and laboratory data

\begin{tabular}{|c|c|c|c|c|}
\hline Furnace & $\begin{array}{l}\text { A verage } \\
\text { gas ve- } \\
\text { locity, } \\
\text { standard } \\
\text { liter per } \\
\mathrm{sec} / \mathrm{cm}^{2}\end{array}$ & 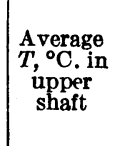 & $\begin{array}{c}k, \text { com- } \\
\text { puted from } \\
\text { furnace } \\
\text { data }\end{array}$ & $\begin{array}{c}k, \text { com- } \\
\text { puted from } \\
\text { laboratory } \\
\text { data }\end{array}$ \\
\hline $\begin{array}{l}\text { Holt, Ala } \\
\text { South Chicago, iil... } \\
\text { Provo, Utah....... }\end{array}$ & $\begin{array}{r}0.12 \\
.15 \\
.12\end{array}$ & $\begin{array}{l}500 \\
500 \\
500\end{array}$ & $\begin{array}{r}0.0012 \\
.0016 \\
.0015\end{array}$ & $\begin{array}{r}0.0015 \\
.0017 \\
.0015\end{array}$ \\
\hline
\end{tabular}

This good agreement between the laboratory and the blast-furnace observations adds considerably to the confidence in the laboratory study.

\section{DEFINITION OF AVERAGE PARTICLE SIZE}

When an average particle size is computed for this work it must be taken as the reciprocal of the average of the reciprocals, for the coefficient is an inverse function of the particle size. For example: A bed contains 80 per cent by rolume of particles $0.2 \mathrm{~cm}$ in diameter and 20 per cent by volume of particles $10 \mathrm{~cm}$ in diameter.

Computation of reciprocal average:

$$
\begin{gathered}
\frac{1}{0.2}=5.0, \\
\frac{1}{10}=0.1 .
\end{gathered}
$$

Average of reciprocals:

$$
\begin{gathered}
\quad 0.8 \times 5.0+0.2 \times 0.1=4.02, \\
\frac{1}{4.02}=0.249 \mathrm{~cm}=\text { average particle size. }
\end{gathered}
$$

If the average particle size were obtained by the usual method of arithmetic averaging, it would be:

$$
0.2 \times 0.8+10.0 \times 0.2=2.16 \mathrm{~cm} \text {. }
$$

If this arithmetic average were used the computed coefficient for the bed would only be about 15 per cent as large as it should be.

To be exact, the average particle size should be the 0.9 root of the average of the reciprocals of the 0.9 power of the diameter, but the first-power reciprocals are sufficiently accurate for the data available.

\section{EXPERIMENTS WITH PRODUCER GAS}

The experiments described so far have been for air or flue gases containing approximately 5 per cent carbon dioxide, 10 per cent water vapor, 10 per cent oxygen, and 75 per cent nitrogen. This gas is not commonly used in industrial processes, so it seemed worth while to do some experimental work with producer gas, which has much wider industrial application. However, producer gas made from coke (about 33 per cent $\mathrm{CO}, 2$ per cent $\mathrm{H}_{2}$, and 65 per cent $\mathrm{N}_{2}$ ) has about the same specific heat, viscosity, and density as air or the gas described above, so it seems logical to assume that the results with producer gas would be approximately the same as with air or flue gas. The gas from a coke producer has the same composition as that in 
the bottom of a blast furnace, so this phase of the study has particular bearing on the ultimate object of this study.

To determine the heat-transfer characteristics of coke producer gas (it is termed "bosh gas" in blast-furnace practice), an apparatus was constructed in which hot gas from the bed of a coke-burning

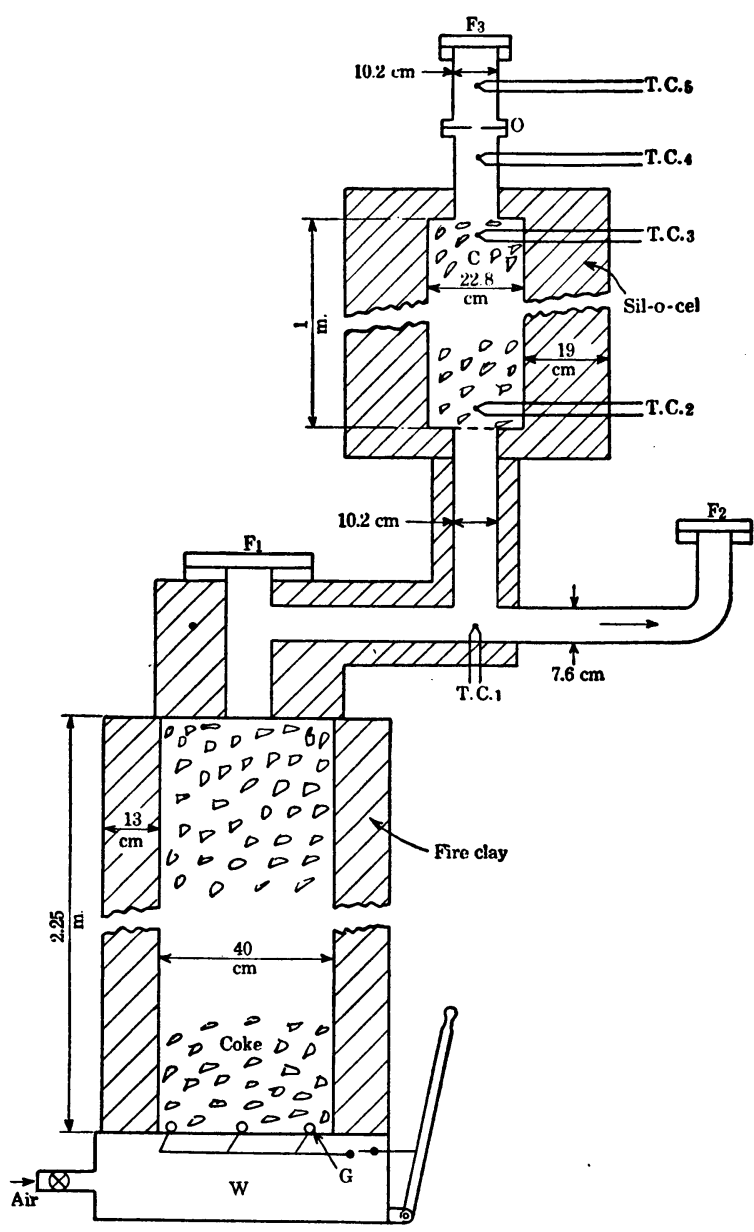

FIGURE 27.-Diagram of apparatus for determination of coefficient of heat transfer from producer gas to a bed of broken solids

er column and out by-pass $B$ until the temperature of the gases at thermocouple $T_{1}$ was constant. Then the gas flow would be stopped momentarily, and blind flange $F_{2}$ would be bolted in place and blind flange $F_{3}$ removed. Then the air would be started through the producer again and the gas forced through column $C$ at a constant mass rate. The rate of gas flow was measured by orifice $O$, made of nichrome plate - the temperature at the orifice being measured by thermocouples $T_{4}$ and $T_{5}$. The true gas temperature at the top and the bottom of the column was measured by shielded thermocouples $T_{2}$ and $T_{3}$. The gas was pulled out over the couple beads by means 
of a vacuum line. The details of this shielded construction are shown in Figure 19.

The coefficients were computed in the same manner described above from the temperature-history data at the top of the column.

The first results obtained by this apparatus on both coke and iron ore were somewhat lower than were those for flue gases. (See Table 1, Appendix 2, runs 152-156, 158.) The gas itself, however, was very dusty, for the fine ash was blown off the coke particles as they burned at the bottom of the producer and this dust was carried on through the rest of the apparatus. After every run column $C$ was filled with the highly insulating, powdery ash. It was easy to see that the presence of this dust would have a deterring effect upon the transfer of heat.

\section{ELIMINATION OF DUST}

To prevent this dusting it was decided to whitewash the pieces of coke in the producer so that a slagging action could take place as the coke burned and prevent the ash from escaping into the gas stream. A thin slurry of a high-temperature whitewash was used. The proportions of the ingredients by weight were: Calcium hydrate, 69.0 per cent; common salt, 14.5 per cent; quick-setting plaster of Paris, 14.5 per cent; 40 per cent solution of sodium silicate, 2.0 per cent. The coke was dipped into the wash. The lime adhered very satisfactorily and apparently did not interfere with combustion. This use of a lime wash almost completely eliminated the dust in the gas stream.

\section{DECREASE OF SULPHUR}

During some of the runs an apparatus was used to bubble a gas sample through cadnium chloride solution to determine the $\mathrm{H}_{2} \mathrm{~S}$ content of the gas. The average $\mathrm{H}_{2} \mathrm{~S}$ content of the gas when the coke in the producer was not whitewashed was 0.026 per cent. When the coke was whitewashed the average $\mathrm{H}_{2} \mathrm{~S}$ content of the gas was 0.0027 per cent. It is evident that the whitewash coating is effective in preventing the sulphur from entering the gas stream. The sulphur is probably retained as $\mathrm{CaS}$ in the slag which the lime forms with the coke ash.

\section{SIMILARITY OF AIR AND PRODUCER GAS}

After the dust was eliminated from the gas stream by whitewashing the coke the coefficients of heat transfer measured in the producer apparatus became as large as for the same materials in a stream of air or flue gas (see Table 1, Appendix 2), so, for practical purposes, the constants given above are applicable to air, flue gas, or producer gas and in all probability to any gas of approximately the same molecular weight.

\section{EFFECT OF MOLECULAR WEIGHT,}

The experiments in the present study have been confined to air or gases of physical properties similar to air. Fortunately, most gases in industrial use have similar physical properties, and the values of $A$ as given in Table 4 have quite wide application. For gases of 
different molecular weight, it is quite probable that the general rules which have been found to apply to transfer in conduits will apply.

It has been found, empirically, ${ }^{41}$ that the coefficient of heat transfer varies directly as the specific heat of the gas and is directly proportional to the 0.5 power of the molecular weight if the standard volume rate of flow is constant. From the similarity of the general relations in heat transfer in beds and in conduits it seems probable that the above relations will also hold for the case under consideration. If this is true, equation 29 can be applied to any gas if $A$ is given the proper value. The values of $A$ for air or a similar gas flowing through beds of various materials are given in Table 4. From the above relations it has been computed that $A$ should be multiplied by the following factors if $k$ is to be computed by equation 29 .

TABLE 7.-Conversion factors for various gases

\begin{tabular}{|c|c|c|c|}
\hline Gas & $\frac{A \text { gas }}{A \text { air }}$ & Gas & $\frac{A \text { gas }}{A \text { air }}$ \\
\hline $\mathrm{H}_{2}$ & $\begin{array}{l}3.8 \\
1.0\end{array}$ & $\left\{\begin{array}{l}25 \\
75 \text { per cent cent } \mathrm{H}_{2} \\
\mathrm{CO}\end{array}\right\}$ & 1.2 \\
\hline $\left.\begin{array}{l}\left\{\begin{array}{l}75 \text { per cent } \mathrm{H}_{2} \text { by volume } \\
25 \text { per cent } \mathrm{CO} \text { by volume }\end{array}\right\} \\
50 \text { per cent } \mathrm{H}_{2} \\
50 \text { per cent } \mathrm{CO}\end{array}\right\}$ & $\begin{array}{l}1.0 \\
1.9 \\
1.4\end{array}$ & $\begin{array}{l}\mathrm{CO}_{2} \\
\mathrm{Dry}_{2} \mathrm{Cteam} \\
\mathrm{CH}_{4} \\
\mathrm{SO}_{2}\end{array}$ & $\begin{array}{l}1.2 \\
1.6 \\
3.2 \\
1.0\end{array}$ \\
\hline
\end{tabular}

Note.-Values for $A$ for air are given in Table 4. The above factors were obtained on the assumption of an analogy to heat transfer in conduits. There has been no direct experimental evidence of the validity of these figures.

\section{THERMAL CONDUCTIVITY OF IRON OXIDE}

The theory of temperature history as developed by Schumann ${ }^{42}$ is strictly applicable only to those systems where the thermal conductivity of the solid particles in the bed is infinite; that is, all of the resistance to heat transfer resides in a thin film upon the surface of of the particles. It seems surprising, therefore, that the theory should be quantitatively applicable, within the limits of experimental error, to materials of refractory nature which have a high internal resistance to heat transfer. Since the theory is applicable, it should be possible to justify its validity by further investigation into the mechanism of heat transmission. To do this it is necessary to know the thermal conductivity of the material in question.

A piece of Raymond iron ore containing 36.6 per cent Fe, 14.1 per cent $\mathrm{SiO}_{2}, 20.8$ per cent $\mathrm{CaO}$, ignition loss 18.4 per cent, specific gravity 3.3 per cent, was ground into a sphere $5.2 \mathrm{~cm}$ in diameter. Its rate of cooling was compared to that of a steel sphere with a specific gravity of 7.92. Each sphere had a thermocouple imbedded in it, the bead of the thermocouple being at the center. The experiments consisted of heating each sphere to $1,020^{\circ} \mathrm{C}$. and then recording the temperature of the center as the sphere cooled, suspended in quiet air at room temperature of $20^{\circ} \mathrm{C}$. The temperature data were taken by a Leeds \& Northrup recording potentiometer. The heating data of this experiment were not valid, for the heating was done in a

4 Walker, W. H., Lewis, W. K., and McAdams, W. H., Principles of Chemical Engineering, 1st ed.: McGraw-Hill Book Co., New York, 1923, p. 149, equation 35.

12 Schumann, T. E. W., Heat Transfer: A Liquid Flowing Through a Porous Prism: Jour. Franklin Inst., vol. 208, 1929, p. 305. 
graphite-lined induction furnace, and the iron ball was heated much more rapidly than was possible by simple conduction from the surroundings, because of the dissipation of inductive electrical energy within the ball itself.

\section{COOLING OF IRON SPHERE}

The cooling data of both the steel and iron ore spheres are shown in Figure 28. The temperatures are plotted on a logarithmic scale.

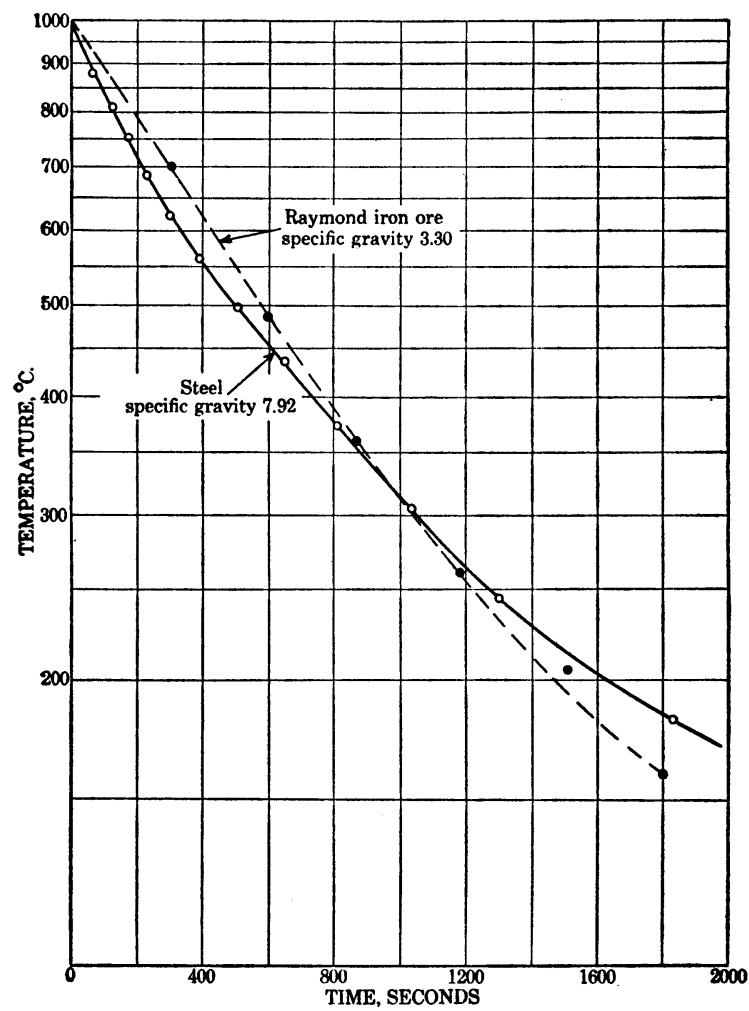

Figure 28. - Temperature history of the center of spheres $5.2 \mathrm{~cm}$ in diameter, cooling in still air

In the case of the steel ball, which has such a high thermal conductivity that there is practically no internal resistance to heat transfer, the rate of temperature change is given by the differential equation,

where

$$
\frac{d \log _{10}\left(T_{s}-T_{r}\right)}{d t}=\frac{-1.301 k}{h_{s^{r}}},
$$

$r=$ the radius in centimeters;

$h_{s}=$ the heat capacity per unit of volume;

$k=$ coefficient of heat transfer;

$T_{s}=$ temperature of the solid; and

$T_{r}=$ temperature of the surroundings.

The derivation of this equation is given in Appendix 3. 
In the case of the steel sphere under consideration, this equation becomes, for the temperature range $500^{\circ}$ to $1,020^{\circ} \mathrm{C}$.,

$$
\frac{d \log _{10}\left(T_{\mathrm{s}}-T_{r}\right)}{d t}=-0.302 k .
$$

The specific heat of iron, at an average temperature of $750^{\circ} \mathrm{C}$., was taken as $0.21 . .^{43}$ Hence, if $k$ is constant the plot of $\log _{10}\left(T_{s}-T_{r}\right)$ against the time $t$ should be a straight line.

From Figure 28 it is obvious that this is not true. In fact, the computed $k$ at $1,000^{\circ} \mathrm{C}$. is almost three times as large as that at $200^{\circ} \mathrm{C}$. There are probably two reasons for this change in the heattransfer constant. First, a large part of the heat loss is due to radiation, and radiation varies as the difference of the fourth power of the temperatures, instead of being proportional to the differences of the first power of the temperatures as is assumed for conduction. Second, since the hot sphere was suspended in open air the convective cooling was brought about by the natural draft induced by the heated body. These draft currents, of course, were more vigorous when the body was hot than when it was cool, so this tended to speed up convection more for the higher temperatures and thus increase coefficient $k$.

However, these facts do not affect the validity of the differential equation 37, for it gives the true transfer coefficient at any particular temperature and is not affected by the previous or subsequent behavior of the constant.

As a first approximation the transfer coefficient $k$ was evaluated between $1,020^{\circ}$ and $500^{\circ} \mathrm{C}$. The time elapsed for this cooling was 500 seconds.

Therefore,

From equation 37,

$$
\frac{\Delta \log _{10}\left(T_{s}-T_{r}\right)}{\Delta t}=\frac{0.301}{500}=0.00602 .
$$

$$
k=\frac{0.00602}{0.302}=0.0020 \text {. }
$$

This is not a true differential evaluation but is sufficiently accurate for the case under consideration.

The value 0.0020 is measured in calories per second per degree per square centimeter and is the average coefficient of heat emission for a surface of iron oxide suspended in still air between the temperatures of $1,020^{\circ}$ and $500^{\circ} \mathrm{C}$. The steel sphere was sufficiently oxidized so that it can be considered that its surface was the same as that of iron ore.

\section{COMPUTATION OF CONDUCTIVITY OF IRON ORE}

To compute the thermal conductivity of the iron ore from its cooling data it is necessary to call upon some additional heat-transfer work. The temperature histories at any position in pieces of various shapes, thermal conductivities, and surface transfer coefficients have been

${ }^{43}$ Ralston, O. C., Iron Oxide Reduction Equilibria: Bull. 296, Bureau of Mines, 1929, p. 188. 
computed by Gurney and Lurie. ${ }^{44}$ The computed data of Gurney and Lurie were correlated in dimensionless groups as follows:

$$
\begin{gathered}
\tau=\frac{K t}{h_{s} r^{2},} \\
m=\frac{K}{k r,} \\
\Delta=\frac{T_{r}-T_{s}}{T_{r}-T_{1} .} .
\end{gathered}
$$

where

$$
\begin{aligned}
K & =\text { thermal conductivity of the material; } \\
t & =\text { time; } \\
h_{s} & =\text { heat capacity per unit volume of solid; } \\
r & =\text { radius of sphere; } \\
k & =\text { coefficient of surface transfer; } \\
T_{r} & =\text { Temperature of surroundings; } \\
T_{s} & =\text { temperature of solid at any time; and } \\
T_{1} & =\text { initial temperature of solid. }
\end{aligned}
$$

Part of the data computed by Gurney and Lurie for the center of spheres is plotted on a somewhat enlarged scale in Figure 29.

These curves may be applied to the data of Figure 28 to determine the thermal conductivity $K$ of the iron ore.

For the iron-ore sphere, since $k$ was determined by the steel sphere to be 0.002 between $1,020^{\circ}$ and $500^{\circ} \mathrm{C}$.,

$$
m=\frac{K}{0.002 \times 2.6}=192 K .
$$
Then,

The specific heat of the iron ore was taken as 0.30 .

$$
\tau=\frac{K t}{0.30 \times 3.30 \times 2.6^{2}}=0.149 K t .
$$

In Figure 28 it is seen that the iron-ore sphere arrived at $500^{\circ} \mathrm{C}$. in 580 seconds.

Then, at this temperature,

$$
\tau=86.5 \mathrm{~K} .
$$

$K$ must be of such a value that equations 41 and 43 are satisfied. The value may be found by trial and error with the aid of Figure 29.

For $500^{\circ}$ C. and room temperature of $20^{\circ}$ C.,

$$
\Delta=\frac{20-500}{20-1,000}=0.49 \text {. }
$$

The trial-and-error computation is outlined in Table 8.

44 Gurney, H. P., and Lurie, J., Charts for Estimating Temperature Distributions in Heating or Cooling Solid Shapes: Ind. and Eng. Chem., vol. 15, 1923, pp. 1170-1172.

772 .

See also Haslam, R. T., and Russel, Robert P., Fuels and Their Combustion: New York, 1926, pp. 765- 


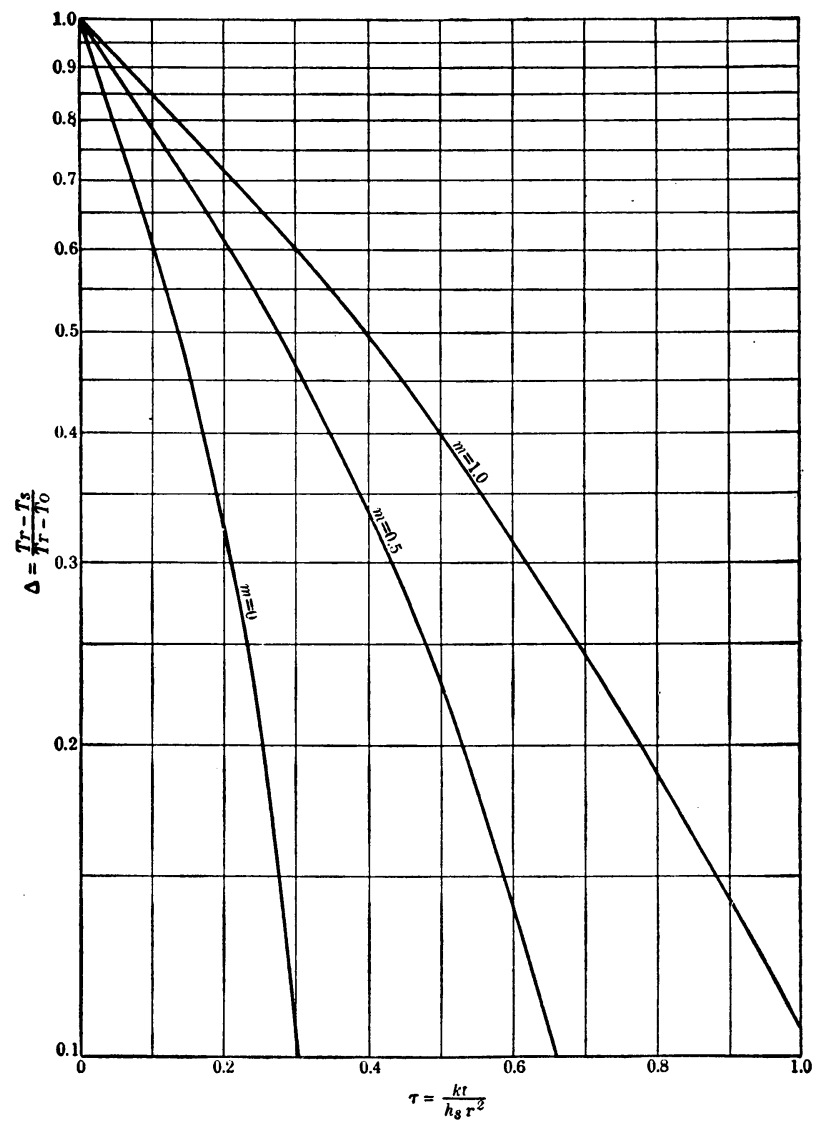

FIGURE 29.-Gurney and Lurie data for temperature history of center of spheres

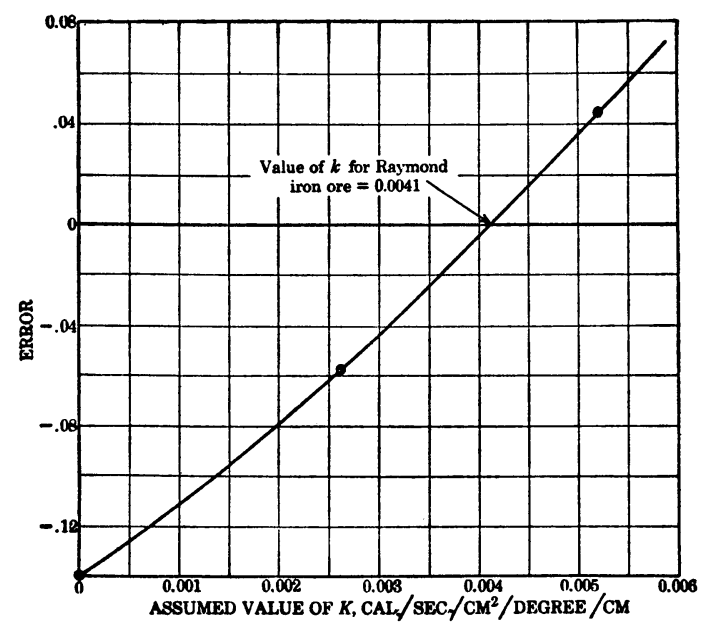

FIGURE 30.-Graphical solution for thermal conductivity of iron ore 
TABLE 8.-Trial-and-error solution for thermal conductivity of iron oxide

\begin{tabular}{|c|c|c|c|c|}
\hline $\begin{array}{c}\text { Assumed } \\
\text { value of } \\
m\end{array}$ & $\begin{array}{c}\text { Value of } K \\
\text { from } \\
\text { equation } \\
41\end{array}$ & $\begin{array}{l}\text { Value of } \tau \\
\text { for } \Delta=0.49 \text {, } \\
\text { from figure } \\
29\end{array}$ & $\begin{array}{c}\text { Value of } \tau \\
\text { from } \\
\text { equation } \\
43\end{array}$ & $\begin{array}{l}\text { Error of } \\
\text { computa- } \\
\text { tion }\end{array}$ \\
\hline $\begin{array}{l}0 \\
0.5 \\
1.0\end{array}$ & $\begin{array}{l}0 \\
0.0026 \\
.0052\end{array}$ & $\begin{array}{r}0.139 \\
.282 \\
.405\end{array}$ & $\begin{array}{r}0.000 \\
.225 \\
.450\end{array}$ & $\begin{array}{r}-0.139 \\
-.057 \\
+.045\end{array}$ \\
\hline
\end{tabular}

The plot of the error for the various assumed values of $K$ is given in Figure 30. The curve crosses the line of zero error where $K=0.0041$ calorie per second per square centimeter per degree per centimeter. This, then, is the value of the thermal conductivity of this sample of iron ore, between $500^{\circ}$ and $1,020^{\circ} \mathrm{C}$.

This method of determination may seem somewhat tedious, but the experimental part is very simple and can be done very easily, and with the Gurney and Lurie plots ${ }^{45}$ available it is a relatively simple matter to handle the computation.

\section{COMPUTATION OF DEGREE OF APPLICABILITY OF SCHUMANN'S THEORY}

With the data of thermal conductivity available it is possible to compute the approximate degree of applicability of Schumann's theory to refractory materials.

It is more or less obvious that when the term "temperature of the solid" is used in the case of refractory materials which are being heated or cooled, the temperature of the solid means the average temperature throughout the piece, or, as defined on page 34 , "the heat content divided by the product of the mass and average specific heat."

If the rate of heat transferred between the gas and solid, divided by the difference between the average temperature of the gas stream and the average temperature of the solid, is constant for the entire period of heating, then the conditions of Schumann's problem have been exactly fulfilled and the theory is strictly applicable. The lack of applicability is determined by the lack of constancy of this ratio. This ratio is the over-all coefficient of heat transfer.

\section{EQUATIONS FOR HEATING SPHERES}

The theoretical consideration will be confined to spheres. The theory for the heating of spheres is sufficiently well developed ${ }^{46}$ to make solution of the problem relatively easy, though somewhat tedious. In the solution the rate of heat transferred per unit of time was divided by the mass average temperature of the mass. The quotient is proportional to the over-all coefficient of heat transfer. The equations necessary to determine these quantities are given in the above reference.

48 Gurney, H. P., and Lurie, J., Charts for Estimating Temperature Distributions in Heating or Cooling Solid Shapes: Ind. and Eng. Chem., vol. 15, 1923, pp. 1170-1172.

See also Haslam, R. T., and Russel, Robert P., Fuels and Their Combustion: New York, 1926, pp. 765-772.

${ }^{t 6}$ Ingersoll, L. B., and Zobel, O. J., The Mathematical Theory of Heat Conduction: New York, 1913, p. 142 . 
In the computations it was assumed that spheres with a thermal conductivity of 0.004 calorie per second per square centimeter per degree per centimeter and with a surface film coefficient of 0.004 calorie per second per square centimeter per degree were being heated. These conditions are about the average of the experimental conditions on iron ore. Spheres having radii of 1,5 , and $10 \mathrm{~cm}$ were considered. As the temperature rises, the amount of heat transmitted to the body of the sphere, per degree difference in average temperature, decreases. The data for the different-size spheres of iron ore are given as the rela-

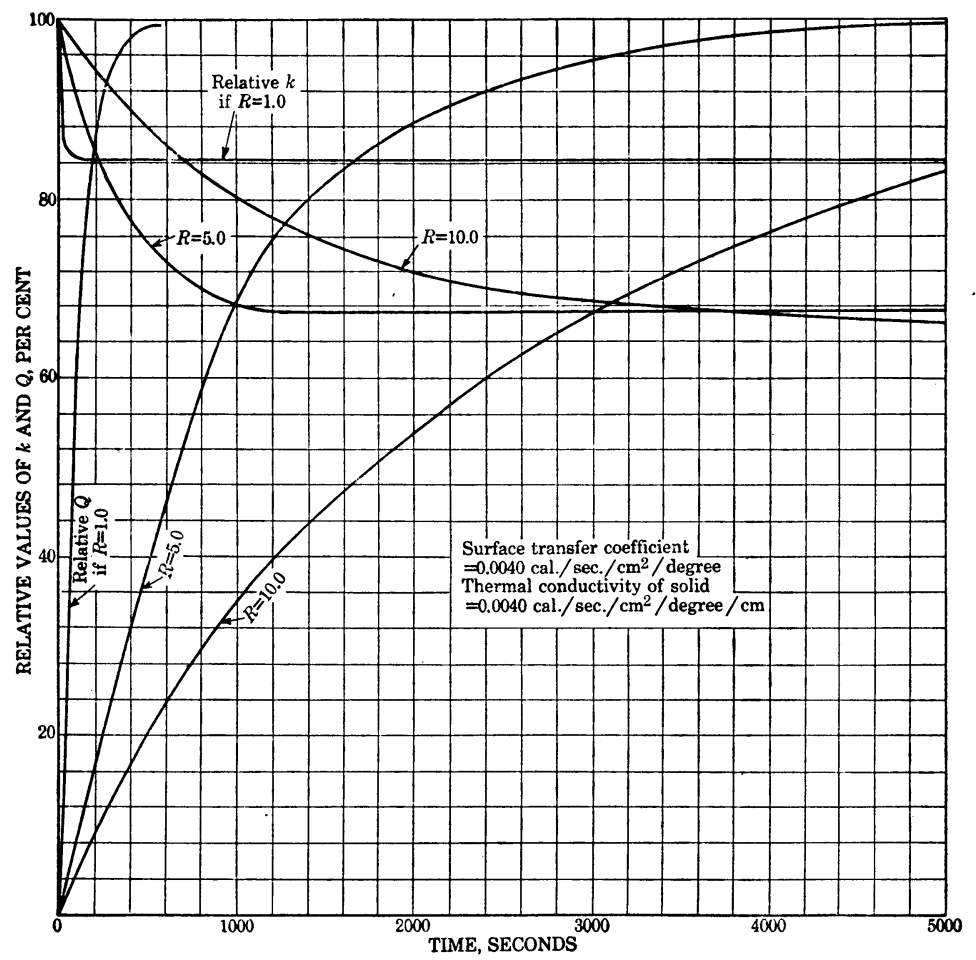

FIGURE 31.-Relative values of over-all heat-transfer coefficient $k$ and of the amount of heat absorbed $Q$ at different times during the heating period

tive over-all heat-transfer coefficients $k$, for different times during the heating period, in Figure 31 .

For a sphere with a radius of $1 \mathrm{~cm}$ the coefficient decreases very rapidly during the first few seconds and becomes practically constant at about 84.5 per cent of the original value within about 100 seconds after the beginning of the heating. The coefficient for the sphere of 5 -cm radius decreases more gradually and at 1,000 seconds approaches a constant value of about 68 per cent of the original. The sphere $10 \mathrm{~cm}$ in radius changes its coefficient even more gradually and only approaches a constant value of about 66 per cent of the original after about 5,000 seconds of heating.

The curves for the relative amount of the total heating which has been done up to the given time are also given in Figure 31 for each size sphere. 
To bring out their significance more clearly these data are plotted in Figure 32 as the relative over-all coefficient against the relative amount of the total heating which has been done.

For spheres with a radius of $1 \mathrm{~cm}$ the coefficient is practically constant after 10 per cent of the total heat has been transmitted to the piece, so the conditions fit Schumann's theory very satisfactorily. For the larger pieces the change is more gradual, and the coefficients do not approach a constant value until about 75 per cent or more of the heating has been accomplished. The average over-all coefficient during the last half of the heating period is about 20 per cent smaller than the average coefficient during the first half. This is a rather large change but hardly as large as might be expected from a qualitative consideration of the difficulty of imparting heat to refractory materials. This 20 per cent variation is about the probable limit of accuracy of the experimental work on this problem.

The fact that the curves computed by Schumann's theory fit the data for large pieces quite accurately, even though the final coefficient is only 65 to 70 per cent of the coefficient at the beginning of the heat-

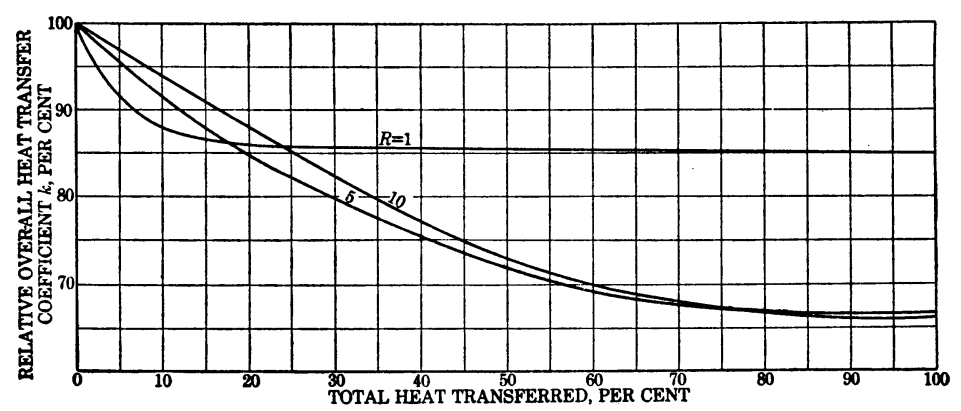

Figure 32.-Relative over-all heat-transfer coefficient for different percentages of heat absorbed

ing, shows that the errors introduced by a variable coefficient tend to neutralize each other. This makes Schumann's curves applicable, as a first approximation, to a wide variety of systems, and they may be expected to find applications in a number of other fields than heat transfer.

\section{IMPORTANT FACTORS IN HEAT TRANSFER}

Sufficient data have now been discussed to permit a critical survey of the field and to determine qualitatively which variables have most importance. An examination of equation 29 , for instance, shows that the gas velocity, the voids in the bed, and the particle size have considerably more effect than the temperature. This is as might be expected from consideration of heat transfer in conduits.

If most of the resistance to heat transfer to the solid piece resides in the surface film, then gas velocity may be expected to have a major effect because of the decreasing thickness of the film with increasing velocity. On the other hand, if most of the resistance to transfer resides in the body of the piece, then the gas velocity will have less effect. In most heat-transfer studies in conduits the coefficient has been found to vary as the 0.8 power of the velocity, while the data of the present study indicate that the coefficient varies as the 0.7 power. 
This shows that the gas velocity has almost as much effect as in conduits, indicating that the internal resistance of the particles does not have any great effect, even in the larger sizes.

A decrease in voids increases the coefficient considerably, probably due to the fact that as the bed becomes more compact the gas stream has to follow a more tortuous path, which causes more head-on collisions with the solid particles, thus aiding the transfer. Decreasing the voids also increases the linear velocity of the gas, which increases the coefficient.

The coefficient as given in equation 29 is per unit of volume of the bed. In the case of spheres, the amount of area per unit volume of bed varies inversely as the first power of the diameter. As shown in equation 29 , it has been found experimentally that the coefficient per unit of volume varies inversely as the 0.9 power of the diameter. This means, then, that the coefficient per unit of area varies directly as the 0.1 power of the particle diameter, assuming that the area variation between sizes is the same for irregular pieces as for spheres. This 0.1 power variation is not large; but it would be expected to be in the other direction, that is, an inverse proportionality. It is surprising that the particle size does not have a larger effect than it does; that is, the exponent should be larger than 0.9 , for internal resistance to heat transfer increases with the size of the particle.

The explanation for this paradox probably lies in the fact that as particle size is decreased there is probably an increasing proportion of the open spaces in the bed that become too small to permit the passage of a significant amount of gas, so that the relative amount of area in contact with the gas stream in the smaller sizes becomes less. This effect more than offsets the change of internal resistance with particle size.

Coefficient $A$ of equation 29 has a constant value for any particular substance and so may be considered a specific measure of the heattransferring ability. The values of $A$ are summarized in Table 4 , and they range from 0.0042 for bituminous coal to 0.015 for Cuyuna ore. There must be some reason for this almost fourfold spread between materials.

The average value of $A$ for the group of iron ores is 0.0083 , with the specific gravities ranging from 3.3 to 4.85 . For limestone with a specific gravity of 2.5 the value of $A$ is 0.0057 . For coke with a density of $1.0, A$ is 0.0049 . From these data it would seem that the value of $A$ is some function of specific gravity. On the other hand, iron balls with specific gravity of 7.9 have a value of $A=0.0059$, which is almost as low as for limestone, so it seems certain that specific gravity does not have a major effect.

If character of surface were the important item it would be expected that coke, with a honeycombed structure, would show a widely different value of $A$ than does smooth-surface bituminous coal or anthracite, yet the values for these substances are almost the same.

The thermal conductivity of the body of the material can not be the determining factor, for the values of $A$ for crushed refractory brick of low thermal conductivity average almost twice as high as the value for iron balls which have a very high thermal conductivity.

It seems probable that the shape of the particles has the major influence upon the value of coefficient $A$. The shape of the particles determines the manner in which they nest in the bed, which in turn 
determines the voids, the degree of tortuousness of the gas stream, and the proportion of the surface area actually in contact with the gas stream. As mentioned above (see p. 45), only about onefourth of the free cross-sectional area in the bed is effective in allowing passage of gas, so it seems probable that only about one-fourth of the surface area is in actual contact with the gas stream. Hence, any factor which would tend to change the proportion of area exposed would have a major influence on the value of the coefficient. The shape of particle probably has considerable effect on the area exposed; hence, it seems probable that it has a major influence in determining the specific ability of a system to transfer heat. No satisfactory way of making a quantitative correlation between shape and the value of $A$ has been found as yet, so that it remains necessary to determine $A$ for each substance used.

\section{PROBLEM ILLUSTRATING THE TRANSFER OF HEAT IN BATCH- TYPE APPARATUS}

The discussion thus far has been limited to batch apparatus; that is, systems where the temperature changes with time. Many pieces of industrial equipment wherein heat is being transferred operate in a "steady state;" that is, the temperature at any particular point does not change with time, but some kinds of apparatus are of the batch type and it is well to give a problem illustrating the use of the data which have been discussed.

Problem.-A column of coke 5 meters high with 45 per cent voids in the bed is being dry quenched by a gas stream of approximately the same density and specific heat as air flowing at the rate of 0.2 standard liter per square centimeter per second. The initial temperature of the coke was $850^{\circ} \mathrm{C}$. The gas enters the bed at $150^{\circ} \mathrm{C}$. The coke has the following size distribution: 2-cm diameter, 5 per cent; $4-\mathrm{cm}, 10$ per cent; $6-\mathrm{cm}, 30$ per cent; $8-\mathrm{cm}, 40$ per cent; $10-\mathrm{cm}, 10$ per cent; and $12-\mathrm{cm}, 5$ per cent. What will the temperature of the outcoming gas and of the top layer of coke be at the end of 15 minutes?

Solution.-(1) Particle size.

Average of reciprocals $=0.05 \times 1 / 2+0.10 \times 1 / 4+0.30 \times 1 / 6+0.40 \times 1 / 8+0.10 \times 1 / 10+$ $0.05 \times 1 / 12=0.164$.

Average particle size $=\frac{1}{0.164}=6.1 \mathrm{~cm}$.

(2) Average temperature of system $=\frac{150+850}{2}=500^{\circ} \mathrm{C} .=773^{\circ} \mathrm{C}$. absolute.

(3) Average heat capacity of gas, $h_{0}=0.00033$ calorie per pubic centimeter per degree. .

(4) Average heat capacity of coke, $h_{s}=0.25$ calorie per cubic centimeter per degree.

(5) Solving for average $k$ :

For cooling coke,

$$
k=\frac{A u^{0.7} T^{0.3} 10^{1.68 f-3.56 / 2}}{d^{1.3}}
$$

The value of $A$ for cooling coke (see p. -$)=0.0120$.

$$
\begin{aligned}
k & =\frac{0.0120 \times(0.2)^{0.7} \times(773)^{0.3} 10^{1.68 \times 0.45-8.58(0.45) 2}}{(6.1)^{1.3}}, \\
& =\frac{0.0120 \times 0.324 \times 7.353 \times 1.084}{10.49},
\end{aligned}
$$

$=0.00296$ calorie per second per centimeter ${ }^{2}$ per degree.

$112607^{\circ}-32-5$ 
(6) Evaluating $y$ :

$$
y=\frac{k x}{h_{0} v}
$$

$x$ is in centimeters.

$v$ is in cubic centimeters per second per centimeter ${ }^{2}$.

$$
y=\frac{0.00296 \times 500}{0.00033 \times 200}=22.4 \text {. }
$$

(7) Evaluating $z$.

At 15 minutes

$$
z=\frac{k t}{h_{s}(1-f)}
$$

$$
z=\frac{0.00296 \times 15 \times 60}{0.25 \times 0.55}=19.4 \text {. }
$$

(8) Solving for gas temperature, $T_{o}$.

From the curve for $\frac{T_{g}}{T_{o}}$ against $z$ for various values of $y$ (fig. 10), interpolating between $y=22$ and $y=25$, at $z=19.4$,

$$
\frac{T_{o}}{T_{o}}=0.350 .
$$

The difference between the entrance gas temperature and the initial solid is $850^{\circ}-150^{\circ}=700^{\circ} \mathrm{C}$. This is the entire temperature change in the system and is equal to $T_{o}$.

Then

$$
T_{g}=0.350 \times 700=245 .
$$

This is the temperature decrease at the top of the column. Changing to the centigrade scale,

$$
T_{o}=850-245=605^{\circ} \mathrm{C} \text {. }
$$

(9) Solving for the solid temperature, $T_{s}$.

This requires the use of the curves of $\frac{T_{s}}{T_{0}}$ against $z$ in Figure 9. From these curves, interpolating for $y=22.4$ at $z=19.4$,

As above, then,

$$
\frac{T_{s}}{T_{o}}=0.295 \text {. }
$$

$$
T_{s}=700 \times 0.295=206 \text {. }
$$

This is the temperature decrease at the top.

Therefore

$$
T_{s}=850-206=644^{\circ} \mathrm{C} \text {. }
$$

\section{POSSIBLE APPLICATIONS OF HEAT-TRANSFER DATA TO OTHER SYSTEMS}

The general theory of transfer in batch apparatus, as derived by Schumann and illustrated in Figures 7 to 14 , does not need to be limited to heat transfer. As mentioned on page 2, the theoretical curves are probably applicable to any batch-transfer system where one of the phases is fixed and where the rate of transfer is directly: proportional to concentration difference. The absorption of coloring matter from sirups or oils by charcoal is a possible field of application. 
In this case the amount of coloring matter adhering to the charcoal is analogous to the solid temperature $T_{s}$. The amount of coloring matter in the liquid is analogous to the gas temperature $T_{g}$. As the clarifying bed is used the color concentration in the liquid at the top of the column would gradually increase until the bed was saturated. This would correspond to the rise in the $T_{a}$ curves. If experimental data would fit the shape of Schumann's curves, then his theory is applicable. It is not known, however, that such an application is possible, for usually absorption on solids is not proportional to the first power of concentration difference, and it is not known whether or not this would vitiate the theory. This color absorption is mentioned as a possible application. Experimental data are needed to check the idea.

Other possible applications are filtration of water by sand beds, drying of solids by gas streams, desulphurization of gas by passing through beds of iron ore, washing of sludges, or the solution of solids.

\section{THE STEADY STATE}

The theory of heat acquisition of static beds, as presented by Figures 7 to 14 , has limited application because many commercial operations involving the type of heat transfer under consideration are for the steady state where a stream of gas is directed countercurrent to a stream of

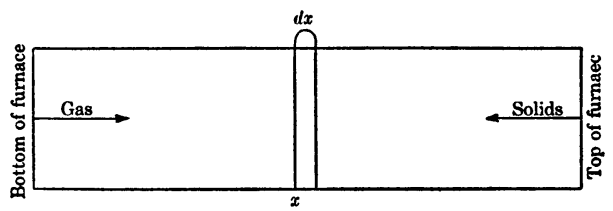
solid material and where the average temperature at any position does not change with time. It is worth while to develop equations for this condition and to show how the data just discussed may be applied.

The equations of such a system are merely those of any countercurrent heat exchanger where only the entrance temperature of the two phases are known. Some of the necessary equations have been developed previously, ${ }^{47}{ }^{49}$ but somewhat modified forms are given here for convenience.

Assumptions. - It will be considered that we are dealing with some sort of a shaft furnace which is a cylinder of constant diameter, that a constant stream of solid material is charged at the top and hot gases or liquids are forced in at the bottom, that the mass rates of flow of both the solid and gas streams are constant throughout, and that the apparatus is at a steady state; that is, the temperature at any point does not change with time. A diagram of such a set-up, with the type of temperature curves to be expected, is shown in Figure 33. The equations developed are applicable to any countercurrent flow system and are not limited to this particular arrangement of materials.

47 Kreisinger, H., and Ray, W. T., The Transmission of Heat into Steam Boilers: Bull. 18, Bureau of Mines, 1912, $180 \mathrm{pp}$.

${ }^{48}$ Stanton, T. E., On the Passage of Heat Between Metal Surfaces and Liquids in Contact with Them: Phil. Trans. Roy. Soc. London, vol. 61, 1897, p. 287.

6 Royds, R., Heat Transmission by Radiation, Conduction, and Convection; London, 1921, ch. 4. 


\section{Nomenclature}

$t_{o}=$ temperature of gas at bottom of furnace (entrance);

$t_{s}=$ temperature of solid at botton of furnace (exit);

$t_{1}=$ temperature of combustion with cold reactants;

$T_{o}=$ temperature of gas at any position $x$ in furnace;

$T_{s}=$ temperature of solid at any position $x$ in furance;

$\boldsymbol{\theta}_{\theta}=$ temperature of gas at top of furnace;

$\boldsymbol{\theta}_{\mathrm{s}}=$ temperature of solid at top of furnace (entrance) arbitrarily set equal to zero;

$k=$ coefficient of heat transfer measured in heat units per unit of volume per unit of time per degree temperature difference;

$\boldsymbol{h}_{\boldsymbol{g}}=$ heat capacity of gas per unit of standard volume per degree;

$h_{s}=$ heat capacity of solid per unit of volume per degree;

$h_{c}=$ heat capacity of that portion of solid charge which is combustible;

$u_{o}=$ rate of gas flow, standard volume per unit cross-sectional area of bed per unit of time;

$u_{s}=$ rate of solid flow in volume of solid material per unit cross-sectional area of bed per unit of time.

Note.-Instead of these units of heat capacity and rate of flow, it is permissible to use heat capacities and rates of flow measured in units of weight.

$u_{c}=$ rate of flow in volume of solid material of that part of solid charge which is combustible;

$L=$ total length of column of solid material;

$x=$ linear distance measured from bottom of column;

$l n=$ logarithm to the base $e$.

$$
\begin{gathered}
C=t_{\sigma}-\frac{h_{s} u_{s}}{h_{o} u_{o}} t_{s}, \\
D=\frac{h_{s} u_{s}}{h_{o} u_{o}}-1 .
\end{gathered}
$$

It will be noticed that in most cases no units have been specified and that the symbols and formulas are perfectly general; it is only necessary that the units used shall be consistent.

The quantities which are known are the entrance temperature of the solid $\theta_{s}$, the distance $L$, the thermal properties $k$ and $h$, and the rate of flow $u$. It is desired to know the exit temperatures of the gas and solid $\theta_{0}$ and $t_{s}$, and the gas and solid temperatures $T_{\sigma}$ and $T_{s}$ for any position $x$.

Derived equations. - The details of the derivation are given in Appendix 3. The derived equations are as follows:

For the solid temperature,

$$
\begin{aligned}
& \ln \left(\frac{C+D T_{s}}{C}\right)=\frac{D k}{h_{s} u_{s}}(L-x), \\
& t_{s}=t_{0}\left(\frac{1-e^{\frac{-D k L}{h_{s} u_{s}}}}{\frac{h_{s} u_{s}}{h_{0} u_{0}} e^{\frac{-D k L}{h_{s} u_{s}}}}\right) .
\end{aligned}
$$

This gives the temperature of the solid at the bottom of the furnace if the entering temperature of the solid is zero. When $t_{8}$ is known $A$ and $B$ can be evaluated, and equation 46 can be used to solve for $T_{s}$ at all values of $x$.

For the temperature of the gas,

$$
\begin{gathered}
T_{o}=t_{0}-\frac{h_{s} u_{s}}{h_{o} u_{o}}\left(t_{s}-T_{s}\right), \\
\ln \frac{C+D T_{g}}{C+D t_{o}}=\frac{-D k x}{h_{s} u_{s}}, \\
\theta_{\theta}=t_{g}-\frac{h_{s} u_{s}}{h_{g} u_{o}} t_{s \cdot}
\end{gathered}
$$


If the temperatures of the solid have been obtained, it is much simpler and more accurate to obtain the gas temperature by substituting in equation 48 rather than to solve equation 49 .

Indeterminate case.-When the heat capacity of the solid stream equals the heat capacity of the gas stream, quantity $D$ becomes 0.0 , and equation 47 becomes indeterminate and has to be handled in a special manner.

For this case, when $D=0.0$,

$$
t_{s}=\frac{k L}{h_{s} u_{s}+k L} t_{g}
$$

The derivation of this equation is given in Appendix 3.

\section{EFFECT OF HEAT CAPACITY ON TEMPERATURE GRADIENT}

In the foregoing equations dealing with the steady state the relative values of the heat capacities of the fluid and solid streams have the

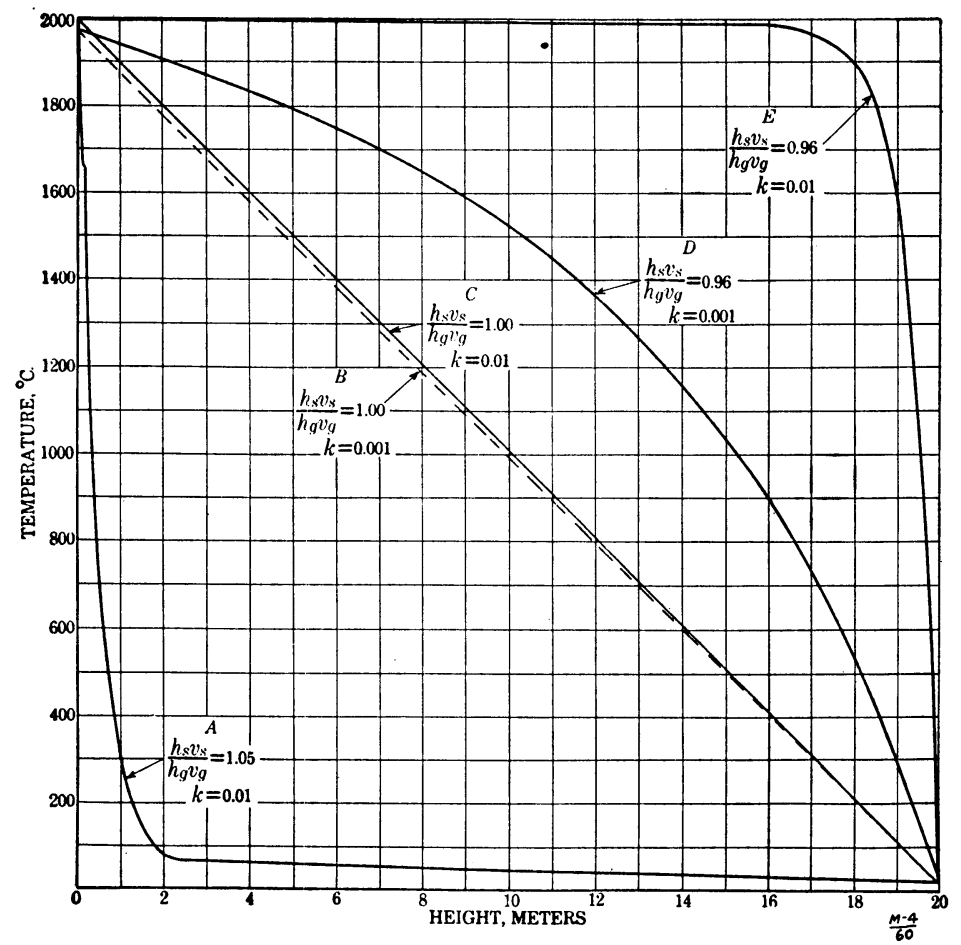

Figure 34. -Effect of relative heat capacities of gas and solid streams upon the temperature gradient in a steady-state apparatus

major effect upon the temperature gradient, as illustrated by Figure 34. The curves in this figure are those of the computed solid temperatures in a shaft furnace 20 meters high carrying a charge similar to that of a blast furnace but with no heats of reaction involved. The curves are for values of $\frac{h_{s} u_{s}}{h_{g} u_{g}}$ of $0.95,1.0$, and 1.04. Curves $A, C$, and $E$ are for heat-transfer coefficients of 0.01 calorie per second per cubic centimeter per degree; and curves $B$ and $D$, for values of the coefficient of 0.001 calorie per second per cubic centi- 
meter per degree. Curve $A$ shows that if the ratio $\frac{h_{s} u_{s}}{h_{o} u_{g}}<1.0$ (that is, the heat capacity of the gas stream is less than that of the fluid stream), the curve of the temperature of the solid against height is concave upward. Curve $E$ shows that if $\frac{h_{s} u_{s}}{h_{o} u_{g}}>1.0$ the curve is concave downward. With the value 0.01 for the coefficient (curves $A$ and $E$ ), the change in the shape of the curves for a change of value of $\frac{h_{s} u_{s}}{h_{0} u_{o}}$ from 1.05 to 0.96 , is very great. In a shaft 20 meters long, the fact that the slopes of these curves change so rapidly near the ends of the column indicates that only a small portion of the entire length of the shaft is necessary to effect the major portion of the heat transfer. Thus, if the solid stream has the greater heat capacity (curve $A$ ) nearly all the temperature is confined to the bottom of the furnace, for the gas stream gives up its supply of heat; but if the heat capacity of the solid stream is larger (curve $E$ ), nearly all the heat is carried to the top of the furnace through the charge which has been already heated, and the transfer to the cold charge is completed in a short section near the top.

These curves, $A$ and $E$, represent an exaggerated condition, for the value of the coefficient (0.01) is higher than would be found in a large piece of equipment. Curve $D$ is the temperature of the solid when $\frac{h_{s} u_{s}}{h_{g} u_{g}}=0.96$, for a value of $k=0.001$ calorie per second per cubic centimeter per degree, which is more nearly that found in a blast furnace. The curve is concave downward as before, but its change in slope is more gradual. Its shape shows that nearly the whole length of the shaft is required for the transfer.

Curves $B$ and $C$ are for the cases when $\frac{h_{s} u_{s}}{h_{g} u_{g}}=1.0 . \quad B$ is for a coefficient of 0.001 and $C$ for a coefficient of 0.01 . Both curves are straight lines, and the only effect of the tenfold change in the coefficient is to lower the temperature of the solid at the bottom of the furnace by $30^{\circ}$.

In commercial blast furnaces, of course, the temperature does not follow such uniform curves because of localized heats of reaction. Usually the temperature in the lower one-fourth of the furnace is concave upward, indicating that the heat capacity of the gas stream is smaller than the solid stream, while in the upper part the curve is concave downward, showing that the heat capacity of the gas stream has increased enough through reduction and calcination to be greater than the heat capacity of the solid stream. Since heat-transfer coefficient $k$ determines the shape of the temperature curve, if the temperature data are known it should be possible to compute the coefficient of heat transfer. This was done for three different furnaces and as is shown in Table 6 . The data obtained agreed very closely with laboratory data.

\section{TEMPERATURE OF COMBUSTION}

In many cases the temperature of the gaseous products of combustion in the bottom of a shaft depends upon the temperature to which the solid fuel is heated before it reaches the combustion zone. 
This necessitates the development of a new equation for the gas temperature $t_{g}$ at the bottom of the furnace.

If $h_{c}$ and $u_{c}$ are the heat capacity and rate of flow, respectively, of that part of the solid charge which is combustible,

$$
t_{o}=t_{1}+\frac{h_{c} u_{c}}{h_{o} u_{o}} t_{s},
$$

where $t_{1}=$ the temperature of combustion when all reactants are cold.

If this value of $t_{s}$ is substituted in equation 47 the equation may be rearranged and solved for $t_{s}$, giving

$$
t_{s}=\frac{h_{0} u_{v} t_{1}}{h_{o} u_{o}\left(\frac{\frac{h_{\mathrm{s}} u_{s}}{h_{o} u_{0}}-e^{\frac{-D k L}{h_{s} u_{e}}}}{1-e^{\frac{-D k L}{h_{s} u_{\theta}}}}\right)-h_{c} u_{o}} .
$$

\section{EQUATIONS FOR VARIABLE K}

The foregoing developments have been for the case where $k$ does not change with temperature. To set up an exact equation for the cases where $k$ is not constant it is only necessary to substitute in place of $k$ in the original differential equation the function of $T$ which determines $k$ and then to integrate the equation. The author has done this for several different exponential variations of $k$ with $\mathrm{T}$ and has found that, though the forms may be integrated without difficulty, the resulting equations are too involved and unwieldy for practical computation. It seems that it is better to assume $k$ to be constant and to use a value which is the average for the temperature range considered.

\section{HEAT LOSSES THROUGH WALLS}

The foregoing equations have been only for those cases where there was no heat loss through the walls of the apparatus. However, heat losses are sometimes too large to be neglected.

The simplest way to handle heat losses through the walls is to add an increment to the heat capacity of the solid to account for the losses. This will only serve as a first approximation, of course, for the heat losses increase with the temperature while the added increment would remain constant, but for most commercial processes the proportional loss is small enough to be handled very satisfactorily by this method.

However, it is possible to derive exact equations for systems where there are heat losses through the walls. The derivation is given in Appendix 3. (See equation 94, p. 88.)

\section{ILLUSTRATIVE PROBLEMS}

The use of the equations involving the steady state can best be illustrated by typical problems.

\section{PROBLEM 1}

Assume a low-temperature coal-carbonization process wherein a stream of waste gas at $800^{\circ} \mathrm{C}$. is forced through a column of bituminous coal 1 meter high, moving countercurrently to the gas stream. The gas is chemically inactive, but has the same physical characteristics as air. It is flowing at the rate of 0.15 
standard liter per second per square centimeter. The coal particles average $0.8 \mathrm{~cm}$ in diameter, have a density of 1.3 , and are flowing at the rate of 0.12 gram per second per square centimeter cross-sectional area of bed. The voids in the bed are 45 per cent. The coal enters at a temperature of $20^{\circ} \mathrm{C}$. Assuming that the algebraic sum of the heats of carbonization reactions is zero, what is the temperature of the exit gas at the top and of the solid particles at the bottom of the column?

Solution.-(1) From the conventions of the problem as given in the table of nomenclature $T$, the temperature of the solid at the top of the column is arbitrarily equal to 0 . The entrance temperature of the gas, then, on this scale is $780^{\circ}$.

(2) Heat capacities.

The gas, being similar to air, has a heat capacity of 0.33 calorie per liter per degree.

$h_{0} u_{0}=0.33 \times 0.15=0.0495$ calorie per second per degree per square centimeter.

The specific heat of coal can be taken from Table 4 as 0.37 .

Then,

$h_{s} u_{s}=0.37 \times 0.12=0.0445$ calorie per second per degree per square centimeter.

(3) Evaluating $D$.

From equation 45 ,

$$
D=\frac{0.0445}{0.0495}-1=-0.1
$$

(4) Solving for $k$.

From equation 29 and the value of $A$ from Table 4, assuming an average temperature of $300^{\circ} \mathrm{C}$.,

$$
k=\frac{0.0042 \times(0.15)^{0.7}(300+273)^{0.3}}{(0.8)^{0.8}} 0^{1.68 \times 0.45-3.56(0.45)^{2}}=0.0099 .
$$

(5) Solving for $t_{s}$, the exit temperature of the solid.

Substituting in equation 47 ,

$$
\begin{aligned}
t_{s}=780 & \left(\frac{1-e^{\frac{-(0.1)(0.0099)(100)}{0.0445}}}{\frac{0.0445}{0.0495}-e^{\frac{-(-0.1)(0.0099)(100)}{0.0445}}}\right) \\
& =780\left(\frac{1-e^{2.2247}}{0.9-e^{2.2247}}\right), \\
& =780\left(\frac{-8.25}{-8.35}\right)=770^{\circ} .
\end{aligned}
$$

On the centigrade scale,

$$
t_{s}=770+20=790^{\circ} \mathrm{C} .
$$

(6) Exit-gas temperature. 50.

To solve for the exit-gas temperature $\theta_{\theta}$, it is most convenient to use equation

$t_{s}$ was determined above as $770^{\circ}$;

$$
t_{0} \text { is } 780^{\circ} \text {. }
$$

$$
\theta_{o}=780-\frac{0.0445}{0.0495} \times 770=87^{\circ} \text {. }
$$

On the centigrade scale, exit temperature $\theta_{o}$, of the gas $=87+20=107^{\circ} \mathrm{C}$. 


\section{PROBLEM 2}

A foundry cupola is $\mathbf{1 . 5}$ meters inside diameter, and the height of the stock column above the combustion zone is 4 meters. The combustion extends approximately 1 meter from the tuyères..$^{50}$ Iron is being melted at the rate of 14 metric tons per hour, using 1.5 tons of coke containing 90 per cent fixed carbon. Air is blown at the rate of 850 cubic meters per ton of metal melted. The top gases contain 13 per cent carbon dioxide, 13 per cent carbon monoxide, and 74 per cent nitrogen. The metal is charged in pieces of average weight of $6 \mathrm{~kg}$ (equivalent to spheres $11.4 \mathrm{~cm}$ in diameter), and the coke averages $4 \mathrm{~cm}$ in diameter. The bed contains 50 per cent voids. The gaseous and solid materials are all initially at $0^{\circ} \mathrm{C}$. What is the temperature of the solid material at the bottom of the cupola, the temperature of the exit gases, and the temperature gradient throughout the stock?

Solution.-(1) Heat capacities.

Average heat capacity of iron $=0.20$ calorie per gram, including heat of fusion;

Average heat capacity of coke $=0.25$ calorie per gram per degree;

Average heat capacity of combustion gases $=350$ calories per cubic meter per degree.

(2) Temperature of combustion.

The temperature of combustion of cold carbon to give gas of the above composition, as computed by the standard method ${ }^{51}$ for flame temperature, is $1,445^{\circ}$ C. $=t_{1}$.

(3) Rate of flow.

The nitrogen content of the air is 79.2 per cent. Therefore, the combustion gases are $(850 \times 79.2 / 74)=910$ standard cubic meters per ton of metal.

Rate of flow

$$
=\frac{910 \times 14}{(1.5)^{2} \times \frac{\pi}{4} \times 3,600}=2.0 \text { cubic meters per square meter per second, }
$$

Rate of flow of coke $=0.20$ liter per square centimeter per second.

$$
=\frac{1.5 \times 10^{6}}{3,600 \times(1.5)^{2} \times \frac{\pi}{4} \times 10^{4}}=0.024 \text { gram per second per square centimeter. }
$$

Rate of flow of iron

$$
=\frac{14 \times 10^{6}}{3,600 \times(1.5)^{2} \times \frac{\pi}{4} \times 10^{4}}=0.220 \text { gram per second per square centimeter. }
$$

(4) Heat capacity of gas and solid streams.

Heat capacity of gas stream,

$h_{o} u_{o}=0.350 \times 0.2=0.070$ calorie per second per square centimeter per degree.

Heat capacity of coke,

$h_{s} u_{s}=0.25 \times 0.024=0.0060$ calorie per second per square centimeter per degree.

Heat capacity of iron,

$h_{s} u_{s}=0.20 \times 0.220=0.044$ calorie per second per square centimeter per degree.

Heat capacity of solid stream,

$h_{s} u_{s}=0.044+0.0060=0.050$ calorie per second per square centimeter per degree.

Heat capacity of the combustible material in the coke stream,

$h_{c} u_{c}=0.0060 \times 0.90=0.0053$ calorie per second per square centimeter per degree.

${ }^{30}$ Kinney, S. P., Royster, P. H., and Joseph, T. L., Iron Blast-Furnace Reactions: Tech. Paper 391, Bureau of Mines, $1927, \mathrm{p} .33$.

s1 Richards, J. W., Metallurgical Calculations: McGraw-Hill Book Co., New York, 1917, pp. 50-58. 
In the cupola-heat balances it is usual to have 20 per cent of the heat of combustion unaccounted for; that is, 20 per cent of the heat carried by the gas stream is lost through the walls, etc. As a first approximation this quantity should be added to the heat capacity of the solid charge.

Therefore,

Total $h_{s} u_{s}$, including heat osses $=0.05+0.20 \times 0.07=0.064$.

(5) Relative volumes of coke and iron.

The specific gravity of the solid pig-iron charge will be considered 7.8. The specific gravity of coke is 1.0. The relative volumes of the two portions, then are iron,

coke,

$$
\frac{14}{7.8}=1.8
$$

coke volume,

$$
\frac{1.5}{1.0}=1.5
$$

iron volume,

$$
=\frac{1.5}{1.8+1.5}=45.5 \text { per cent }
$$

$$
=54.5 \text { per cent }
$$

(6) Heat-transfer coefficient.

The coefficient of heat transfer is an additive property of the charge; that is, 45.5 per cent is attributable to the coke and 54.5 per cent to the iron. The value of $k$ is obtained from equation 29 .

$$
k=\frac{A u^{0.7} T^{0.3} 10^{1.68 f-3.56 f 2}}{d^{0.9}} .
$$

Consider, as a first approximation, that the average temperature is $1,000^{\circ} \mathrm{C}$. absolute. From Table 4, the value of $A$ for coke=0.0049 and for iron, 0.0059 . Therefore, for coke,

For iron,

$$
\begin{aligned}
k & =\frac{0.0049 \times(0.2)^{0.7} \times 1,000^{0.3} \times 10^{1.68(0.50)-3.58(0.25)}}{4^{0.9}} \\
& =0.00322 .
\end{aligned}
$$

$$
\begin{aligned}
k & =\frac{0.0059 \times(0.2)^{0.7} \times 1,000^{073} \times 10^{1.68(0.50)-3.56(0.25)}}{(11.4)^{0.9}}, \\
& =0.00152 .
\end{aligned}
$$

For the composite bed,

$$
\begin{aligned}
k & =0.00322 \times 0.455+0.00152 \times 0.545 \\
& =0.0023 \text { calorie per second per square centimeter per degree. }
\end{aligned}
$$

(7) Temperature of gas and solid at bottom.

The temperature of the solid at the bottom of the furnace may pe obtained from equation 53. The quantities necessary for the solution of this equation are:

$$
\begin{aligned}
L & =400, \\
h_{c} u_{c} & =0.0053, \\
t_{l} & =1,445^{\circ} \mathrm{C} ., \\
h_{s} u_{s} & =0.064, \\
h_{0} u_{o} & =0.070, \\
D & =\frac{0.064}{0.070}-1=-0.085, \text { from equation } 45, \\
k & =0.0023, \\
\frac{D k L}{h_{s} u_{s}} & =-1.23
\end{aligned}
$$


Substituting in equation 53,

$$
\begin{aligned}
t_{s} & =\frac{0.070 \times 1,445}{0.070\left(\frac{0.915-e^{+1.23}}{1-e^{1.23}}\right)-0.0053}, \\
& =\frac{101}{0.070 \times 1.035-0.0053} \\
& =1,505^{\circ} \mathrm{C} .
\end{aligned}
$$

This is the temperature of the solid at the bottom of the cupola, or, more strictly, as it enters the combustion zone. Cast iron, of course, is melted before this temperature has been reached, so in the average foundry practice the metal has become liquid and has dropped out of the heating zone before this temperature has been attained, but this is the temperature which the metal would reach if it could remain solid down to the combustion zone. This temperature of $1,505^{\circ} \mathrm{C}$. is just $40^{\circ}$ to $50^{\circ}$ under the melting point of pure iron. According to these computations, then, this cupola can not acquire quite enough temperature to melt pure iron or soft steel if it could be kept from carburizing. This conclusion is borne out in practice.

The temperature of the gas at the bottom is given by equation 52 . Substituting in this equation,

$$
t_{o}=1,445+\frac{0.0053}{0.070} \times 1,505=1,560^{\circ} \mathrm{C} .
$$

(8) Temperature of top gas.

The temperature of the top gas may most conveniently be obtained from equation 50 .

Substituting in this equation,

$$
\theta_{0}=1,560-0.915 \times 1,505=185^{\circ} \mathrm{C} .
$$

(9) Temperature gradient.

The temperature gradient of the solid materials can be computed by means of equation 46. All of the quantities necessary for the use of this equation have been evaluated except $C$. By observing equations 44 and 50 , it will be seen that $C$ is identical with $\theta_{g}$.

Therefore,

Substituting in equation 46 ,

$$
C=185 \text {. }
$$

$$
\ln \left(\frac{185-0.085 T_{s}}{185}\right)=-0.00306(400-x) .
$$

The values of $T_{s}$ have been computed from this equation, and the values are given as the top curve of Figure 35 .

\section{EFFECT OF CHANGE OF PARTICLE SIZE}

If the size of the material entering the furnace is made 216 per cent greater (iron $24.6 \mathrm{~cm}$ in diameter, coke $8.6 \mathrm{~cm}$ in diameter) the heattransfer coefficient will be one-half as great, and the material at the bottom of the cupola will be colder and the top gas hotter than in the preceding case. The author has made computations for this case, when $k=0.00115$, and the temperature gradient of the solid is shown in Figure 35. The temperature of the solid as it enters the combustion zone is $1,410^{\circ} \mathrm{C}$., the gas temperature at the bottom is $1,550^{\circ} \mathrm{C}$., and the gas temperature at the top is $260^{\circ} \mathrm{C}$.

\section{SHORTENING THE COLUMN}

If the length of the stock column above the combustion zone is shortened from 4 to 2 meters the effect on the end temperatures is just the same as decreasing the heat-transfer coefficient by one-half.

The computed temperature gradient for this case is shown as the bottom curve of Figure 35. In this case, the particle size was the same as in the original problem-iron $11.4 \mathrm{~cm}$ and coke $4 \mathrm{~cm}$ in 
diameter. The temperature of the solid at the combustion zone is $1,410^{\circ} \mathrm{C}$., the gas temperature at the bottom is $1,550^{\circ} \mathrm{C}$., and the gas temperature at the top is $260^{\circ} \mathrm{C}$.

\section{CONVERSION OF UNITS}

The various groups of variables used in the solution of the above problem, with the exception of empirical equation 29 , are dimension-

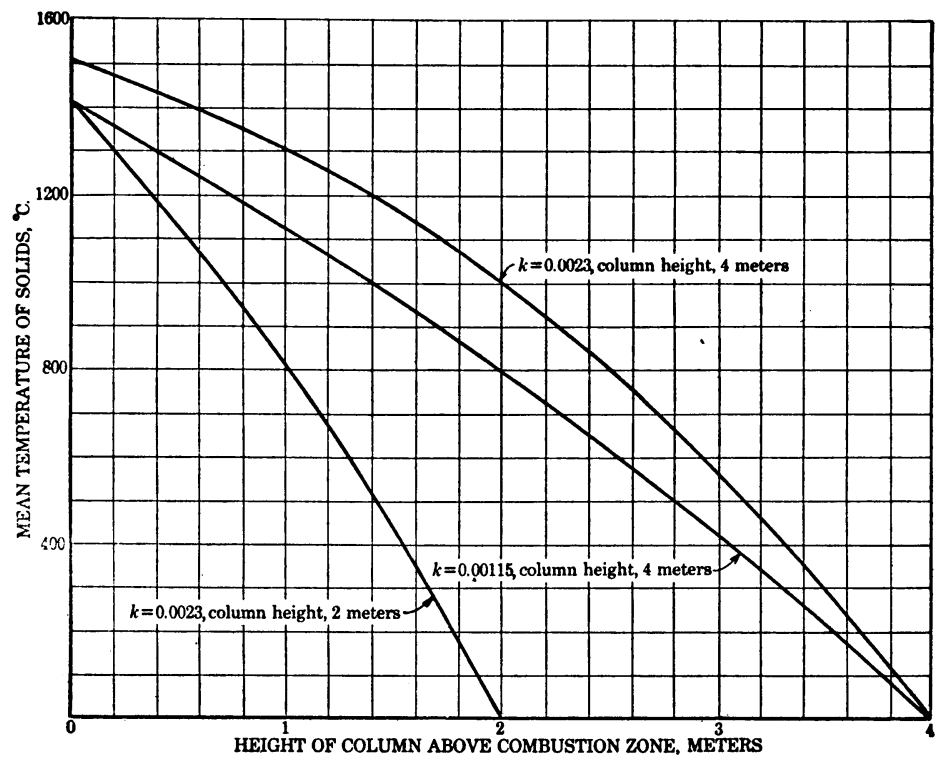

Figure 35.-Computed temperature of solids in the column of a cupola

less and so any system of units may be used provided all units are consistent. Conversion factors are given in Appendix 1.

\section{APPENDIX 1.-NOMENCLATURE}

Unless otherwise designated immediately after the equations in which they are used, all mathematical symbols have the following significance:

$A=\mathrm{a}$ constant characteristic of the substance. (See Table 4, p. 41, and Table 1, Appendix 2.)

$C_{p}=$ specific heat, relative to water, no units.

$C=t_{o}-\frac{h_{s} u_{s}}{h_{o} u_{g}} t_{s}$.

$D=\frac{h_{8} u_{s}}{h_{\vartheta} u_{g}}-1$.

$d_{1}=$ average particle diameter in centimeters (feet in English system).

$e=$ the base of the natural logarithm.

$f=$ the fractional voids in the bed of broken solids, no units.

$h_{c}=$ heat capacity of the combustible portion of a solid, calories per cubic centimeter per degree centigrade.

$h_{s}=$ heat capacity of solid material, calories per cubic centimeter per degree centigrade.

$h_{0}=$ heat capacity of gas, calories per cubic centimeter per degree centigrade.

$I_{o}=$ symbol for a modified Bessel function of first kind and zeroth order.

$i=$ unit of the imaginary number.

$J_{0}=$ symbol for a Bessel function of the first kind and zeroth order. 
$k=$ coefficient of heat transfer, calories per second per cubic centimeter per degree centigrade. (In English units, B. t. u. per second per cubic foot per degree Fahrenheit.)

$k_{a}=$ coefficient of heat transfer per unit of area, calories per second per square centimeter per degree centigrade. (In English units, B. t. u. per square foot per second per degree Fahrenheit.)

$k_{r}=$ value of $k$ when $d=1.0 \mathrm{~cm}, u=0.1$ liter per second per square centimeter with normal voids.

$k,=$ value of $k$ when $d=1.0 \mathrm{~cm}, u=0.1$ liter per second per square centimeter, and $f=0.50$.

$K=$ coefficient of thermal conductivity, calorie per second per square centimeter per degree per centimeter.

$K_{1}=$ heat loss coefficient in calories per second per degree difference inside and outside per cubic centimeter of volume of apparatus.

$L=$ length in centimeters.

$l n=$ logarithm to the base $e$.

$m=$ molecular weight of the gas.

$n=$ an exponent. No units.

$\boldsymbol{Q}=$ quantity of heat absorbed, calories per cubic centimeter.

$r=$ radius of a particle, centimeters.

$R=$ rate of penetration of line of calcination in limestone, centimeters per hour.

$\rho=$ specific gravity, relative to water.

$S=$ shape factor of a conduit. For cylinders (English units) it is equal to 4 divided by the pipe diameter in feet.

$t=$ time in seconds.

$t_{0}=$ temperature of gas at the bottom of a shaft furnace (entrance), centigrade degrees with $\theta_{s}=0$.

$t_{\varepsilon}=$ temperature of solid at the bottom of a shaft furnace (exit) centigrade degrees with $\theta_{s}=0$.

$t_{1}=$ temperature of combustion for cold reactants.

$T=$ temperature, degrees centigrade absolute.

$T_{0}=$ average temperature of fluid on any plane at any time.

$T_{r}=$ temperature of surroundings of a cooling solid, degrees centigrade.

$T_{8}=$ average temperature of the solid on any plane at any time, degrees centigrade.

$T_{o}=$ initial temperature of fluid, in degrees centigrade, considering initial $T,=0$.

$T_{1}=$ initial temperature of solid, degrees centigrade.

$\boldsymbol{\theta}_{0}=$ temperature of gas at the top (exit) of a shaft furnace, degrees centigrade with $\theta_{s}=0$.

$\boldsymbol{\theta}_{s}=$ temperature of solid at the top (entrance) of a shaft furnace, arbitrarily set equal to 0 .

$u=$ rate of fluid flow, standard liters per second per square centimeter. (In English units, standard cubic feet per second per square foot.)

$\boldsymbol{v}=$ rate of fluid flow, standard cubic centimeters per second per square centimeter.

$U=$ arbitrary dependent variable.

$V=$ arbitrary dependent variable.

$W=$ distance between centers of adjacent pipes in a heater, inches.

$x=$ distance from the bottom of a column of broken solids, centimeters.

$y=a$ dimensionless dependent variable defined by equation 10 .

$z=\mathbf{a}$ dimensionless dependent variable defined by equations 9 and 11 .

\section{CONVERSION OF UNITS}

To convert $k$ in the metric to $k$ in the English system, multiply by 62.4 . The units are given in the table above.

To convert $k_{a}$ in the metric to $k_{a}$ in the English system, multiply by 2.047. The units are given in the table above.

To convert $u$ in the metric to $u$ in the English system, multiply by 32.8. The units are given in the table above.

If the coefficient $A$ of equation 29 is in the metric system (the values of $A$ in

Table 4 are in the metric system), it must be multiplied by 0.210 to convert the equation to the English system. Then, $k$ and $u$ will be in the English units given in the above table

$d=$ average particle diameter in feet.

$T=$ degrees Fahrenheit absolute.

Norr.-For the case of cooling coke this conversion factor for $A$ does not hold. See page 42. 


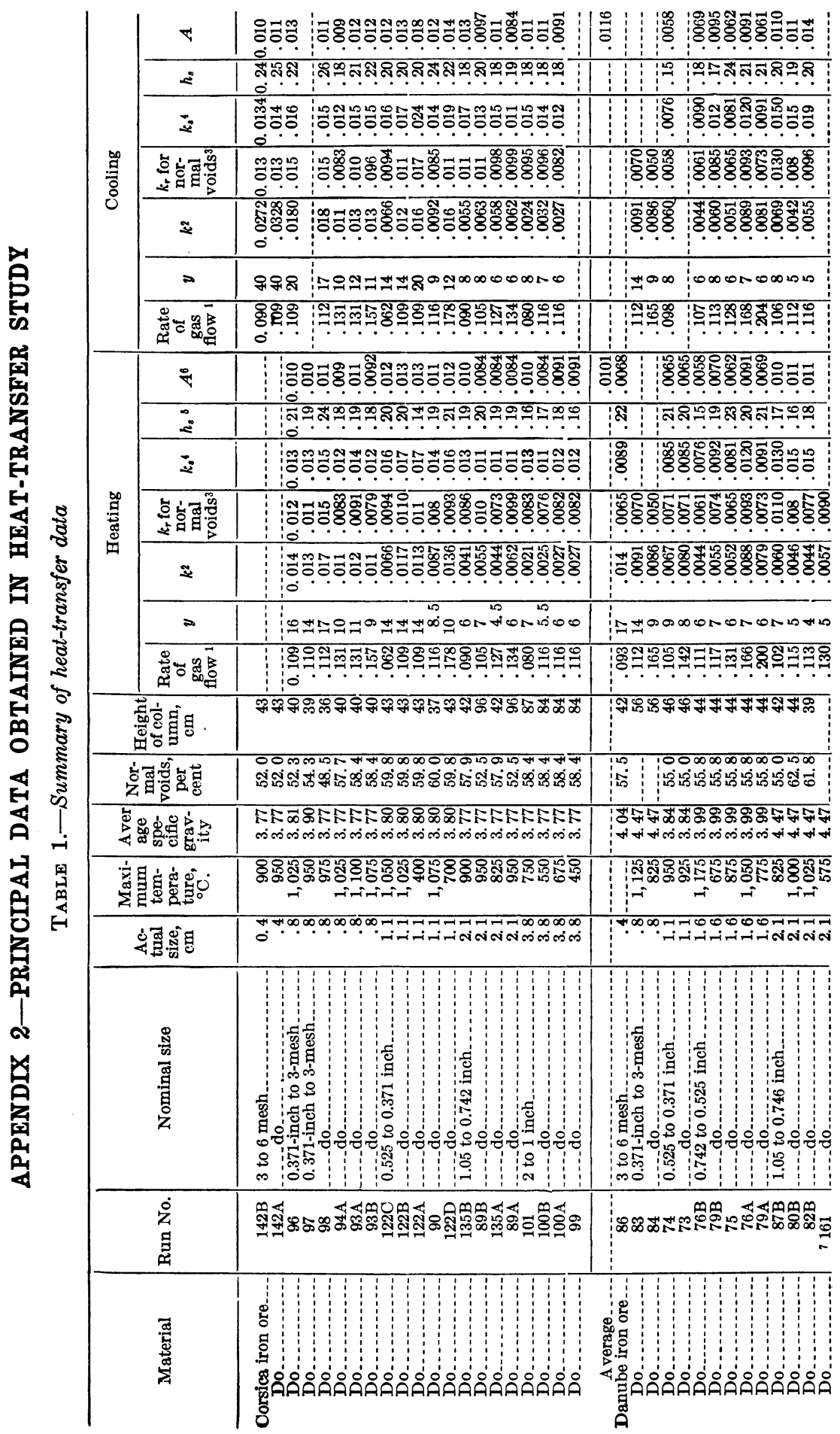




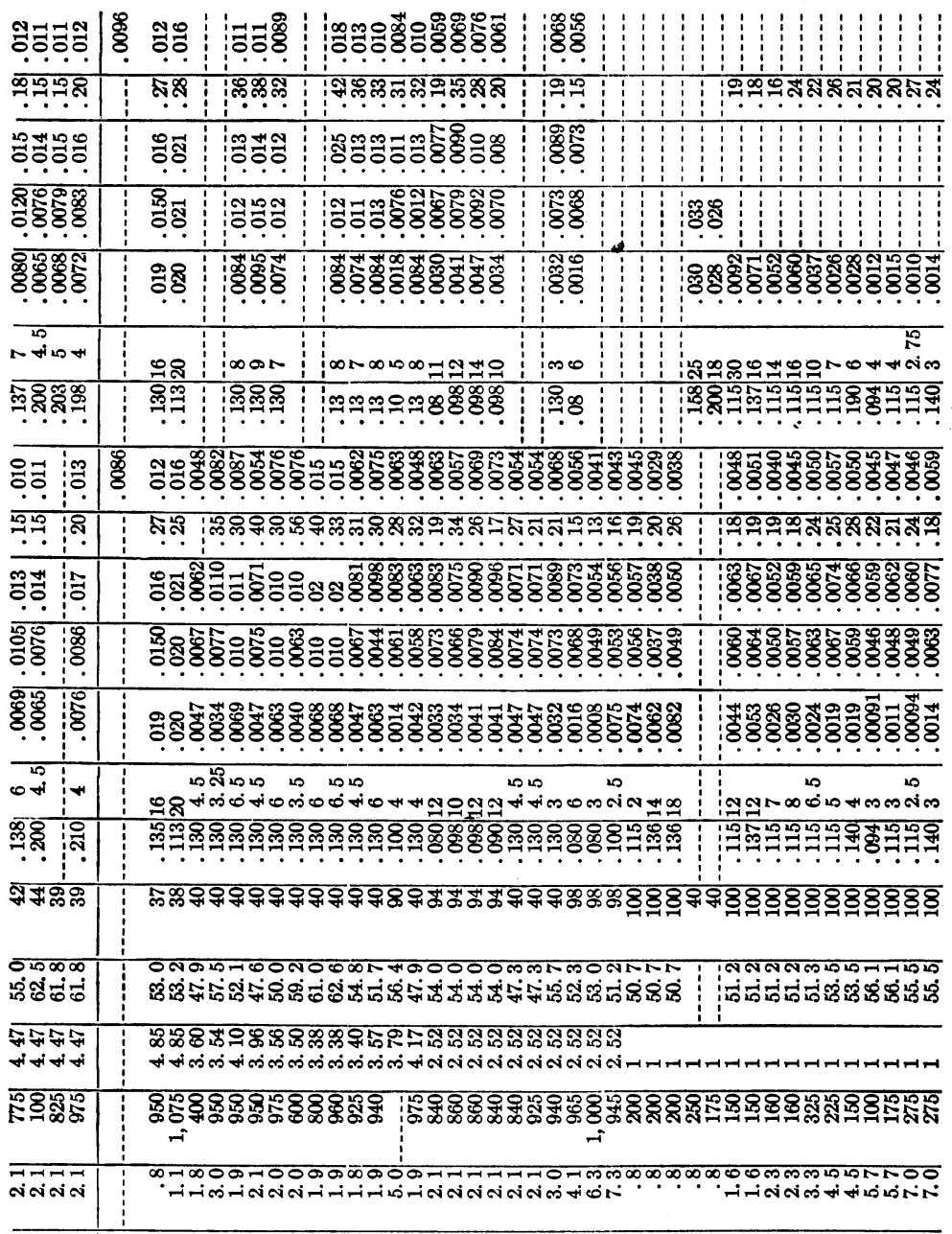

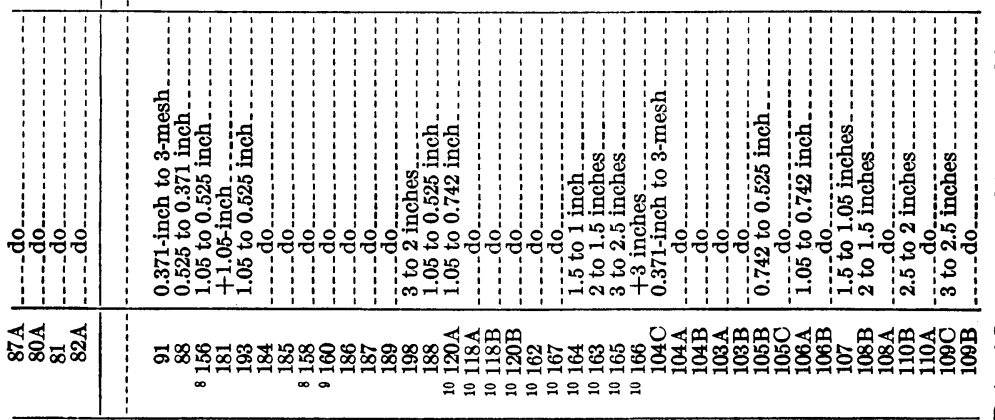




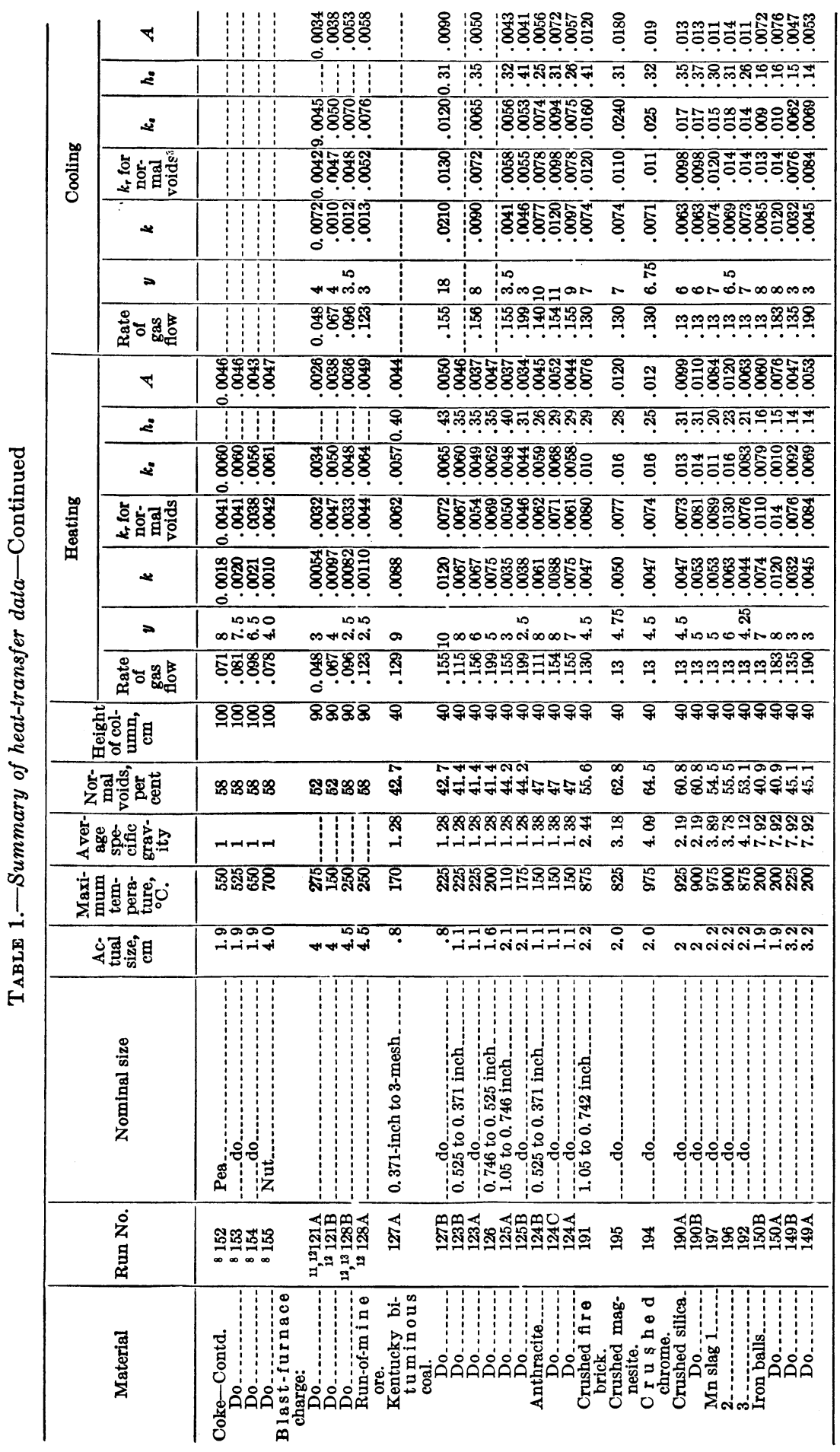




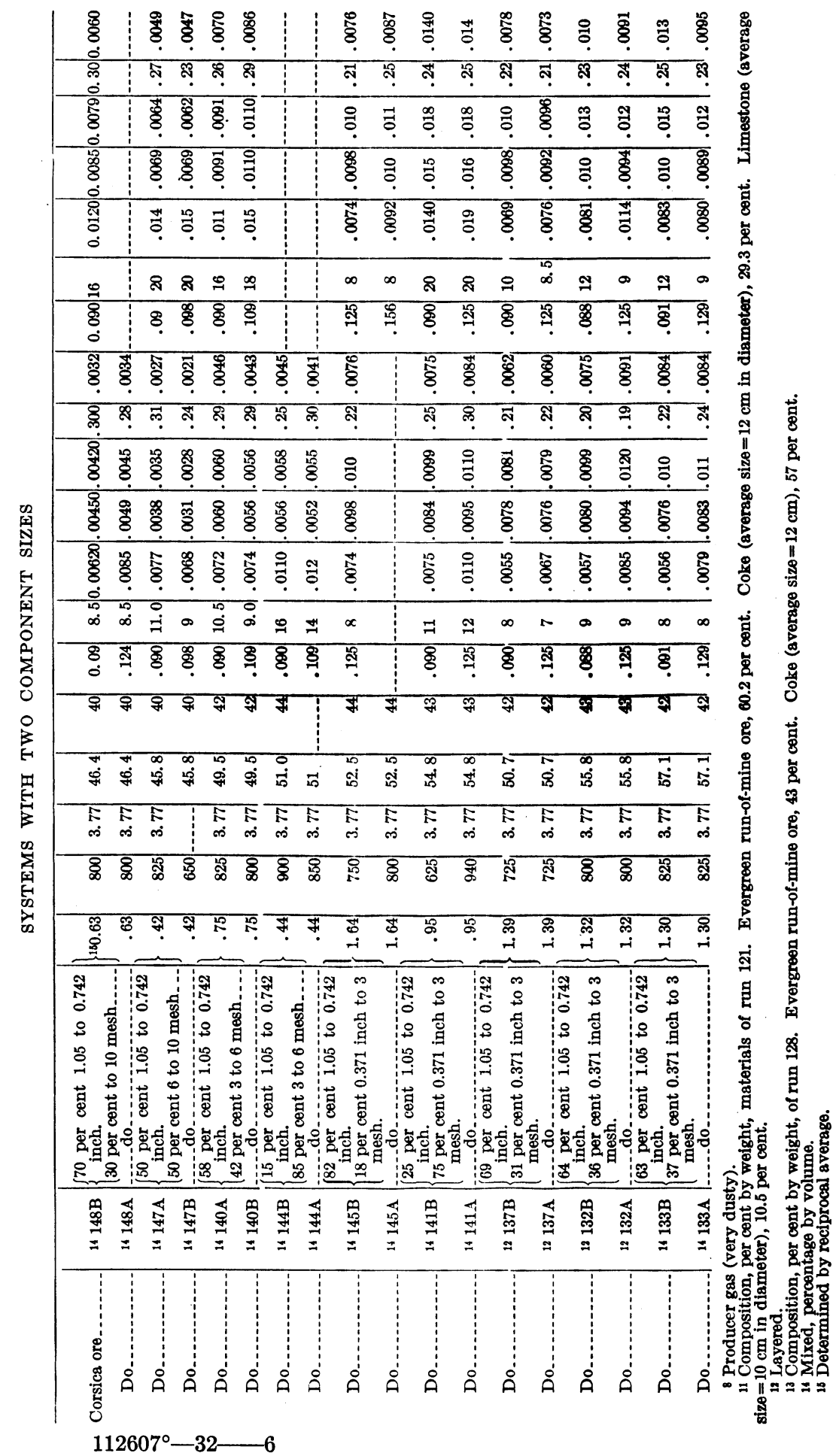




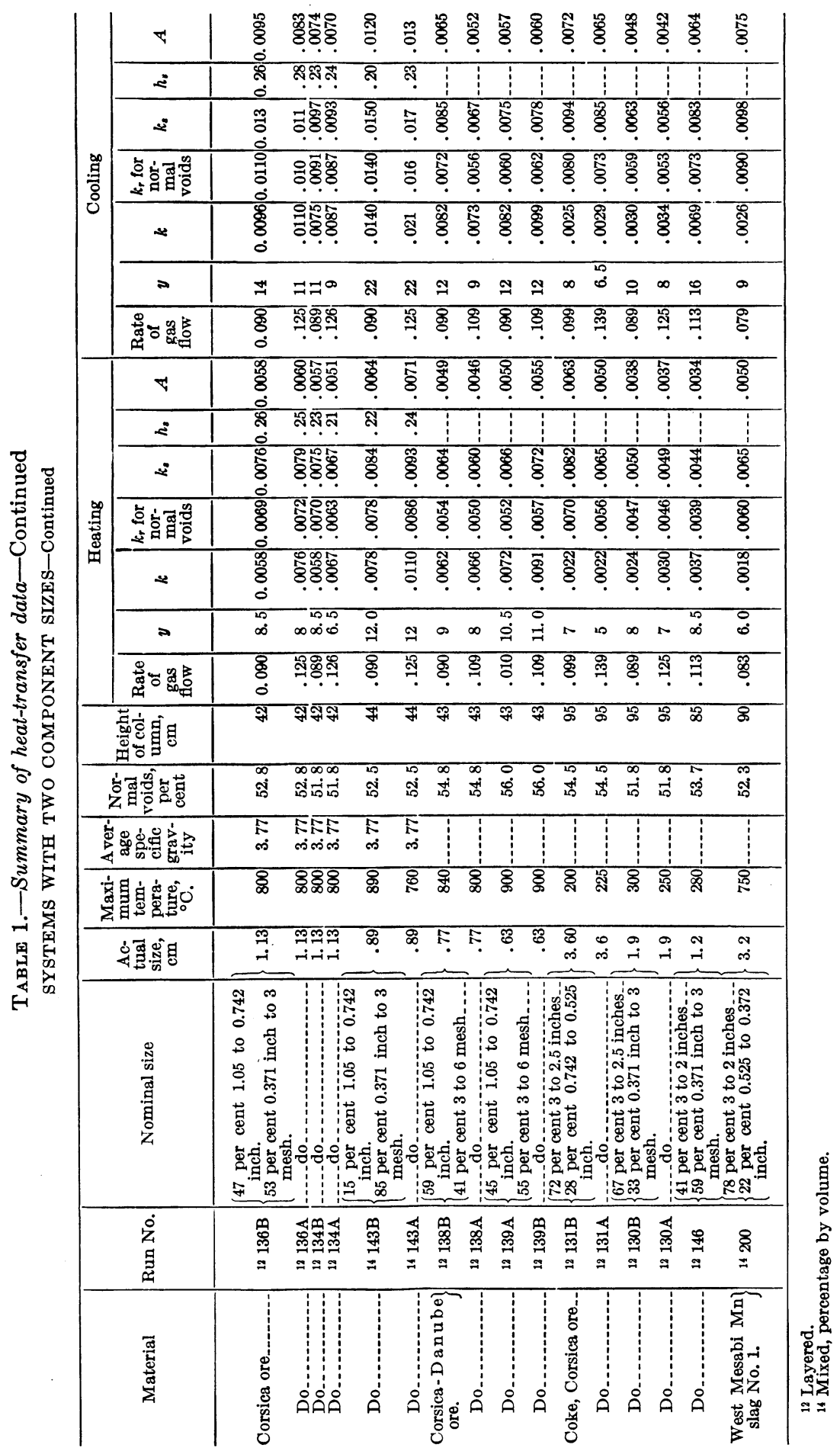


TABLE 2.-Composition of some ores in heat-transfer study

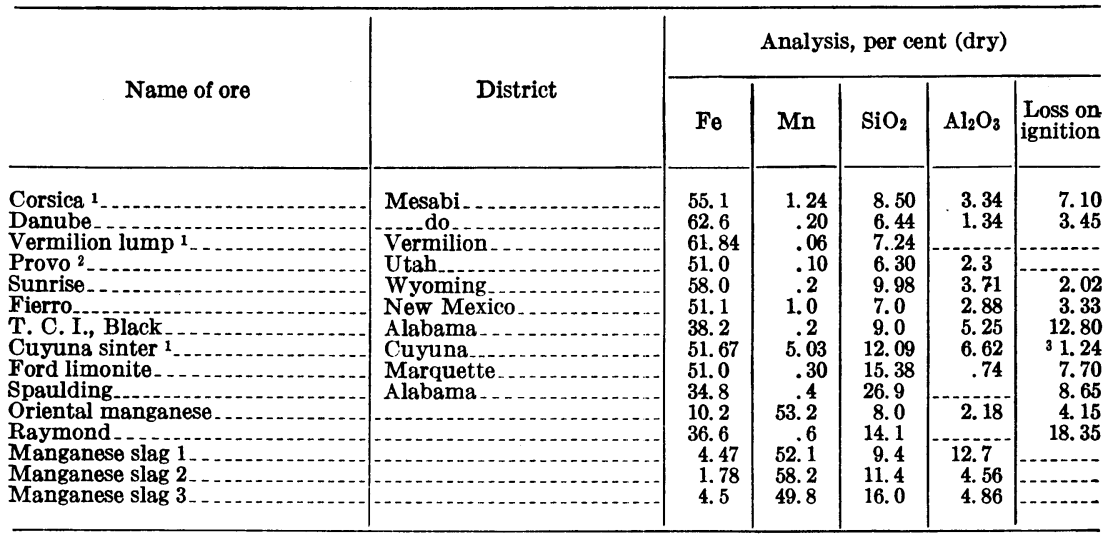

1 A verage for mine for 1930.

2 Average of 122 cars, August and September, 1927.

3 Gain of weight on ignition.

TABLE 3.-Composition of limestone used in heat-transfer study

\begin{tabular}{|c|c|c|}
\hline $\begin{array}{l}\text { Constituent: } \\
\text { } \mathrm{CaO}_{-} \mathrm{Fe}_{-} \\
\mathrm{SiO}_{2} \\
\mathrm{MgO}\end{array}$ & $\begin{array}{r}\text { Per cent } \\
54.33 \\
.36 \\
.50 \\
1.14\end{array}$ & $\begin{array}{l}\text { Constituent-Continued } \\
\mathrm{Al}_{2} \mathrm{O}_{3} \ldots \\
\mathrm{CO}_{2} \\
\text { Loss on ignition }\end{array}$ \\
\hline
\end{tabular}




\section{APPENDIX 3.-DERIVATION OF EQUATIONS FOR RATE OF HEATING AND THE STEADY STATE}

\section{DERIVATION OF EQUATION 36 FOR RATE OF HEATING OF A HIGHLY CONDUCTIVE SPHERE}

If the body of a sphere is made of material of high thermal conductivity such as iron, then all of the resistance to heat transfer resides in the very thin film on the surface. The temperature of the sphere is constant throughout its mass at any given time, and the rate of heat transfer is proportional to the area exposed and to the difference in temperature between the surroundings and the interior of the sphere. The rate of heat transferred to or from the sphere is also proportional to the volume and heat capacity per unit volume of the sphere. These two heat quantities are equal.

Expressed as a differential equation,

$$
\begin{gathered}
4 \pi r^{3} h_{s} \frac{d T_{s}}{d t}=-4 \pi r^{2} k\left(T_{s}-T_{r}\right), \\
\frac{d T_{s}}{T_{s}-T_{r}}=\frac{-3 k d t}{h_{s} r}, \\
d l n\left(T_{s}-T_{r}\right)=\frac{-3 k d t}{h_{s} r}, \\
d \log _{10}\left(T_{s}-T_{r}\right)=\frac{-1.301 k d t}{h_{s} r} .
\end{gathered}
$$

This is for a cooling sphere.

If the sphere is being heated,

$$
d \log _{10}\left(T_{r}-T_{s}\right)=\frac{1.301 k d t}{h_{8} r} .
$$

\section{DERIVATION OF EQUATIONS FOR THE STEADY STATE; NO HEAT LOSSES THROUGH WALLS}

The diagram of the steady state is shown in Figure 33. The equations derived here are for the countercurrent system where one phase flows in the opposite direction to the other. They are applicable to any form of a countercurrent, steady-state system, but for convenience of description we will assume that the apparatus is an upright shaft furnace with cold, solid materials being fed in continuously at the top and hot gas being blown in continuously at the bottom. The apparatus has been running a sufficient length of time so that the temperature at any given point in the apparatus does not change with time. The symbols are explained in the table of nomenclature, Appendix 1.

\section{DETERMINATION OF TEMPERATURE GRADIENT OF SOLID}

Since the furnace is in a steady state the amount of heat left in a given volume by the gas is equal to the amount of heat acquired by the solid in the same given volume. 
Therefore,

$$
\frac{d T_{o}}{d x} h_{o} u_{o}=\frac{d T_{s}}{d x} h_{s} u_{s}
$$

This same principle may be applied to finite sections of the column, and the differential of temperature may be replaced by temperature differences between points.

Therefore,

$$
\begin{gathered}
h_{\sigma} u_{0}\left(t_{o}-T_{0}\right)=h_{s} u_{s}\left(t_{s}-T_{s}\right), \\
T_{o}=t_{\sigma}-\frac{h_{s} u_{s}}{h_{0} u_{o}}\left(t_{s}-T_{s}\right) .
\end{gathered}
$$

In terms of the temperature change in the solid material, the coefficient of heat transfer $k$, by definition, is

$$
h_{8} u_{s} \frac{d T_{s}}{d t}=k\left(T_{o}-T_{s}\right) \text {. }
$$

The length of time which the material stays in any given length, $x$, of the apparatus is

Therefore,

$$
t=\frac{-x}{u_{s}} .
$$

$$
d t=\frac{-d x}{u_{s}} .
$$

(The negative sign is used because in the conditions of our problem, time and distance are measured in opposite directions.)

Therefore,

$$
h_{s} u_{s} \frac{d T_{s}}{d x}=-k\left(T_{o}-T_{s}\right)
$$

Substituting for $T_{v}$ from equation 55 ,

Let

$$
h_{s} u_{s} d T_{s}=-k\left[t_{0}-\frac{h_{s} u_{s}}{h_{g} u_{o}} t_{s}+T_{s}\left(\frac{h_{s} u_{s}}{h_{g} u_{o}}-1\right)\right] d x .
$$

and

$$
t_{o}-\frac{h_{s} u_{s}}{h_{0} u_{o}} t_{s}=C,
$$

Then,

$$
\frac{h_{s} u_{s}}{h_{o} u_{o}}-1=D \text {. }
$$

Integrating,

$$
d T_{s} h_{s} u_{s}=-k\left(C+D T_{s}\right) d x .
$$

$$
\frac{1}{D} \ln \left(C+D T_{s}\right)=-\frac{k x}{h_{s} u_{s}}+C_{1} .
$$

For convenience, let the entrance temperature of the solid equal 0 ; the temperature scale can be adjusted accordingly.

Then, when

Substituting in equation 59 ,

$$
x=L, T_{s}=0 .
$$

$$
C_{1}=\frac{1}{D} \ln C+\frac{k L}{h_{s} u_{s}}
$$

Substituting this value back in equation 59 ,

$$
\ln \left(\frac{C+D T_{s}}{C}\right)=\frac{D k}{h_{s} u_{s}}(L-x) .
$$




\section{SOLID TEMPERATURE AT BOTTOM OF FURNACE}

To determine the temperature of the solid at the bottom of the furnace, let $x=0$.

Then,

$$
\ln \frac{C+D t_{s}}{C}=\frac{D k L}{h_{s} u_{s}} .
$$

It is not convenient to separate $T_{s}$ from the constant terms as the equation stands, but if the values of $C$ and $D$ are resubstituted from equations 57 and 58 into the above equation, the equation can be rearranged into

$$
t_{s}=t_{0}\left(\frac{1-e^{\frac{-D k L}{h_{s} u_{s}}}}{\frac{h_{s} u_{s}}{h_{0} u_{o}}-e^{\frac{-D k L}{h_{s} u_{s}}}}\right) .
$$

This gives the temperature of the solid at the bottom of the furnace if the temperature at the top is 0 . Obviously, it is necessary to evaluate $t_{s}$ before $C$ can be determined for the solution of equation 60 .

GAS TEMPERATURES

If the differential equation is expressed in terms of gas temperatures,

$$
h_{o} u_{o} \frac{d T_{o}}{d x}=-k\left(T_{o}-T_{s}\right) .
$$

As in the case for the solid temperatures the finite temperature differences are given by the equation

and

$$
h_{\sigma} u_{\sigma}\left(t_{\sigma}-T_{\sigma}\right)=h_{s} u_{s}\left(t_{s}-T_{s}\right) \text {, }
$$

Let

$$
T_{s}=t_{s} \frac{-h_{g} u_{g}}{h_{s} u_{s}}\left(t_{0}-T_{o}\right)
$$

$$
\begin{aligned}
& h_{o} u_{o} \\
& h_{s} u_{s}-t_{s}=C^{1}, \\
& 1-\frac{h_{o} u_{o}}{h_{s} u_{s}}=D^{1} .
\end{aligned}
$$

Substituting these three values in the above differential equation,

Integrating,

$$
h_{o} u_{0} d T_{o}=-k\left(C^{1}+D^{1} T_{o}\right) d x .
$$

By definition,

$$
\frac{1}{D^{1}} \ln \left(C^{1}+D^{1} T_{o}\right)=-\frac{k x}{h_{0} u_{o}}+C_{1} .
$$

Then,

$$
\text { when } x=0, T_{o}=t_{0} \text {. }
$$

Then,

$$
C_{1}=\frac{1}{D^{1}} \ln \left(\mathrm{C}^{1}+D^{1} t_{0}\right)
$$

$$
\ln \frac{C^{1}+D^{1} T_{o}}{C^{1}+D^{1} t_{o}}=\frac{-D^{1} k x}{h_{o} u_{o}}
$$



that

By comparing equations 63 and 64 with 57 and 58, it can be seen

and

$$
C^{1}=\frac{h_{o} u_{o}}{h_{s} u_{s}} C,
$$

Therefore,

$$
D^{1}=\frac{h_{o} u_{o}}{h_{s} u_{s}} D \text {. }
$$

$$
\ln \frac{C+D T_{o}}{C+D t_{o}}=-\frac{D k x}{h_{s} u_{s}} \text {. }
$$

Equations 55, 60, 61, and 65 completely determine the temperature curves for both gas and solid throughout the furnace.

If the temperatures of the solid have been obtained it is much simpler and more accurate to obtain the temperature of the gas by substituting the values of $T_{s}$ in equation 55 .

Equations 55, 60, 61, and 65 are the same as equations $48,46,47$, and 49 in the body of the text. (See p. 64.)

\section{INDETERMINATE FORM}

In computations, some difficulties are encountered when the heat capacity of the gas stream, $h_{g} u_{g}$, equals the heat capacity of the solid stream, $h_{s} u_{s}$. In this case, quantity $D$ is equal to 0 . If this value is substituted in equation 61 ,

This is an indeterminate form.

$$
t_{s}=t_{\sigma} \frac{0}{0} \text {. }
$$

Then

Substitute the quantity $\frac{h_{s} u_{s}}{h_{o} u_{g}}=1$ in equation 56 .

$$
\frac{h_{s} u_{s} d T_{s}}{d x}=-k\left(t_{o}-t_{s}\right) .
$$

Since $t_{\sigma}$ and $t_{s}$ are both constant the curve of the solid temperature against height of column is a straight line. The same must be true for the temperature of the gas, for the differential equation is the same in both cases; furthermore, the slopes are the same, so the lines are parallel.

Since the slope is constant throughout the length of the column,

$$
\frac{d T_{s}}{d x}=\frac{t_{s}}{L}
$$

for $t_{s}$ is the entire temperature drop from the top to the bottom of the column.

Since the curves of $T_{\sigma}$ and $T_{s}$ are parallel, $T_{\sigma}-T_{s}$ is constant and equal to $t_{0}-t_{s}$. From equation 66 ,

$$
\frac{t_{s}}{L}=\frac{k}{h_{s} u_{s}}\left(t_{o}-t_{s}\right) .
$$

Rearranging and simplifying,

$$
t_{s}=\frac{k L}{h_{s} u_{s}+k L} t_{o} .
$$


Since the solid and gas temperature curves are parallel,

$$
\theta_{0}=t_{0}-t_{s} \text {. }
$$

Subtracting $t_{\sigma}$ from both sides of equation 67 , rearranging and simplifying,

$$
\theta_{o}=t_{o}-t_{s}=\frac{h_{s} u_{s} t_{o}}{h_{s} u_{s}+k L} \text {. }
$$

Equations 67 and 68 are for the indeterminate case when

$$
\frac{h_{s} u_{s}}{h_{0} u_{o}}=1.0 .
$$

The temperature of the gas at any point in the apparatus may be determined graphically by drawing a straight line from the value $\theta_{\theta}$ at $x=L$ to the value $t_{g}$ at $x=0$. This straight line is the temperature gradient. The solid temperatures may be determined in a similar manner.

\section{TEMPERATURE OF COMBUSTION}

In many cases the temperature of the gaseous products of combustion in the bottom of a shaft depends upon the temperature to which the solid fuel is heated before it reaches the combustion zone. This necessitates the development of a new equation for the gas temperature $t_{0}$ at the bottom of the furnace.

If $h_{c}$ and $u_{c}$ are the heat capacity and rate of flow, respectively, of that part of the solid charge which is combustible, then,

$$
t_{o}=t_{l}+\frac{h_{c} u_{c}}{h_{0} u_{o}} t_{s}
$$

where $t_{l}=$ the temperature of combustion when the solid reactants are cold.

If this value of $t_{g}$ is substituted in equation 61 , the equation may be arranged and again solved for $t_{s}$, giving

$$
t_{s}=\frac{h_{0} u_{o} t_{l}}{h_{o} u_{o}\left(\frac{\frac{h_{s} u_{s}}{h_{o} u_{o}}-e^{-\frac{D k L}{h_{o} u_{s}}}}{1-e^{-\frac{D k L}{h_{s} u_{s}}}}\right)-h_{c} u_{c}} .
$$

Equations 69 and 70 are the same as equations 52 and 53 in the body of the text. (See p. 67.)

\section{EQUATIONS INVOLVING HEAT LOSS THROUGH WALLS}

In all the preceding derivations it was assumed that all of the heat passing from the fluid stream went into the solid charge. Actually, of course, a certain proportion is always lost through the walls. In many cases, this quantity of heat may be negligible, but usually it must be taken into account. As a first approximation, it may be taken care of by adding a sufficient increment to the heat capacity of the solid, $h_{s}$, to account for the average loss through the walls, but if the heat loss is large, or accurate computations are desired, it is necessary to use equations which are more exact. 
If there are no heat losses, the differential equation for steady state apparatus is

$$
\frac{d T_{o}}{d x} h_{o} u_{o}=\frac{d T_{s}}{d x} h_{s} u_{s} ;
$$

but if there is a loss through the walls, the equation becomes

$$
\frac{d T_{o}}{d x} h_{o} u_{o}=\frac{d T_{s}}{d x} h_{s} u_{s}-K_{1} T_{s},
$$

where $K_{1}$ is the over-all coefficient of heat transfer through the walls measured in calories per second per degree difference in inside and outside temperatures per cubic centimeter volume of the bed. The negative sign is used for $K_{1}$ because $\frac{d T_{s}}{d x}$ is negative. This equation only holds if the outside temperature is zero, which is in accordance with the previous arbitrary assumption that all solid materials enter the shaft at $0^{\circ}$.

The heat loss was arbitrarily assumed to be proportional to the temperature of the solid rather than that of the gas. It is a debatable question which actually controls the heat loss; but the solution of the equations is simpler if the solid temperature is used, and the value of $K_{1}$ must be such that it will account for heat losses on the basis of solid temperatures.

Integrating equation 71 between limits 0 and $x$,

Then,

$$
h_{o} u_{o}\left(T_{0}-t_{0}\right)=h_{s} u_{s}\left(T_{s}-t_{s}\right)-\int_{0}^{x} K_{1} T_{s} d x .
$$

$$
T_{\sigma}=t_{\sigma}+\frac{h_{s} u_{s}}{h_{\theta} u_{o}}\left(T_{s}-t_{s}\right)-\frac{K_{1}}{h_{\theta} u_{o}} \int_{0}^{x} T_{s} d x .
$$

By definition of the coefficient of heat transfer within the column,

$$
h_{s} u_{s} \frac{d T_{s}}{d x}-K_{1} T_{s}=-k\left(T_{0}-T_{s}\right) .
$$

Substituting the value of $T_{0}$ in equation 73 ,

Then,

$$
h_{s} u_{s} \frac{d T_{s}}{d x}-K_{1} T_{s}=-k\left[t_{\theta}+\frac{h_{s} u_{s}}{h_{0} u_{0}}\left(T_{s}-t_{s}\right)-\frac{K_{1}}{h_{0} u_{\theta}} \int_{0}^{x} T_{s} d x-T_{s}\right] .
$$

Let

$$
\frac{d T_{s}}{d x}=-\frac{k t_{o}}{h_{s} u_{s}}+\frac{k t_{s}}{h_{g} u_{o}}-\frac{k T_{s}}{h_{g} u_{0}}+\frac{K_{1} T_{s}}{h_{s} u_{s}}+\frac{k T_{s}}{h_{s} u_{s}}+\frac{K_{1} k}{h_{s} u_{s} h_{\theta} u_{o}} \int_{0}^{x} T_{s} d x .
$$

$$
\begin{gathered}
k\left(\frac{t_{s}}{h_{\rho} u_{\sigma}}-\frac{t_{\sigma}}{h_{s} u_{s}}\right)=E, \\
k\left(\frac{1}{h_{s} u_{s}}-\frac{1}{h_{o} u_{o}}\right)+\frac{K_{1}}{h_{s} u_{s}}=F, \\
\frac{k K_{1}}{h_{0} u_{o} h_{s} u_{s}}=G .
\end{gathered}
$$

Then,

$$
\frac{d T_{s}}{d x}=E+F T_{s}+G \int_{0}^{x} T_{s} d x
$$


Adopting the prime nomenclature for convenience (that is, $\left.\frac{d T_{s}}{d x}=T_{s}{ }^{\prime}\right)$,

$$
T_{s}^{\prime}=E+F T_{s}+G \int_{0}^{x} T_{s} d x .
$$

Differentiating,

$$
T_{\mathrm{s}}{ }^{\prime \prime}=F T_{\mathrm{s}}{ }^{\prime}+G T_{\mathrm{s}} .
$$

The general form ${ }^{52}$ of the solution of this differential equation is

Provided

$$
T_{8}=C_{n} e^{m x} .
$$

If this is true, then

$$
m^{2}-F m-G=0 .
$$

$$
m=\frac{F \pm \sqrt{F^{2}+4 G}}{2},
$$

or

$$
\begin{aligned}
& m_{1}=\frac{F+\sqrt{F^{2}+4 G}}{2}, \\
& m_{2}=\frac{F-\sqrt{F^{2}+4 G}}{2}
\end{aligned}
$$

The particular solution then is

$$
T_{8}=C_{1} e^{m_{1} x}+C_{2} e^{m_{2 x}}
$$

where $C_{1}$ and $C_{2}$ are constants which can be evaluated from the boundary conditions and $m_{1}$ and $m_{2}$ are given by equations 80 and 81 . Equation 82 is general and must fit all boundary conditions. These conditions are

(1) When

(2) When

$$
x=L, T_{8}=0 ;
$$

$$
x=0, T_{s}=t_{s} .
$$

From condition 1 and equation 82,

then,

$$
C_{1} e^{m_{1} L}=-C_{2} e^{m_{2} L},
$$

$$
C_{1}=-C_{2} \frac{e^{m_{2} L}}{e^{m_{1} L}}
$$

Therefore,

$$
T_{s}=-C_{2}\left[\frac{e^{m_{2} L}}{e^{m_{1} L}} e^{m_{1} x}-e^{m_{2} x}\right] .
$$

\footnotetext{
${ }^{32}$ See, for example, Mellor, J. W., Higher Mathematics for Students of Chemistry and Physics: Long-
} mans, Gre en \& Co., New York, 1922, pp. 399-400. 
When

$$
\begin{aligned}
x & =0, T_{s}=t_{s}, \\
t_{s} & =C_{2}\left[1-\frac{e^{m_{2} L}}{e^{m_{1} L}}\right], \\
C_{2} & =\frac{t_{s} e^{m_{1} L}}{e^{m_{1} L}-e^{m_{2} L}} .
\end{aligned}
$$

Substituting in 84 ,

$$
T_{\mathrm{s}}=t_{\mathrm{s}}\left[\frac{e^{m_{1} L_{2} e^{m_{2} x}-e^{m_{2} L} e^{m_{1} x}}}{e^{m_{1} L}-e^{m_{2} L}}\right]
$$

The use of the two boundary conditions has brought the equation to terms involving $t_{s}$, which is still unknown and indeterminate as the equation stands. However, the differentiation in equation $\mathbf{7 9}$ and the subsequent integration meant the loss of determinacy of one constant, so if the value of $t_{s}$ as given in equation 86 can be resubstituted in an equation before 79 it should be possible to determine $t_{s}$ in terms of the known quantities.

Let

Then

$$
I=\left[\frac{e^{m_{1} L} e^{m_{2} x}-e^{m_{2} L} e^{m_{1} x}}{e^{m_{1} L}-e^{m_{2} L}}\right]
$$

$$
T_{s}=I t_{s}
$$

Let

Let

$$
I^{\prime}=\frac{d I}{d x}
$$

$$
\int_{0}^{X} I d x=J
$$

Substituting in equation 78 ,

$$
I^{\prime} t_{s}=E+F I t_{s}+G J t_{s} .
$$

Substituting for $E$, its value

$$
\begin{aligned}
& I^{\prime} t_{s}=\frac{k t_{s}}{h_{g} u_{o}}-\frac{k t_{o}}{h_{s} u_{s}}+F I t_{s}+G J t_{s}, \text { or } \\
& t_{s}\left[I^{\prime}-\frac{k}{h_{o} u_{o}}-F I-G J\right]=-\frac{k t_{o}}{h_{s} u_{s}}
\end{aligned}
$$

In order to determine $t_{s}$ it is only necessary to substitute $x=0$ in the functions of $x$ in the above equation. $I, I^{\prime}$, and $J$ are functions of $x$. When equation 87 is integrated between limits 0 and $x$ to give $J$ it is found that $J=0$ when $x=0$, so term $G J$ drops out.

If equation 87 is differentiated with respect to $x$,

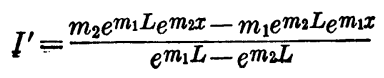


The value of $I^{\prime}$ necessary to solve for $t_{s}$ is that when $x=0$. Represent this by $I_{0}^{\prime}$.

$$
I_{0}^{\prime}=\frac{m_{2} e^{m_{1} L}-m_{1} e^{m_{2} L}}{e^{m_{1} L}-e^{m_{2} L}} .
$$

From equation 87 , when $x=0, I=1$.

Substituting these values in equation 90 ,

$$
t_{s}=\frac{k t g}{h_{s} u_{s}\left[F+\frac{k}{h_{o} u_{o}}-I_{0}^{\prime}\right]}
$$

Substituting this value for $t_{s}$ in equation 88 ,

$$
T_{s}=\frac{I k t g}{h_{s} u_{s}\left[F+\frac{k}{h_{o} u_{o}}-I_{o}^{\prime}\right]} \text {. }
$$

where $I, F$, and $I_{0}^{\prime}$ are defined by equations 87,76 , and 92 .

If the value of $F$ is substituted this equation can be simplified still further to

$$
I_{s}=\frac{I k t g}{k+k_{1}-n_{s} v_{s} I_{0}} .
$$

